OPEN ACCESS

Edited by:

Franziska Richter Assencio, University of Veterinary Medicine Hannover, Germany

Reviewed by:

Lisa Fellner,

Innsbruck Medical University, Austria Kelvin C. Luk,

University of Pennsylvania, United States

${ }^{*}$ Correspondence:

Maria Xilouri

mxilouri@bioacademy.gr

${ }^{\dagger}$ These authors have contributed equally to this work

Specialty section:

This article was submitted to

Molecular Medicine,

a section of the journal

Frontiers in Cell and Developmental

Biology

Received: 07 May 2020

Accepted: 14 August 2020

Published: 04 September 2020

Citation:

Fouka M, Mavroeidi P, Tsaka G

and Xilouri M (2020) In Search

of Effective Treatments Targeting

$\alpha$-Synuclein Toxicity

in Synucleinopathies: Pros and Cons.

Front. Cell Dev. Biol. 8:559791.

doi: 10.3389/fcell.2020.559791

\section{In Search of Effective Treatments Targeting $\alpha$-Synuclein Toxicity in Synucleinopathies: Pros and Cons}

\author{
Maria Fouka ${ }^{\dagger}$, Panagiota Mavroeidit, Grigoria Tsaka ${ }^{\dagger}$ and Maria Xilouri* \\ Center of Clinical Research, Experimental Surgery and Translational Research, Biomedical Research Foundation of the \\ Academy of Athens, Athens, Greece
}

Parkinson's disease (PD), multiple system atrophy (MSA) and Dementia with Lewy bodies (DLB) represent pathologically similar, progressive neurodegenerative disorders characterized by the pathological aggregation of the neuronal protein $\alpha$-synuclein. PD and DLB are characterized by the abnormal accumulation and aggregation of $\alpha$ synuclein in proteinaceous inclusions within neurons named Lewy bodies (LBs) and Lewy neurites (LNs), whereas in MSA $\alpha$-synuclein inclusions are mainly detected within oligodendrocytes named glial cytoplasmic inclusions (GCls). The presence of pathologically aggregated $\alpha$-synuclein along with components of the protein degradation machinery, such as ubiquitin and p62, in LBs and GCls is considered to underlie the pathogenic cascade that eventually leads to the severe neurodegeneration and neuroinflammation that characterizes these diseases. Importantly, $\alpha$-synuclein is proposed to undergo pathogenic misfolding and oligomerization into higher-order structures, revealing self-templating conformations, and to exert the ability of "prionlike" spreading between cells. Therefore, the manner in which the protein is produced, is modified within neural cells and is degraded, represents a major focus of current research efforts in the field. Given that $\alpha$-synuclein protein load is critical to disease pathogenesis, the identification of means to limit intracellular protein burden and halt $\alpha$ synuclein propagation represents an obvious therapeutic approach in synucleinopathies. However, up to date the development of effective therapeutic strategies to prevent degeneration in synucleinopathies is limited, due to the lack of knowledge regarding the precise mechanisms underlying the observed pathology. This review critically summarizes the recent developed strategies to counteract $\alpha$-synuclein toxicity, including those aimed to increase protein degradation, to prevent protein aggregation and cellto-cell propagation, or to engage antibodies against $\alpha$-synuclein and discuss open questions and unknowns for future therapeutic approaches.

Keywords: $\alpha$-synuclein, autophagy, immunotherapy, propagation, protein aggregation, proteasome, synucleinopathies, therapeutics

\section{INTRODUCTION}

$\alpha$-synuclein is a neuronal presynaptic protein, which physiologically regulates neurotransmitter release, whereas its pathological accumulation is the key histopathological hallmark of certain neurodegenerative disorders with similar clinical phenotypes, designated as synucleinopathies (Spillantini and Goedert, 2000). Specifically, in Parkinson's disease (PD) and dementia with Lewy 
bodies (DLB), $\alpha$-synuclein mostly accumulates in Lewy bodies (LBs) and Lewy neurites (LNs) in neurons (Spillantini et al., 1997, 1998), whereas in multiple system atrophy (MSA) $\alpha$-synuclein deposits mostly within the cytoplasm of oligodendrocytes forming glial cytoplasmic inclusions (GCIs) (Wakabayashi et al., 1998a,b; Nakamura et al., 2015). It is widely accepted that PD, DLB and MSA pathogenesis is the result of complex molecular events and that common pathogenic mechanisms may lead to $\alpha$ synuclein deposition in these disorders. However, the diversity of $\alpha$-synuclein pathology observed in $\alpha$-synucleinopathies is attributed to various events, such as the presence of more than one $\alpha$-synuclein strain, the intracellular milieu, the interaction of $\alpha$-synuclein with multiple molecular partners, and the propagation of $\alpha$-synuclein within different brain regions (Peng et al., 2018b; Longhena et al., 2019). The precise genetic and/or environmental trigger for $\alpha$-synuclein misfolding still remains unknown; however, genetic mutations, mitochondrial dysfunction, proteolytic systems failure and neuroinflammation have been proposed to facilitate $\alpha$-synuclein spread in the diseased brain (Polymeropoulos et al., 1997; Bose and Beal, 2016; Rocha et al., 2018). Under physiological conditions, neuronal $\alpha-$ synuclein is found either in the cytosol in a soluble and natively unfolded monomeric or tetrameric form (Weinreb et al., 1996; Bartels et al., 2011; Wang et al., 2011; Fauvet et al., 2012) or in a membrane-bound or vesicle-associated state (Pirc and Ulrih, 2015; Gustafsson et al., 2018; Lautenschlager et al., 2018). On the other hand, pathological $\alpha$-synuclein in oligomeric, pre-fibrillar and fibrillar form can spread within the diseased brain via various cell-to-cell transmission mechanisms, which are responsible either for its release from neurons or its uptake by neighboring cells. The tendency of $\alpha$-synuclein to form aggregates lies in the core of its neurotoxic potential and strategies seeking to alleviate the total protein load represent an obvious therapeutic approach.

Current therapeutic approaches for PD and related synucleinopathies can provide only palliative treatment, aiming to control the motor symptoms and delay disease progression. The lack of reliable in vivo markers and appropriate animal models to recapitulate the symptoms of these diseases challenge therapy development; however numerous studies have suggested various therapeutic efforts to counteract $\alpha$-synuclein-related pathology. In the current review, we summarize advances in understanding the pivotal role of $\alpha$-synuclein in the pathogenesis of synucleinopathies and critically discuss the potential of current therapeutic approaches favoring pathology amelioration with the pros and cons of each strategy.

\section{THE STRUCTURE, FUNCTION AND AGGREGATION OF $\alpha$-SYNUCLEIN}

The synuclein protein was originally identified through several and independent lines of investigation. In 1985, a neuron-specific protein of 143 amino acids (aa) was identified in Torpedo californica cholinergic synaptic vesicles (Maroteaux et al., 1988). Later studies in amyloid plaques from an Alzheimer's disease (AD) brain discovered two unknown peptides, in addition to the major amyloid beta fragment, which were named NAC (non-A beta component of AD amyloid) peptide and its precursor, NACP (Ueda et al., 1993) and identified two proteins of 140 and 134 aa, which were highly expressed in the human brain (Jakes et al., 1994). These results revealed the existence of a new protein family expressed predominantly in presynaptic nerve terminals. The 140 aa protein was named $\alpha$-synuclein, while the 134 aa protein $\beta$ synuclein (Jakes et al., 1994). The third and last protein of the family, $\gamma$-synuclein, was found to be highly expressed in ovarian and breast carcinomas (Ji et al., 1997; Bruening et al., 2000).

Structurally, $\alpha$-synuclein encoded by the SNCA gene, lacks a single stable 3D structure in aqueous solutions, transmembrane domain or lipid anchor, concluding that it may behave as a peripheral membrane protein (Weinreb et al., 1996). $\alpha$-synuclein is composed of three distinct domains namely N-terminal lipidbinding domain, amyloid-binding central region (NAC) and C-terminal binding domain (Figure 1). The N-terminal domain is a positively charged lysine-rich region characterized by the presence of a series of seven imperfect amphipathic 11 aa repeats containing a highly conserved KTKEGV hexameric motif, which enable the protein to acquire alpha-helical structure, thus reducing the tendency to form $\beta$-structure and modulating the interactions with membranes (Chandra et al., 2003; Ulmer et al., 2005; Sode et al., 2006). The central NAC region is composed of nonpolar side-chains and assembles cross b-structures, which are involved in fibril formation and aggregation. Based on that, it has been proven that the deletion of specific residues (74-84) within the core region can abolish $\alpha$-synuclein aggregation (Giasson et al., 2001; Rodriguez et al., 2015). Lastly, the C-terminal domain is a highly acidic tail reported to interact with metals, small molecules, proteins and other $\alpha$-synuclein domains (Kim et al., 2002; Ly and Julian, 2008).

Even though $\alpha$-synuclein is considered a natively unfolded, intrinsically disordered amyloid protein, it can adopt an a-helical conformation in the presence of membranes enriched with acidic phospholipid headgroups and high curvature (Davidson et al., 1998; Pirc and Ulrih, 2015) and form fibrillar assembles by converting soluble monomers into $\beta$-sheet-like secondary structures. The existence of the protein above a crucial concentration, along with its thermodynamically unstable innate behavior, favors the aggregation and accumulation process, which is closely related to its neurotoxic potential (Ferreon and Deniz, 2007; Afitska et al., 2019). Up to date the native state of $\alpha$ synuclein remains controversial. Although some studies have reported that $\alpha$-synuclein purified from human cells is a helically folded dynamic tetramer (Bartels et al., 2011; Wang et al., 2011; Gould et al., 2014) that resists aggregation (Bartels et al., 2011), other studies suggested that $\alpha$-synuclein exists predominantly as an unfolded monomer (Fauvet et al., 2012). Interestingly, it was suggested that the PD-linked mutations A53T and E46K shift native tetramers to monomers and this underlies the disease initiation (Dettmer et al., 2015). Nonetheless, it is widely accepted that $\alpha$-synuclein in the cellular milieu exists in various conformations and oligomeric states in a dynamic equilibrium, which can be affected by factors that alter the aggregation process (Cremades et al., 2012). Which particular species of $\alpha$-synuclein are toxic has been debated, since some consider the amyloid-like insoluble fibrils as the mediators of $\alpha$-synuclein-induced toxicity 


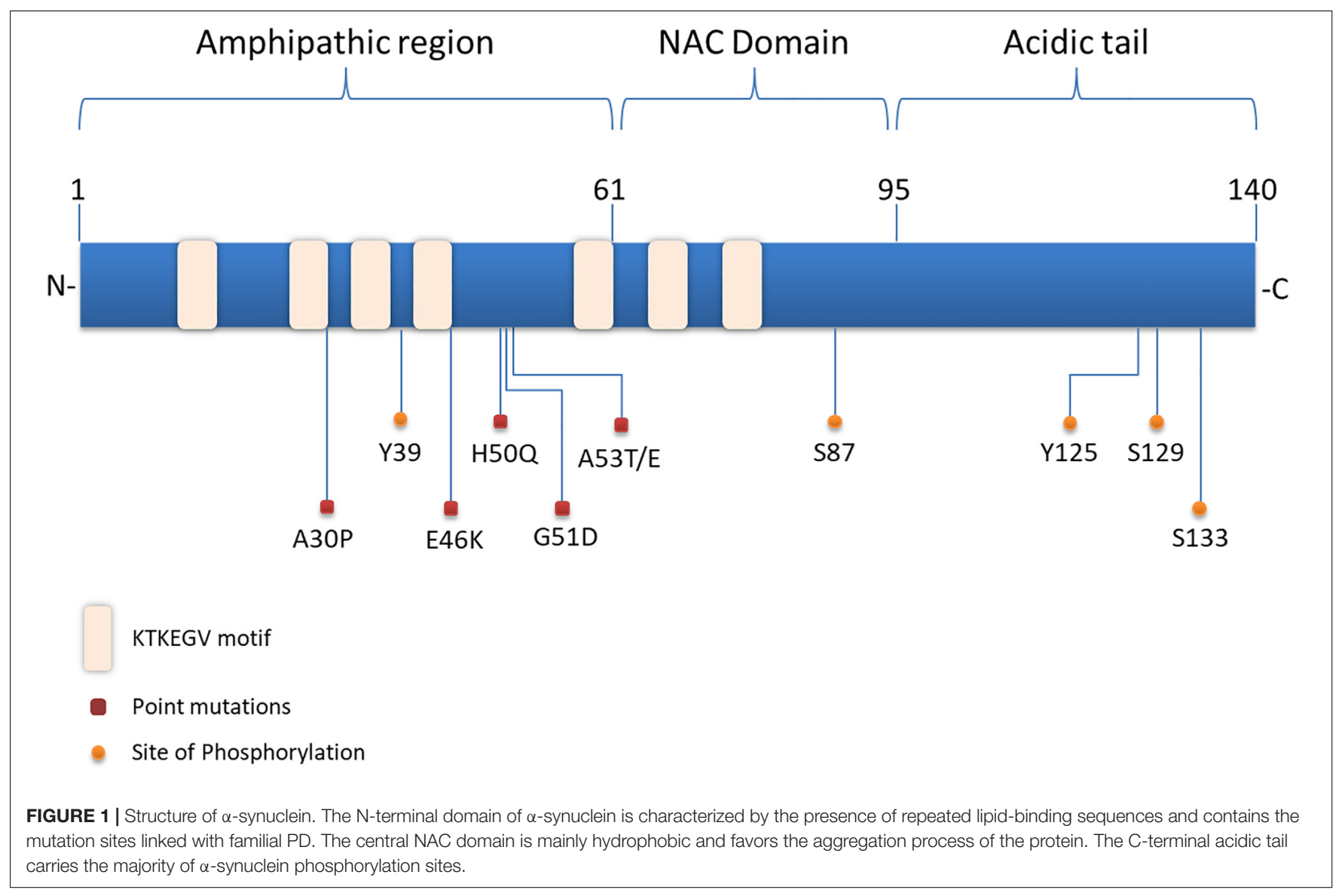

(Conway et al., 1998), whereas others suggest that oligomers or protofibrils are the toxic ones (Danzer et al., 2007; Karpinar et al., 2009; Winner et al., 2011).

Slight alterations in the physicochemical features of $\alpha$-synuclein via post-translational modifications (PTMs), truncations and solution condition modifications could favor the aggregation process (Uversky et al., 2001). Interestingly, the majority of PTMs occur in the acidic tail of the protein (Figure 1) and the serine (Ser) and tyrosine phosphorylation are the most extensively studied ones. Experiments utilizing ESI-MS (electrospray ionization mass spectrometry) technology revealed several modifications of $\alpha$-synuclein in PD brains, such as $\mathrm{N}$ - or C-terminal truncations and phosphorylation at Ser129 (Kellie et al., 2014). In healthy brain, only a small proportion of $\alpha$-synuclein is phosphorylated (Gonzalez et al., 2019), whereas under pathological conditions phosphorylated $\alpha$-synuclein -mostly at Ser129- is increased in the majority of pathological inclusions, including LBs in PD and DLB, GCIs in MSA and LB-type inclusions of AD (Fujiwara et al., 2002; Saito et al., 2003; Nishie et al., 2004; Waxman et al., 2009). Even though initially phosphorylation of $\alpha$-synuclein was considered to act prophylactically to protein aggregation, it is now widely accepted that it precedes fibril formation (Shahpasandzadeh et al., 2014; Tenreiro et al., 2014; Oueslati, 2016). Another common phosphorylation site is at Ser87, which is also found to be increased in synucleinopathies (Paleologou et al., 2010).
Tyrosine phosphorylation of $\alpha$-synuclein (Y39) seems to have both prophylactic and harmful effects (Mahul-Mellier et al., 2014; Brahmachari et al., 2016) and phosphorylation at Y125 and Y133 has been suggested to be protective against $\alpha$-synuclein toxicity (Kleinknecht et al., 2016; El Turk et al., 2018). Beyond phosphorylation, other posttranslational modifications have been shown to affect the aggregation process of $\alpha$-synuclein, such as nitration, oxidation, acetylation and SUMOylation, but possibly with a protective manner (Krumova et al., 2011; Dikiy and Eliezer, 2014; Vinueza-Gavilanes et al., 2020). Regarding truncation, it is known that truncated forms of $\alpha$ synuclein account for $10-30 \%$ of total protein in patient-derived LB inclusions. In comparison with the full-length protein, C-truncated $\alpha$-synuclein forms fibrils more rapidly, with distinct coil structures than the linear fibrils formed by the full-length protein. Additionally, $\alpha$-synuclein can be oxidized through interaction with dopamine, generating dopamine-modified $\alpha$-synuclein adducts, leading to a decrease in fibril formation and a subsequent increase in protofibril accumulation (Conway et al., 2001), which may enhance toxicity (Norris et al., 2003). Up to date, the physiological or pathological significance of $\alpha$-synuclein cleavage remains unclear.

The physiological role of $\alpha$-synuclein is still poorly understood and only its contribution to certain cellular functions is known so far. The presence of $\alpha$-synuclein in the presynaptic terminals denotes a potential role of the protein in synaptic function 
and vesicle trafficking (Jensen et al., 1998). The ability of $\alpha$ synuclein to promote, as well as to sense, membrane curvature immediately suggested a possible relationship of the protein with the synaptic vesicle cycle. Overexpression of human $\alpha$-synuclein was found to induce loss of synaptic vesicles and expansion of the plasma membrane through inhibition of both slow and fast vesicle endocytosis (Busch et al., 2014; Xu et al., 2016) and to promote dilation of the fusion pore, thereby accelerating the discharge of cargo (Logan et al., 2017). Importantly, $\alpha-$ synuclein interacts with the soluble $\mathrm{N}$-ethylmaleimide-sensitive factor attachment protein receptor (SNARE) complex, while the loss or overexpression of the protein causes reduction or redistribution of the complex, respectively (Burre et al., 2010, 2014; Garcia-Reitbock et al., 2010) $\alpha$-synuclein was also reported to promote vesicle clustering through its interaction with vesicle associated membrane protein 2 (VAMP2)/ synaptobrevin-2 and phospholipids (Diao et al., 2013).

Through its predominant role in vesicle trafficking $\alpha$ synuclein can affect neurotransmitter release and particularly dopamine neurotransmission (Butler et al., 2017), via regulation of dopamine biosynthesis and trafficking of dopamine transporter (DAT), as well as, via modulation of DAT-mediated dopamine efflux (Butler et al., 2017). More specifically, $\alpha$-synuclein was found to down-regulate indirectly the activity of tyrosine hydroxylase $(\mathrm{TH})$ via inhibition of PP2A phosphatase, thus modulating dopamine production (Peng et al., 2005). However, the main effect of $\alpha$-synuclein involves the regulation of DAT, where overexpressed $\alpha$-synuclein enhances its interaction with DAT, altering the ionic conductance of the transporter and influencing the action potential-independent dopamine release, thus resulting in overall decrease of dopamine uptake (Swant et al., 2011; Butler et al., 2015). $\alpha$-Synuclein also develops physical and functional interactions with other monoamine transporters (MATs), such as NET and SERT. In both cases, $\alpha$-synuclein has been shown to negatively modulate the cell-surface expression and uptake activity of the transporters in a NAC-domain dependent manner (Wersinger et al., 2006a,b; Jeannotte and Sidhu, 2007). This finding indicates that $\alpha$ synuclein may exert a homeostatic role, thus supporting that normal MAT expression may depend upon a certain baseline level of $\alpha$-synuclein-MAT interaction. However, the mechanism by which $\alpha$-synuclein expression alters MAT distribution should be further investigated. An opposite reported effect of $\alpha$-synuclein on the dopaminergic pathway is the suppression of apoptosis of dopaminergic neurons (Jin et al., 2011). Supportive of a protective role of $\alpha$-synuclein at the synapse are also findings showing a cooperative function of the protein with the synaptic vesicle protein cysteine-string protein-alpha (CSPalpha) and SNARE proteins, resulting in protection of nerve terminals against injury (Chandra et al., 2005).

Furthermore, $\alpha$-synuclein can also act as a molecular chaperone, due to its high homology and interaction with the 14-3-3 proteins and their ligands, such as molecules of the Ras signaling pathway (Xu et al., 2013), thus possibly contributing to neuronal differentiation (Fu et al., 2000). Moreover, $\alpha$-synuclein is part of a chaperone complex containing the Hsc70/Hsp70 chaperones, participating in the efficient neurotransmitter release
(Witt, 2013). The chaperone activity of $\alpha$-synuclein operates via its $\mathrm{N}$-terminal interaction with the substrate protein, whereas the C-terminal region is responsible for the solubilization of the chaperone complex (Park et al., 2002).

\section{$\alpha$-SYNUCLEIN AS THE PRIMARY CULPRIT FOR SYNUCLEINOPATHIES}

Substantial genetic, neuropathological and biochemical evidence implicates $\alpha$-synuclein in the pathogenesis of PD and related synucleinopathies. Copy number variations, such as duplication or triplications of the SNCA gene encoding for $\alpha$-synuclein, as well as point mutations and single nucleotide polymorphisms (SNPs) cause PD and DLB or increase the risk of developing the disease (Singleton et al., 2003; Chartier-Harlin et al., 2004; Zarranz et al., 2004; Nalls et al., 2014; Orme et al., 2018). Up to date six missense mutations in the SNCA gene are associated with autosomal dominant PD (Figure 1): Ala53Thr (A53T), Ala30Pro (A30P), Glu46Lys (E46K), His50Gln (H50Q), Gly51Asp (G51D), and Ala53Glu4 (A53E) (Polymeropoulos et al., 1997; Kruger et al., 1998; Zarranz et al., 2004; Kiely et al., 2013; Proukakis et al., 2013; Pasanen et al., 2014). The PD-linked mutations identified so far are located in the $\mathrm{N}$-terminus of $\alpha$-synuclein further underscoring the contribution of this region to protein aggregation. Most of them are described to cause early onset PD with rapid disease progression and additional clinical features, such as hallucinations, dementia, pyramidal tract impairment, and autonomic failure. Both mutant A53T and A30P $\alpha$-synuclein mutations are disordered in dilute solution (like the wild-type protein). However, at higher concentrations, LB-like fibrils and discrete spherical assemblies are formed most rapidly by the A53T mutant (Conway et al., 1998). The A53T mutation has a moderate effect in a small region around the site of mutation, resulting in a local structural tendency for oligomerization (Conway et al., 2000; Bussell and Eliezer, 2001). On the other hand, the A30P mutation is associated with reduced formation of LB inclusions and it seems to promote formation of oligomers, rather than fibrils (Conway et al., 2000; Lazaro et al., 2014). The E46K mutation, through its conformational changes in the monomeric protein enhances the contacts between $\mathrm{N}$ - and C-terminus of the protein and promotes fibrillization with an increased tendency to inclusion formation (Fredenburg et al., 2007; Rospigliosi et al., 2009; Lazaro et al., 2014). The H50Q point mutation was discovered at the same year with the G51D and was linked with a late-onset phenotype of PD. H50Q was directly associated with increased $\alpha$-synuclein aggregation and toxicity (Khalaf et al., 2014). Some of the families harboring these rare mutations have clinical manifestations or neuropathological features of both PD and MSA (Fanciulli and Wenning, 2015; Kiely et al., 2015). In particular, the A53T, A53E and G51D mutations, as well as the SNCA gene triplications are associated with a more aggressive MSA-like clinical and pathological phenotype (Kiely et al., 2015).

The genetic link between mutations and copy number variations of the SNCA locus and MSA is still controversial, given that common variation in the SNCA gene was first identified 
as a risk factor for MSA in 2009 (Scholz et al., 2009), but this association was not confirmed in subsequent genome-wide association studies (GWAS) (Chen et al., 2015; Sailer et al., 2016). It is interesting to note that the G51D and A53E $\alpha$ synuclein mutations seem to play an essential role in the inclusion formation in both neuronal and oligodendroglial cells (Pasanen et al., 2014; Whittaker et al., 2017). During the last decade, GWAS of risk in idiopathic PD revealed that SNCA is the major contributor (Satake et al., 2009). However, variability in LRRK2 (leucine-rich repeat kinase 2), GAK (cyclin G-associated kinase) and MAPT (microtubule-associated protein tau) has been also implicated, with variants in SNCA and MAPT found to represent also risk factors for MSA (Scholz et al., 2009; Simon-Sanchez et al., 2009; Vilarino-Guell et al., 2011). Overall, it is apparent that all point mutations of $\alpha$-synuclein alter its secondary structure, indicating that a single mutation in the SNCA gene is adequate for the development of a PD-like phenotype.

$\alpha$-synuclein is the main component of the proteinaceous inclusions that represent the main histopathological hallmark of synucleinopathies, designated as LBs and LNs in PD and DLB (Spillantini et al., 1997, 1998) and GCIs in MSA (Wakabayashi et al., 1998a,b). Moreover, in vitro and in vivo overexpression of wild-type or mutant $\alpha$-synuclein in neurons results in protein aggregation and toxicity, thus leading to phenotypes resembling PD (Giasson et al., 2002; Kirik et al., 2002; Lo Bianco et al., 2002; Vekrellis et al., 2009). Similarly, overexpression of human wild-type $\alpha$-synuclein in oligodendroglial cell lines (Stefanova et al., 2005; Kragh et al., 2009) or in vivo (Kahle et al., 2002; Shults et al., 2005; Yazawa et al., 2005; Stemberger et al., 2010) results in the formation of fibrillar $\alpha$-synuclein forms, which may cause toxicity in oligodendrocytes and/or in neurons (in the animal models) or increase cell susceptibility to oxidative stress, thus recapitulating many features of MSA. Such data clearly demonstrate that the total protein load and aggregation of $\alpha$-synuclein is a critical determinant of its neurotoxic potential, giving rise to the " $\alpha$-synuclein burden hypothesis" which pinpoints a critical role of the protein in idiopathic PD pathogenesis, either through enhanced transcription or through impaired degradation (Vekrellis and Stefanis, 2012). There are conflicting results regarding the mRNA levels of $\alpha$ synuclein in PD and MSA brains, probably due to the difficulty to maintain a proper RNA integrity in tissues undergone extensive neurodegeneration. Even though the factors controlling SNCA transcription in vivo remain largely unknown, a number of regulatory transcriptional elements have been identified in neuronal cells, such as the GATA-1 and -2 transcription factors that enhance SNCA transcription through binding in the Intron 1 region of SNCA gene (Scherzer et al., 2008). Subsequent studies surmised that a signal transduction pathway involving the MAPK 3 and PI3K pathways could be important for controlling SNCA transcription (Clough and Stefanis, 2007) and that the transcription factor ZSCAN21 (Zipro1) could play a significant role (Clough et al., 2009; Brenner et al., 2015; Dermentzaki et al., 2016; Lassot et al., 2018). Recently, the CCAAT/enhancer binding protein $(\mathrm{C} / \mathrm{EBP}) \delta$ was identified as a novel repressor of $\alpha$-synuclein transcription, following its binding to the SNCA genomic region in both mice and humans
(Valente et al., 2020). Post-transcriptional regulation through microRNAs (Junn et al., 2009; Doxakis, 2010; Surgucheva et al., 2013; Choi D.C.et al., 2018; Kim et al., 2018) or lncRNAs (Lin D.et al., 2018; Elkouris et al., 2019; Zou et al., 2020) has also been reported to alter SNCA mRNA levels.

The pathological effects of misfolded $\alpha$-synuclein involve, amongst others, dysregulation of mitochondrial activity and endoplasmic reticulum (ER)-Golgi trafficking, plasma membrane integrity, synaptic vesicle trafficking and function of the ubiquitin-proteasome (UPS) and the autophagy-lysosome pathway (ALP) (Vekrellis et al., 2011). Overexpression of $\alpha$-synuclein causes mitochondrial fragmentation (Kamp et al., 2010), event that is associated with an increase in mitochondrial fission rather than a fusion deficiency (Nakamura et al., 2011). Recently, it was reported that $\alpha$-synuclein is normally localized at mitochondrial-associated membranes, while under pathological conditions $\alpha$-synuclein dislocates from its sites and affects mitochondrial morphology (Guardia-Laguarta et al., 2014). Another study showed that under pathological conditions and in contrast with the native monomeric $\alpha$-synuclein, aggregated forms of the protein preferentially bind to mitochondria, leading to mitochondrial dysfunction and cellular respiration limitation (Wang et al., 2019). Moreover, aggregated $\alpha$-synuclein alters the membrane fusion and fission processes of mitochondria, resulting in fragmentation of the organelle and mitophagy inhibition (Chen and Chan, 2009). This mitochondrial damage is followed by a series of events, such as reactive oxygen species (ROS) production, electron leakage and caspase activation leading eventually to neuronal death (Ganjam et al., 2019). It has also been proposed that ROS production leads to a LRKK2mediated impairment of endosomal and lysosomal function, resulting in pSer129 $\alpha$-synuclein accumulation (Di Maio et al., 2018). Since pSer129 $\alpha$-synuclein is considered an inhibitor of mitochondrial protein import, its aggregation is directly linked to mitochondrial senescence and ROS production, thus creating a positive feedback loop (Di Maio et al., 2018). Along with the mitochondrial dysfunction, $\alpha$-synuclein aggregation also affects the activity of the ER, inducing protein-folding abnormalities, impaired ER-Golgi transport and calcium leakage, which ultimately lead to further aggregation of the protein (Volles and Lansbury, 2002; Thayanidhi et al., 2010; Colla et al., 2012; Colla, 2019). However, one of the main mechanisms through which $\alpha$-synuclein causes neurotoxicity is the abnormal interaction of various protein assemblies with membranes, causing membrane disruption, lipid bilayer thinning and vesicle trafficking dysregulation (Hellstrand et al., 2013; Wang and Hay, 2015; Fusco et al., 2017). In the healthy brain, monomeric $\alpha$-synuclein plays an important role in synaptic function; however, in pathological conditions, $\alpha$-synuclein aggregation impairs the SNARE complex assembly, through its abnormal interaction with essential proteins for the synaptic vesicle cycle function (Dalfo et al., 2004; Gitler et al., 2008; Choi et al., 2013). It has been also shown that fibrillar $\alpha$-synuclein may induce synaptic vesicle endocytosis and blockage of vesicle recycling, further contributing to the development of synaptopathy, which characterizes PD and related synucleinopathies (Nemani et al., 2010; Busch et al., 2014; Xu et al., 2016). Formation of 
aberrant $\alpha$-synuclein species has been widely shown to impair the function of the UPS and the ALP pathway, as discussed below. Similar effects are observed in MSA where the pathological accumulation of $\alpha$-synuclein in oligodendrocytes causes severe disruption of most cellular functions, with the myelination process being a major target of the protein's aberrant effects. The demyelination, along with the reduction of trophic factors, leads to a secondary neuronal cell loss (Shults et al., 2005; Ubhi et al., 2010; Stefanova and Wenning, 2016).

Emerging evidence also suggest that activation of the inflammatory process due to the presence of abnormal $\alpha$ synuclein species plays a central role in the development of synucleinopathies. Postmortem brain examination, brain imaging and animal studies converged that both the innate and adaptive immune systems are activated in PD contributing to disease progression (Tansey and Romero-Ramos, 2019). Activated microglia, which are considered the most efficient scavengers of extracellular $\alpha$-synuclein aggregates (Lee et al., 2008 b), increase the production of pro-inflammatory cytokines and induce an oxidative stress response (Klegeris et al., 2008; $\mathrm{Su}$ et al., 2008; Couch et al., 2011) even in the absence of neuronal loss (Sanchez-Guajardo et al., 2010; Barkholt et al., 2012; Watson et al., 2012). Increased pro-inflammatory mediators such as tumor necrosis factor alpha (TNF- $\alpha$ ), interleukin-1- $\beta$ (IL-1 $\beta$ ), interleukin-6 (IL-6) have been shown in the cerebral spinal fluid (CSF) and in the striatum of human PD brains (Mogi et al., 1994a,b; Vawter et al., 1996; Nagatsu et al., 2000), supporting a chronic pro-inflammatory milieu in the brain of PD patients. Apart from $\alpha$-synuclein mediated activation of microglia in the CNS, a more complex relationship between gut microbial-induced inflammation and $\alpha$-synuclein expression and aggregation has been proposed to occur in the periphery (Chen S.G.et al., 2016; Choi J.G.et al., 2018). Clinical, epidemiological and animal studies suggest a complex cross-talk between intestinal inflammation and PD pathology initiation and progression (Houser and Tansey, 2017; Chen et al., 2019). Similarly, $\alpha$-synuclein-evoked microglial activation is commonly detectable in the brains of MSA patients (Ishizawa et al., 2004) and MSA experimental models (Stefanova et al., 2007; Vieira et al., 2015; Monzio Compagnoni and Di Fonzo, 2019). Even though the activation of the inflammatory cascade in synucleinopathies may not represent a primary event but a secondary in response to other phenomena, it definitely contributes to the neuronal degeneration that characterizes these diseases.

\section{$\alpha$-SYNUCLEIN AND PROTEIN-DEGRADATION PATHWAYS: A COMPLICATED RELATIONSHIP}

Unraveling the pathway involved in the degradation of $\alpha$-synuclein is crucial in understanding the pathogenetic mechanisms underlying its aberrant accumulation in synucleinopathies. Both the UPS and the ALP have been proposed to clear $\alpha$-synuclein (Figure 2); however to a different extent and in a cell-, conformation- and tissue- specific manner
(Bennett et al., 1999; Webb et al., 2003; Vogiatzi et al., 2008). Initial studies in purified systems and in neuronal cells, have demonstrated that $\alpha$-synuclein can undergo both ubiquitindependent (Rott et al., 2011; Haj-Yahya et al., 2013) and ubiquitin-independent (Tofaris et al., 2001; Liu et al., 2003) degradation via the $26 \mathrm{~S} / 20 \mathrm{~S}$ proteasome. Additional studies performed in PC12, HEK293 and primary mesencephalic cells failed to detect significant $\alpha$-synuclein accumulation following pharmacological proteasomal inhibition (Rideout et al., 2001; Rideout and Stefanis, 2002; Vogiatzi et al., 2008). Others have found that only a small proportion of soluble-cell-derived intermediate $\alpha$-synuclein oligomers, not including monomeric $\alpha$-synuclein, are targeted to the $26 \mathrm{~S}$ proteasome for degradation (Emmanouilidou et al., 2010b). In an elegant in vivo study it was shown that the UPS is the main degradation pathway for $\alpha$-synuclein under normal conditions, while with increased $\alpha$-synuclein burden the ALP is recruited (Ebrahimi-Fakhari et al., 2011). We and others have shown that only the wild-type $\alpha$-synuclein and not the PD-linked A53T and A30P forms, the phosphorylated or the dopamine-modified $\alpha$-synuclein, is degraded via the selective process of chaperone-mediated autophagy (CMA) (Cuervo et al., 2004; Martinez-Vicente et al., 2008; Vogiatzi et al., 2008; Mak et al., 2010). CMA can degrade only monomeric or dimeric forms of the protein, whereas macroautophagy is the only process that can clear oligomeric $\alpha$-synuclein (Xilouri et al., 2013b). Not only mutations but also post-translational modifications such as phosphorylation, sumoylation and ubiquitination may also alter the partitioning of $\alpha$-synuclein to proteasomal or lysosomal degradation (Xilouri et al., 2016b).

The UPS and the ALP not only degrade $\alpha$-synuclein but can also be a direct target of the protein's aberrant effects (Xilouri et al., 2016b; Zondler et al., 2017). Initial studies indicated that overexpression of the A30P and A53T mutants make cells more vulnerable to proteasomal inhibition-mediated cell death compared to cells overexpressing the wild-type protein (Tanaka et al., 2001). Additional evidence suggested that overexpression of mutant $\alpha$-synuclein variants inhibits the activity of the $20 S / 26 S$ proteasome leading to UPS failure thus, contributing to $\alpha$ synuclein aggregation (Stefanis et al., 2001), although another study showed that overexpression of wild-type or mutant (A30P, A53T) $\alpha$-synuclein in PC12 cells or in transgenic mice did not significantly affect proteasomal function (Martin-Clemente et al., 2004). More recently, it was shown that the function of the $20 \mathrm{~S}$ proteasome was not affected upon administration of recombinant $\alpha$-synuclein oligomers and fibrils or upon transient expression of wild-type or mutant $\alpha$-synuclein (Zondler et al., 2017).

Studies in human post-mortem material also indicate that proteasome function is impaired in the substantia nigra of PD patients (Bentea et al., 2017), further cementing a role of a proper UPS function in PD pathogenesis. Beyond the UPS, increased $\alpha$-synuclein has been reported to impair macroautophagy both in vitro and in vivo (Winslow et al., 2010), possibly through its interaction with Rabla, which causes the mislocalization of Atg9, an autophagosome formation-related protein (Winslow et al., 2010). Similarly, Atg9 mislocalization and impaired autophagosome formation has been observed in cells expressing 


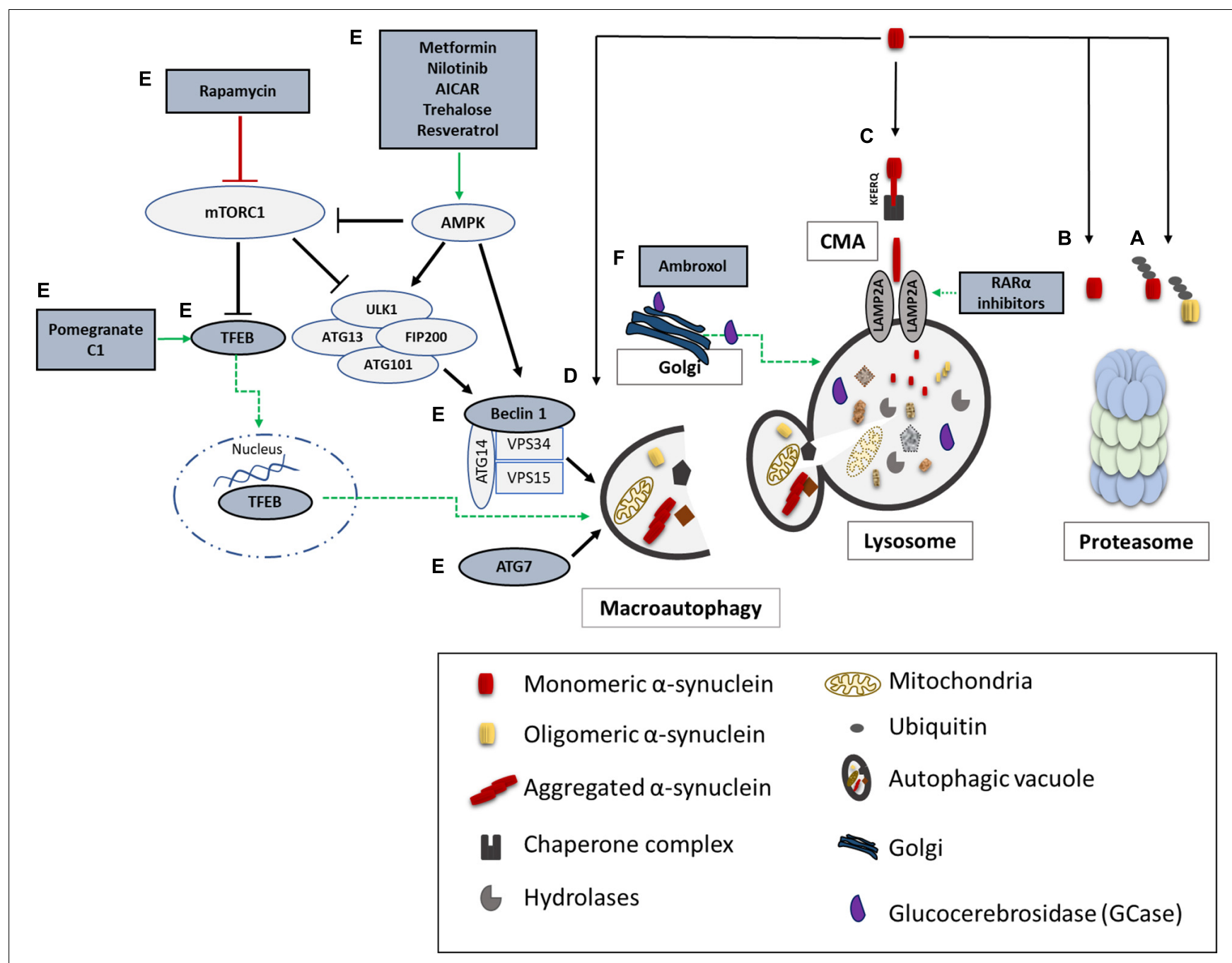

FIGURE 2 | $\alpha$-synuclein degradation pathways and reported therapeutic approaches to enhance protein clearance. A schematic representation of the main proteolytic pathways implicated in $\alpha$-synuclein clearance and the proposed targets for potential therapeutic interventions (highlighted in dark grey and green). Wild type and mutant $\alpha$-synuclein can undergo both ubiquitin-dependent (A) and ubiquitin-independent (B) degradation via the 20S/26S proteasome. Monomeric wild-type $\alpha$-synuclein is degraded via CMA, following its binding to the CMA-specific receptor, LAMP2A (C). Molecular upregulation of LAMP2A expression or chemical enhancement of CMA through retinoic acid receptor alpha (RAR $\alpha$ ) antagonists has been proven successful in alleviating $\alpha$-synuclein-associated toxicity. Macroautophagy has been also proposed to degrade mutant and aggregated forms of $\alpha$-synuclein (D). Boosting macroautophagy via mTOR-dependent (rapamycin) or mTOR-independent pharmacological and nutritional modulators (Metformin, Nilotinib, AICAR, Trehalose, Resveratrol, Pomegranate, C1) enhance autophagosome formation, lysosome biogenesis, and lysosome function thus promoting $\alpha$-synuclein clearance (E). Molecular modulation of macroautophagy via Atg7, Beclin1 or TFEB overexpression is also reported to exert beneficial effects on $\alpha$-synuclein-related toxicity (E). Lastly, restoration of proper enzymatic activity of GCase has been shown to improve lysosomal function and lessen $\alpha$-synuclein levels (F).

the PD-linked mutant form of the retromer protein VPS35 (Zavodszky et al., 2014). There is also evidence suggesting that the PD-linked $\alpha$-synuclein mutations could have a different impact on macroautophagy machinery. In particular, the E46K $\alpha$-synuclein mutation impairs autophagy at an early stage of autophagosome formation via dysregulation of the JNK1/Bcl2, an mTOR-independent pathway (Yan et al., 2014). Also, the A30P mutant $\alpha$-synuclein inhibits autophagosome formation via activation of the autophagy transcriptional repressor ZKSCAN3 in a JNK-dependent manner (Lei et al., 2019). Furthermore, the A53T mutation has been shown to dysregulate mitophagy (Choubey et al., 2011), resulting in massive mitochondrial removal accompanied by bioenergetics deficits and neuronal degeneration. However, another study in A53T $\alpha$-synuclein transgenic mice showed that $\alpha$-synuclein accumulation leads to activation of the p38 MAPK pathway, which in turn directly phosphorylates Parkin thus inhibiting Parkin-mediated mitophagy (Chen et al., 2018). Several independent studies have proposed that autophagy is controlled by the GTP-asep38 MAPK signaling (Obergasteiger et al., 2018), a pathway that may be disturbed in PD. Additionally, mutations in the GBA1 gene, which encodes for the lysosomal enzyme $\beta$ glucocerebrosidase (GCase) and cause Gaucher's disease (GD), are among the most common known genetic risk factors for 
PD and DLB (Mata et al., 2008; Clark et al., 2009). Various studies in cell culture and animal models and in human postmortem material suggest an inverse relationship between $\alpha$ synuclein accumulation and GCase protein levels and activity where reduced GCase activity coincides with increased levels of $\alpha$-synuclein (Mazzulli et al., 2011; Osellame et al., 2013; Sardi et al., 2013; Murphy et al., 2014; Du et al., 2015; Liu et al., 2015; Rocha et al., 2015; Chen M.et al., 2016).

The first connection between CMA and PD was established in 2004, where monomeric and dimeric wild-type $\alpha$-synuclein species were shown to be CMA substrates, whereas the A30P and A53T PD-linked mutant $\alpha$-synuclein forms bound more tightly to LAMP2A, CMA's specific receptor, but were not up taken and degraded within lysosomes, thus becoming toxic by inhibiting the CMA-mediated degradation of other cytosolic substrate proteins (Cuervo et al., 2004). Subsequently, it was shown that post-translational modifications of wild-type $\alpha$ synuclein, such as oxidation and nitration of the protein, alter its binding and uptake into lysosomes, while phosphorylation and dopamine-modification almost completely prevents its CMAdependent degradation (Martinez-Vicente et al., 2008; Xilouri et al., 2009). Reciprocally, CMA inhibition is reported to lead to the formation of detergent-insoluble or high molecular weight oligomeric $\alpha$-synuclein conformations in vitro (Vogiatzi et al., 2008; Xilouri et al., 2009), or to increased intracellular $\alpha$ synuclein accumulation in nigral neurons in vivo (Xilouri et al., 2016b). Furthermore, the protein levels of the two key CMA markers LAMP2A and HSC70, were reported to be decreased in the human substantia nigra and amygdala of PD brains compared to controls (Alvarez-Erviti et al., 2010), while, more recently, decreased protein levels of LAMP2A correlated with increased $\alpha$-synuclein accumulation were found in $\mathrm{PD}$ brain regions harboring $\alpha$-synuclein pathology (anterior cingulate cortex) and not in other regions that are spared (occipital cortex) (Murphy et al., 2014). Importantly, these decreases correlated directly to CMA activity, since the protein levels of the other two LAMP2 isoforms (2B and $2 \mathrm{C}$ ) that do not participate in CMA, were found unaltered between PD and control brains (Murphy et al., 2015). Macroautophagy alterations have also been found in nigral neurons of PD brains (Anglade et al., 1997).

Beyond PD, evidence from human postmortem material from MSA brains suggests the possibility of macroautophagic alterations linked to $\alpha$-synuclein accumulation in GCIs. More particularly, the detection of SQSTM1/p62 and, in some cases, of LC3 (but not of more mature lysosomal markers) and of the autophagic adaptor protein NBR1 within GCIs together with $\alpha$-synuclein suggests a possible initial induction of macroautophagy and a subsequent defect in macroautophagy maturation in MSA brains (Chiba et al., 2012; Odagiri et al., 2012; Schwarz et al., 2012; Tanji et al., 2013). In addition, the FBXO27 gene, which encodes a protein associated with ubiquitination and protein degradation, was identified in a recent GWAS as a potential risk factor for MSA (Sailer et al., 2016). These neuropathological studies have also suggested the possibility of impaired proteasomal function as a driving force for GCI formation. Studies in oligodendroglial cells showed that, upon pharmacological proteasomal inhibition, p62 and LC3 accumulate in forming aggregates, in an apparent compensatory response of macroautophagy activation (Schwarz et al., 2012). In addition, dysfunctional macroautophagy evoked through mitochondrial impairment or macroautophagy inhibition resulted in the accumulation of $\alpha$-synuclein in oligodendroglial cells (Pukass et al., 2015), whereas more recently it was reported that macroautophagy block through genetic or pharmacological inhibition of autophagy was inefficient to increase intracellular accumulation of $\alpha$-synuclein in oligodendrocytes exposed to monomeric or fibrillar $\alpha$-synuclein (Fellner et al., 2018). Nonetheless, additional work is needed to elucidate the precise role of UPS and ALP dysfunction in the accumulation of $\alpha$-synuclein-rich GCIs in MSA brains.

\section{CELL-TO-CELL PROPAGATION OF $\alpha$-SYNUCLEIN PATHOLOGY IN SYNUCLEINOPATHIES: THE STRAIN HYPOTHESIS}

According to Braak staging, Lewy pathology manifested by positive $\alpha$-synuclein inclusions spreads throughout the brain as PD progresses, primarily affecting the brainstem and olfactory system, thereafter gradually invading the neocortex (Braak et al., 2003). Amongst numerous studies that have tested this hypothesis (Braak et al., 2006; Lebouvier et al., 2010; Pouclet et al., 2012; Grathwohl et al., 2013; Paillusson et al., 2013; Holmqvist et al., 2014), recently it was shown that $\alpha$-synuclein pre-formed fibrils (PFFs) injected into the duodenal and pyloric muscularis layer evoked a spread of pathologic Ser129 phosphorylated $\alpha$-synuclein in various brain regions. Interestingly, truncal vagotomy prevented the gut-tobrain transmission of $\alpha$-synuclein pathology, supporting the Braak hypothesis of a prion-like templating mechanism (Kim et al., 2019). Similarly, a cohort study of vagotomized patients supported that the vagus nerve is involved in the development of PD (Svensson et al., 2015). Recently, $\alpha$-synuclein inclusions were detected in stomach and heart of a bacterial artificial chromosome (BAC) transgenic rat model injected into the gut wall of the pylorus and duodenum with $\alpha$-synuclein PFFs. Their findings suggest a secondary anterograde (Dorsal Motor nucleus of the Vagus [DMV]-to-stomach) spreading of $\alpha$-synuclein pathology, followed by a primary retrograde (duodenum-toDMV) spreading (Van Den Berge et al., 2019).

However, there are studies presenting controversial results, suggesting that $\alpha$-synuclein transmission from a peripheral injection site reaches the dorsal nucleus of vagus nerve, but does not further spread in the CNS (Manfredsson et al., 2018; Uemura et al., 2018). The hypothesis of $\alpha$-synuclein prion-like propagation has gained attention in the recent years, since it has been shown that transplantation of healthy fetal mesencephalic neurons in PD patients led to the formation of LB-like inclusions, indicating the direct transfer of pathogenic $\alpha$-synuclein from host brain to grafted neurons (Kordower et al., 2008; Li et al., 2008). Similar studies have verified that neurons inside the grafts were positive for LB-like $\alpha$-synuclein aggregates (Li et al., 2008, 2010; 
Kordower et al., 2011; Kurowska et al., 2011). Moreover, inoculation of brain extracts from PD and DLB patients into the striatum and substantia nigra of mice (Masuda-Suzukake et al., 2013) and non-human primates induced $\alpha$-synuclein aggregation and neurodegeneration (Recasens et al., 2014).

The first clinical evidence to support $\alpha$-synuclein spread throughout the nervous system was the detection of the protein in human CSF, indicating that $\alpha$-synuclein can be released into the extracellular space (El-Agnaf et al., 2003). Subsequent studies verified the secretion of $\alpha$-synuclein from neuronal cells, in part via vesicle- and exosomal-related trafficking (Lee et al., 2005; Emmanouilidou et al., 2010a; Jang et al., 2010; Danzer et al., 2012). On the other hand, conventional endocytosis (Sung et al., 2001; Lee et al., 2008a; Desplats et al., 2009; Hansen et al., 2011; Angot et al., 2012), exosomal transport (Emmanouilidou et al., 2010a; Delenclos et al., 2017), receptor-mediated internalization (Shrivastava et al., 2015; Mao et al., 2016; Ihse et al., 2017), passive diffusion (Ahn et al., 2006), or even direct penetration of the plasma membrane (Kayed et al., 2004; Jao et al., 2008; Lee et al., 2008a; Tsigelny et al., 2012) have been proposed as the main pathways for $\alpha$-synuclein uptake (Figure 3). Amongst the receptors that have been proposed to mediate the uptake of the protein by neurons is the FcyRIIB inhibitory Fc receptor, which has been shown to be responsible for fibrillar $\alpha$-synuclein cellto-cell transmission mediated by the FcgRIIB-SHP-1/2 signaling (Choi Y.R.et al., 2018) and the LAG3 receptor reported to interact with fibrillar but not monomeric $\alpha$-synuclein (Mao et al., 2016). Moreover, heparan sulfate proteoglycans (HSPGs) seem to regulate $\alpha$-synuclein uptake via macropinocytosis in neurons, whereas GM1 ganglioside is responsible for $\alpha$-synuclein entry in microglial cells (Park et al., 2009; Holmes et al., 2013). Fibrillar $\alpha$-synuclein has been shown to interact in vitro with HSPGs via specific sequence motifs and thus be effectively endocytosed (Zhang et al., 2020). Recent data revealed that N-linked glycans on the cell surface of neurons interact with acetylated $\alpha$-synuclein and mediate its internalization and subsequent pathological aggregation (Birol et al., 2019).

It has also been reported that neurons can take up naked $\alpha$-synuclein following it's binding to specific membrane proteins, which are then partially localized within the lysosomal compartment (Lee et al., 2008a; Karpowicz et al., 2017). Disruption of the lysosomal function has been shown to play an important role in the transmission of $\alpha$-synuclein pathology and the subsequent neurodegeneration (Xilouri et al., 2016a; Jiang et al., 2017; Klein and Mazzulli, 2018; Minakaki et al., 2018). Importantly, in cases of compromised cell proteolytic machineries, vesicle-associated $\alpha$-synuclein release seems to be enhanced (Jang et al., 2010; Alvarez-Erviti et al., 2011; Danzer et al., 2012; Lee et al., 2013; Fussi et al., 2018). However, cell-tocell spread of $\alpha$-synuclein pathology does not necessarily require cell contacts, since tunneling nanotubes may also represent a possible transmission mechanism (Abounit et al., 2016; Figure 3). Exogenous $\alpha$-synuclein, once taken up by neuronal or glial cells is directed to their cytosol where it recruits the aggregation of the endogenous $\alpha$-synuclein into the formation of aberrant species, via an up-to-date unknown mechanism (Volpicelli-Daley et al., 2014; Rey et al., 2016; Karampetsou et al., 2017; Karpowicz et al.,
2017; Kaji et al., 2018; Luna et al., 2018; Mavroeidi et al., 2019). Many in vitro and in vivo studies have proposed that exogenously added human $\alpha$-synuclein PFFs are used as a template and recruit the endogenous soluble monomeric $\alpha$-synuclein into the formation of insoluble LB-like inclusions (Luk et al., 2009, 2012a; Volpicelli-Daley et al., 2011; Masuda-Suzukake et al., 2013; Sacino et al., 2013a, 2014a,b; Wu et al., 2019). Similar results were obtained in vivo when PD brain- or symptomatic $\alpha$-synuclein transgenic mice-derived homogenates were delivered in the living brains of mice and monkeys (Mougenot et al., 2012; Recasens et al., 2014; Schweighauser et al., 2015).

Two seeding processes have been demonstrated to govern the aggregation of the endogenous $\alpha$-synuclein: homotypic (or self-seeding) and heterotypic seeding. The term "homotypic seeding" is referred to the sequence-specific templating of $\alpha$ synuclein that requires the presence of the hydrophobic NAC region (El-Agnaf et al., 1998; Giasson et al., 2001). On the other hand, heterotypic seeding is a process that involves other proteins (such as tau, huntingtin and $A \beta$ ) in the initiation of $\alpha$-synuclein recruitment and fibrillization (Charles et al., 2000; Masliah et al., 2001; Giasson et al., 2003; Pletnikova et al., 2005; Badiola et al., 2011; Tomas-Zapico et al., 2012). Many studies utilizing the $\alpha$-synuclein PFF-brain inoculation as a PD model, suggest the "connectomic" transmission of pathological $\alpha$ synuclein from the injection site to various interconnected brain regions (Luk et al., 2012a; Masuda-Suzukake et al., 2013, 2014; Paumier et al., 2015; Peelaerts et al., 2015; Ulusoy et al., 2015; Rey et al., 2016) and that this $\alpha$-synuclein spread based on the anatomical connections between brain areas (Luk et al., 2012b; Rey et al., 2013, 2016; Peelaerts et al., 2015), party occurs via gap junction channels composed of connexins, formed between adjacent cells (Diaz et al., 2019; Reyes et al., 2019). Finally, a recent study pinpoints 14-3-3 proteins as potential regulators of $\alpha$-synuclein transmission, proposing that they normally prevent $\alpha$-synuclein oligomerization and resultant toxicity, whereas 14-33 protein dysfunction mediates $\alpha$-synuclein oligomerization and seeding, that govern PD pathology (Wang et al., 2018). Numerous in vitro and in vivo studies utilizing $\alpha$-synuclein PFFs as seeds, have proposed an induction in the endogenous neuronal $\alpha$ synuclein aggregation, thus favoring the prion-like hypothesis of $\alpha$-synuclein spread (Luk et al., 2009, 2012a; Volpicelli-Daley et al., 2011; Masuda-Suzukake et al., 2013; Sacino et al., 2014b; Paumier et al., 2015; Peelaerts et al., 2015; Abdelmotilib et al., 2017). Interestingly, not only PFFs but also isolated exosomes from the CSF of PD and DLB patients, containing pathological species of $\alpha$-synuclein, were able to transfer the disease pathology when applied in human H4 neuroglioma cells (Stuendl et al., 2016).

Beyond PD, the self-propagation of $\alpha$-synuclein resulting in the formation of insoluble aggregates within the cytoplasm of oligodendrocytes termed MSA also as a prion-like disease. Prusiner et al. originally reported that $\mathrm{TgM}_{83}{ }^{+/-}$mice expressing human A53T $\alpha$-synuclein when inoculated with MSA, but not $\mathrm{PD}$, brain homogenates developed neurodegeneration, suggesting that a distinct strain of $\alpha$-synuclein displays prion characteristics during the development of MSA (Watts et al., 2013; Prusiner et al., 2015). Accordingly, treatment of HEK293T cells stably expressing fluorescently-tagged $\alpha$-synuclein with 


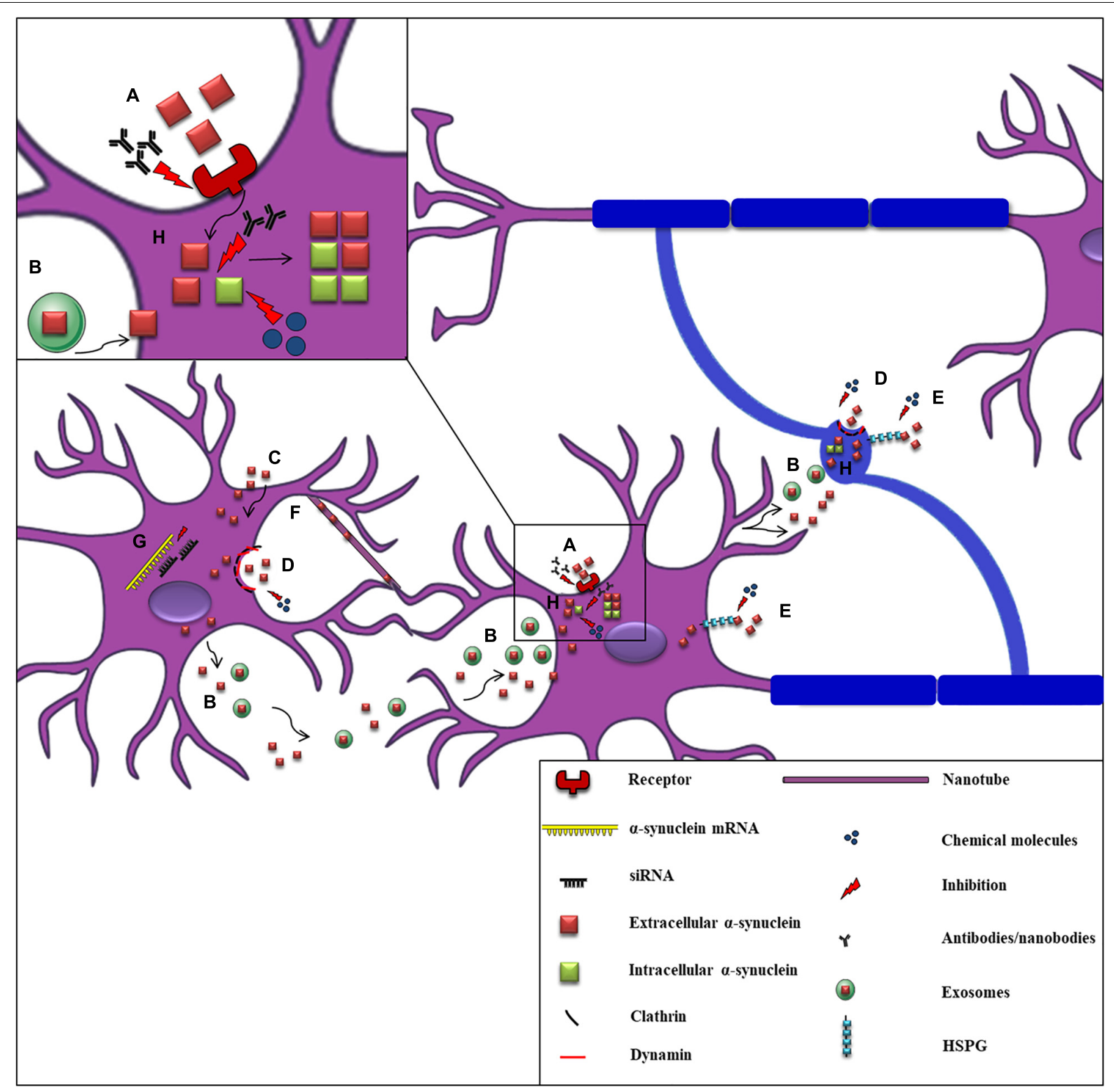

FIGURE 3 | Proposed mechanisms of $\alpha$-synuclein cell-to-cell propagation and application of candidate therapeutic strategies. A schematic representation of $\alpha$-synuclein transfer from neurons to neurons (purple) or to oligodendrocytes (blue) via various mechanisms: (A) Neuronal receptors (i.e., LAG3) interact with extracellular $\alpha$-synuclein and mediate its internalization via endocytosis. Antibodies against these receptors effectively inhibit $\alpha$-synuclein propagation. (B) Neuronally-derived, free or exosomal-bound $\alpha$-synuclein enters neighboring neurons or oligodendrocytes. (C) $\alpha$-synuclein is taken-up by cells via passive diffusion or direct penetration of their plasma membrane. (D) Clathrin- or dynamin- mediated endocytosis is responsible for $\alpha$-synuclein internalization in neurons and oligodendrocytes. Inhibitors targeting these endocytic pathways have been effectively used. (E) Heparan Sulfate ProteoGlycans (HSPGs) regulate $\alpha$-synuclein uptake via macropinocytosis in neurons and oligodendrocytes. Disruption of HSPGs by chemical molecules (heparin or chloral hydrate) inhibits $\alpha$-synuclein uptake by cells. (F) Tunneling nanotubes (thin membranous bridges) have been also proposed as a possible cell-to-cell transmission mechanism of $\alpha$-synuclein. (G) siRNAs (small interfere RNAs) designed against $\alpha$-synuclein mRNA are used for the reduction of $\alpha$-synuclein production as an effective therapeutic strategy. (H) $\alpha$-synuclein entrance in neuronal or oligodendroglial cells is followed by its aggregation and the spread of $\alpha$-synuclein pathology (seeding), finally leading to the formation of aberrant protein species. Various antibodies targeting the NAC or the C-terminal region of $\alpha$-synuclein and chemical molecules and compounds (i.e., NPT200-11, NPT100-18A, NPT088 etc.) inhibiting $\alpha$-synuclein aggregation have been used to prevent $\alpha$-synuclein misfolding.

either healthy-control brain extracts or brain samples derived from PD or MSA patients, revealed that only in the case of MSA-added material, cells developed $\alpha$-synuclein accumulation (Woerman et al., 2015). The prion-like transmission of $\alpha$ synuclein pathology was further supported by intrastriatal delivery of MSA homogenates in the brain of human-wild type $\alpha$-synuclein-expressing mice and detection of pathological $\alpha$ synuclein aggregates formed in many brain regions (Bernis et al., 2015). Two possible scenarios have been proposed to explain the origin of $\alpha$-synuclein in oligodendrocytes and the mechanisms 
underlying $\alpha$-synuclein accumulation in GCIs present in MSA brains: either oligodendrocytes pathologically overexpress $\alpha$ synuclein in the context of MSA (Asi et al., 2014) or they take up neuronally derived protein from their environment (Kisos et al., 2012; Konno et al., 2012; Rockenstein et al., 2012; Ettle et al., 2014; Pukass and Richter-Landsberg, 2014; Reyes et al., 2014; Pukass et al., 2015; Kaji et al., 2018). We have recently suggested that the presence of endogenous oligodendroglial $\alpha$ synuclein, however minute in amount, is a critical factor for the generation of pathological GCI-like $\alpha$-synuclein structures within oligodendrocytes and myelin dysregulation evoked by PFFadministration both in vitro and in vivo (Mavroeidi et al., 2019).

Furthermore, as already mentioned, neuroinflammation is a key mediator of $\alpha$-synuclein-related toxicity, since microglia and astroglia activation, gliosis and increased secretion of proinflammatory factors are often observed in synucleinopathies (Nagatsu and Sawada, 2005; Politis et al., 2012; Tufekci et al., 2012; Fellner and Stefanova, 2013; Kaufman et al., 2013). Many studies focused on $\alpha$-synuclein transfer between neurons and glial cells (Lee et al., 2010; Sacino et al., 2013b; Reyes et al., 2014). It has been proposed that $\alpha$-synuclein attracts and activates microglia; however these cells fail to clear $\alpha$-synuclein, thus leading to an excessive pro-inflammatory response via Tolllike receptor (TLR) and finally to neurodegeneration (Stefanova et al., 2011; Kim et al., 2013; Roodveldt et al., 2013; Tang and Le, 2016). A recent study suggests that the differential activation state of microglial cells plays a crucial role in neuronto-neuron $\alpha$-synuclein spread and that IL-4-activated microglia seems to engulf extracellular $\alpha$-synuclein, thus reducing neuronto-neuron $\alpha$-synuclein transmission (George et al., 2019). Others have suggested that pathological $\alpha$-synuclein spreads through tunneling nanotubes in macrophages and possibly in microglial cells as well (Onfelt et al., 2004). The neuron-to-astrocyte and astrocyte-to-astrocyte transmission of $\alpha$-synuclein has been shown both in in vitro and ex vivo experiments, however $\alpha$ synuclein aggregates are preferably formed within neurons rather than in astrocytes (Lee et al., 2010; Loria et al., 2017). This fact could be attributed to the protective role of astrocytes against $\alpha$-synuclein aggregation, via enhanced proteolytic processing of exogenously added PFFs (Loria et al., 2017).

Interestingly, it has been proposed that $\alpha$-synuclein joins into distinct polymorphisms possibly responsible for the variety of disease phenotypes giving rise to the strain hypothesis, underlying the pathogenesis of synucleinopathies. Based on this scenario, the central idea is that $\alpha$-synuclein fibrils behave as strains with discrete biochemical and structural characteristics, into distinct brain regions and cell types (Cremades et al., 2012; Bousset et al., 2013; Kim et al., 2016; Ma et al., 2016; Pieri et al., 2016; Lau et al., 2020). Supportive of this hypothesis are findings showing that pathological $\alpha$-synuclein in PD and MSA inclusions is conformationally and biologically distinct and different $\alpha$ synuclein strains are generated in discrete intracellular milieus (Peng et al., 2018a). We have also shown that the pathologyrelated S129 $\alpha$-synuclein phosphorylation in primary cultures and human post-mortem brain material might involve different $\alpha$-synuclein strains present in oligodendroglial and neuronal synucleinopathies (Mavroeidi et al., 2019).
Most importantly, it is reported that $\alpha$-synuclein fibrils amplified from the brains (Strohaker et al., 2019) or CSF (Shahnawaz et al., 2020) of PD patients are structurally different than those from MSA, further suggesting that distinct conformational strains of $\alpha$-synuclein may underlie the different pathology detected in two synucleinopathies. Therefore, it is surmised that based on the diversity of the human strains and via the protein misfolding cyclic amplification (PMCA) technique, we can discriminate between $\mathrm{PD}$ and MSA pathology in patient-derived CSF samples with high sensitivity (Shahnawaz et al., 2020). These strains can recruit and seed endogenous $\alpha$-synuclein, and also propagate by imprinting their unique structural properties on its nonpathogenic counterpart (Bousset et al., 2013; Peelaerts et al., 2015; Mavroeidi et al., 2019). Through their neurotoxic behavior as oligomeric or fibrillar assemblies, $\alpha$-synuclein strains are the crucial pathogens responsible for the induction of $\alpha$ synuclein - and tau-specific disease phenotypes (Guo et al., 2013; Peelaerts et al., 2015; Candelise et al., 2019). In addition, it has been recently reported that MSA strains show several similarities with PD strains, but are significantly more potent in inducing motor deficits, nigrostriatal neurodegeneration, $\alpha$ synuclein pathology, spreading, and inflammation, reflecting the aggressive nature of this disease (Van der Perren et al., 2020). In contrast, DLB-amplified strains displayed very modest neuropathological features.

\section{THERAPEUTIC APPROACHES TO HALT $\alpha$-SYNUCLEINOPATHY}

Unfortunately, up-to-date no disease-modifying therapies exist for $\alpha$-synucleinopathies only symptomatic therapies to relief motor impairment, including dopamine replacement, deep brain stimulation and pharmacological treatment of non-motor symptoms (Aarsland et al., 2002; Fahn et al., 2004; Ravina et al., 2005; Burn et al., 2006; Okun, 2012). Given the critical role of $\alpha$ synuclein levels to disease pathogenesis, one obvious approach is to curtail total protein levels, either by reducing protein production or by enhancing protein degradation. Another approach would be to inhibit protein aggregation and misfolding or to alter $\alpha$-synuclein post-translational modifications such as phosphorylation, which are suggested to affect the aggregation process and the development of toxic species. Targeting the extracellular levels of the protein with antibodies and intervening in the proposed mechanisms of uptake is also an attractive approach, since this may combat $\alpha$-synuclein propagation and disease progression.

\section{REDUCING $\alpha$-SYNUCLEIN PRODUCTION}

Decreasing the production and the cytoplasmic levels of $\alpha$-synuclein with the use of RNA interference (RNAi) technology represents an attractive approach for therapy in synucleinopathies (Figure 3). Specifically, there are in vivo studies showing that delivery of either naked small interfering 
RNAs (siRNAs) or lentiviral-mediated RNAi for SNCA silencing in the rodent brain, can effectively reduce $\alpha$-synuclein levels (Sapru et al., 2006; Lewis et al., 2008). Accordingly, similar siRNA delivery in the substantia nigra of squirrel monkeys led to a significant suppression of $\alpha$-synuclein expression with no toxic effects in the animal physiology (McCormack et al., 2010). Another study also suggested a non-toxic but rather a neuroprotective role of $\alpha$-synuclein reduction in rats injected with shRNAs against SNCA via adeno-associated virus (AAV) (Zharikov et al., 2015).

In vitro and in vivo experiments using an amido-bridged nucleic acid (AmNA)-modified antisense oligonucleotide (ASO) resulted in decreased mRNA and protein levels of $\alpha$-synuclein and improved motor deficits in a PD mouse model (Uehara et al., 2019). In addition, AAV-mediated delivery of an anti- $\alpha$ synuclein ribozyme (rAAV-SynRz) prevented the death of the nigral dopaminergic neurons in the rat MPTP intoxication model (Hayashita-Kinoh et al., 2006). The rescue of dopaminergic cells loss via gene silencing has also been studied using an AAV harboring a short-hairpin (sh)RNA targeting human SNCA in the rat striatum, previously injected with AAV-hSNCA for human $\alpha$-synuclein overexpression (Khodr et al., 2011). In vitro studies from the same group revealed that the miR-30-embedded shRNA silencing vector successfully decreased $\alpha$-synuclein levels (Han et al., 2011); yet delivery of AAV-mir30-hSNCA in the rat brain did not produce encouraging results towards a potential PD therapy (Khodr et al., 2014).

However, there are controversial studies that present degenerative outcomes following a reduction of $\alpha$-synuclein levels in the substantia nigra of rats and non-human primates (Gorbatyuk et al., 2010; Kanaan and Manfredsson, 2012; Collier et al., 2016; Teki and Griffiths, 2016; Benskey et al., 2018). siRNA-mediated reduction of $\alpha$-synuclein has been also shown to regulate dopamine release in SH-SY5Y cells and to be used as a protective mechanism against $\mathrm{MPP}^{+}$-induced neurotoxicity (Fountaine and Wade-Martins, 2007). Moreover, exosomal-associated siRNA intravenous-delivery targeting $\alpha$-synuclein mRNA in both wild type and $\alpha$-synuclein transgenic mice, prevented protein aggregation (Cooper et al., 2014). Additionally, $\alpha$-synuclein knockdown in the brain of wild-type mice, using siRNAs and an anti-sense oligonucleotide molecule (ASO), did not display any harmful effects on neuronal function (Alarcon-Aris et al., 2018). Finally, beta-2-adrenoreceptor (beta-2AR) ligands were shown to modulate SNCA transcription through histone 3 lysine 27 acetylation of SNCA promoter and enhancers. Beta-2AR agonists (clenbuterol and salbutamol) when used in various cellular and in vivo models, led to the reduction of $\alpha$-synuclein expression, whereas beta-2AR antagonist propranolol increased SNCA transcription and $\alpha$-synuclein production (Mittal et al., 2017).

\section{ENHANCING $\alpha$-SYNUCLEIN DEGRADATION}

Given the well-recognized role of ALP in $\alpha$-synuclein degradation (Figure 2) the mammalian target of rapamycin (mTOR) has emerged as a therapeutic target for PD. Towards this direction, rapamycin, an inhibitor of mTOR, was shown to reduce $\alpha$ synuclein accumulation in WT, A30P and A53T $\alpha$-synucleinoverexpressing PC12 cells (Webb et al., 2003), to attenuate dopaminergic degeneration in neurotoxin-induced (Dehay et al., 2010; Malagelada et al., 2010; Liu et al., 2013) and $\alpha$-synucleinoverexpressing PD models (Crews et al., 2010) and to improve motor function in A53T $\alpha$-synuclein transgenic mice (Bai et al., 2015). However, a considerable limitation of rapamycin is that it interferes with numerous other autophagy independent pathways, including immunosuppression (Staats et al., 2013) and that prolonged exposure to rapamycin inhibits mTORC2 (Schreiber et al., 2015), thus leading to the stimulation of other important cellular pathways. To overcome these unwanted side effects, studies focused on TFEB, a down-stream target of mTOR, and showed that TFEB overexpression promoted the clearance of pathologic $\alpha$-synuclein and restored neurodegeneration in PD animal models (Dehay et al., 2010; Decressac et al., 2013). Similarly, oligodendroglial-targeted TFEB overexpression efficiently prevented $\alpha$-synuclein accumulation and rescued nigrostriatal neurodegeneration in the PLP- $\alpha$-synuclein MSA mouse model (Arotcarena et al., 2019).

Moreover, several compounds associated with the activation of the AMP-activated protein kinase (AMPK)-dependent autophagy, such as metformin (Dulovic et al., 2014; Patil et al., 2014; Lu et al., 2016), or nilotinib (Hebron et al., 2013; Karuppagounder et al., 2014; Mahul-Mellier et al., 2014), have been reported to inhibit $\alpha$-synuclein accumulation and to exert neuroprotection in several PD models. The tyrosine-kinase inhibitor nilotinib -a medication widely used for the treatment of chronic myelogenous leukemia- has now been repurposed for the treatment of PD and a Phase 1 clinical trial in 11 PD and DLB patients showed cognitive and motor improvement following nilotinib administration (NCT02281474). A larger Phase 2 clinic trial including 75 PD patients is currently being conducted with so far promising results (NCT02954978). Comparable findings have been reported upon application of 5-aminoimidazole-4-carboxamide ribonucleotide (AICAR) (a drug used for the treatment of acute lymphoblastic leukemia) in various PD models ( $\mathrm{Ng}$ et al., 2012; Dulovic et al., 2014). Trehalose, also leads to an AMPK-dependent and mTORindependent induction of autophagosome biogenesis and has been also shown to exert beneficial effects on cell survival and autophagy-dependent $\alpha$-synuclein clearance in cellular (Sarkar et al., 2007; Casarejos et al., 2011; Lan et al., 2012) and animal PD models (Sarkar et al., 2014; Tanji et al., 2015; Wu et al., 2015; He et al., 2016). Collectively, given the pleiotropic actions and the limited specificity of these agents for the autophagic process, it's challenging to determine whether the observed beneficial effects are mediated by AMPK activation or are a result of other off-target effects, which limit their potential therapeutic utility in synucleinopathies.

In search of non-chemical methods to modulate autophagy, experimental evidence shows that the natural inducer of autophagy curcumin, counteracted the accumulation of the A53T $\alpha$-synuclein through down-regulation of the mTOR/p70S6K signaling pathway in SH-SY5Y cells (Pandey et al., 2008; 
Jiang et al., 2013) and conferred neuroprotection in rotenonetreated dopaminergic neurons (Satish Bollimpelli and Kondapi, 2015). A curcumin analog, C1, has been recently identified as a novel mTOR-independent activator of TFEB (Song et al., 2016), resulting in enhanced autophagy and increased lysosome biogenesis in the rat brain (Song et al., 2016). Likewise, the natural compound pomegranate has been shown to enhance TFEB activity and activate mTOR-independent autophagy and mitophagy (Tan et al., 2019). The natural plant phenol resveratrol, possibly following the interaction with its direct target SIRT1, was also shown to induce an AMPK-dependent autophagy and exert beneficial effects in several in vitro and in vivo $\mathrm{PD}$ models (Wu Y. et al., 2011; Ferretta et al., 2014; Lin et al., 2014; Guo et al., 2016; Ur Rasheed et al., 2016). A major concern of broad macroautophagy enhancement is the multifunctional role and status of activation in different cell types and tissues and the fact that excessive stimulation of macroautophagy under specific circumstances can exert detrimental effects (Yang et al., 2007; Choi et al., 2010; Xu et al., 2014). We have previously shown that CMA inhibition conferred by aberrant $\alpha$-synuclein overexpression in neuronal cells resulted to a compensatory induction of macroautophagy and subsequent death, whereas pharmacological and molecular macroautophagy inhibition exerted a protective effect (Xilouri et al., 2009). Furthermore, the activation of mitophagy in primary cortical neurons overexpressing A53T $\alpha$-synuclein caused mitochondrial destruction and neuronal degeneration that could be rescued by inhibition of macroautophagy (Choubey et al., 2011).

Another promising approach implicates the restoration of proper GCase activity as means to facilitate $\alpha$-synuclein degradation. In vivo studies demonstrated that enhancing GCase activity (either pharmacologically or molecularly) could prevent or diminish formation of toxic $\alpha$-synuclein species and related toxicity (Sardi et al., 2011, 2013). Enzyme-replacement therapies for GD showed that GCase does not cross the blood-brain barrier (BBB), therefore, recent strategies focused on the development of small-molecule chaperones to correct the folding of GCase, enhance GCase activity and restore lysosomal function to facilitate $\alpha$-synuclein clearance (Schapira and Gegg, 2013; Blanz and Saftig, 2016). Ambroxol is a drug commonly used as an anti-mucolytic respiratory agent (Malerba and Ragnoli, 2008) and has been shown to restore lysosomal function and reduce oxidative stress in GBA1 mutant fibroblasts (McNeill et al., 2014; Ambrosi et al., 2015). More recently, ambroxol treatment was found to increase GCase levels, improve autophagy and decrease $\alpha$-synuclein levels in neural crest stem cell-derived dopaminergic neurons from GBA1 mutation patients (Yang et al., 2017) and $\alpha$-synuclein transgenic mice (MigdalskaRichards et al., 2016). The same group reported that oral administration of ambroxol increased GCase activity in the nonhuman primate brain indicating that ambroxol represents a promising novel disease modifying therapy for the treatment of PD and neuropathic GD (Migdalska-Richards et al., 2017). A phase 2 clinical trial assessing the safety and efficacy of ambroxol to improve motor and cognitive features of PDGD patients has been recently completed (NCT02914366) (Silveira et al., 2019). Moreover, another clinical trial of PD patients (with or without GBA1 mutations) treated with up to $420 \mathrm{mg} /$ day of ambroxol at 5 intra-dose escalations over the course of 6 months, confirmed the safety, tolerability and CSF penetration of this drug (NCT02941822) (Mullin et al., 2020). Furthermore, treatment with LTI-29, another activator of GCase activity, has been shown to reduce glucosylceramide levels in vivo ${ }^{1}$ and the safety and tolerability of this therapeutic candidate are being tested in a phase 1 clinical trial in GBAPD patients (NTR6960, EudraCT2017 004086 27). Finally, new glucosylceramide synthase inhibitors capable of crossing the BBB and prevent the substrate buildup in mouse models have arisen as another strategy for intervention (Sardi et al., 2017, 2018). Toward this direction, a phase 1 clinical trial assessing the safety and tolerability of the glycosylsynthase inhibitor Venglustat (GZ/SAR402671) in GBA-PD patients has successfully been completed (NCT02906020) and this therapeutic approach is currently into phase 2 (Judith Peterschmitt et al., 2019).

Restoration of CMA activity could also provide therapeutic benefit in synucleinopathies, by not only promoting the clearance of $\alpha$-synuclein, but also by mitigating its detrimental effects on lysosomal function. To this end, we have shown that overexpression of LAMP2A, CMA's rate-limiting step in human neuroblastoma SH-SY5Y cells, rat primary cortical neurons and nigral dopaminergic neurons in vivo, was capable of alleviating $\alpha$-synuclein-related toxicity (Xilouri et al., 2013a). Similarly, LAMP2A overexpression promoted autophagic flux and prevented $\alpha$-synuclein-induced PD-like symptoms in the Drosophila brain (Issa et al., 2018). Moreover, pharmacological manipulation of the CMA pathway using AR7, a retinoic acid receptor alpha $(\mathrm{RAR} \alpha)$ antagonist, in $\mathrm{LRRK} 2^{\mathrm{R} 1441 \mathrm{G}}$ mutant mouse fibroblasts restored the impaired lysosomal function and attenuated the progressive accumulation of both intracellular and extracellular $\alpha$-synuclein oligomers, surmising that CMA activation could successfully prevent the accumulation of such species (Ho et al., 2020). Based on the findings supporting that pathogenic forms of $\alpha$-synuclein lead to abnormal LAMP2A binding and disruption of the receptor's assembly (Cuervo et al., 2004; Martinez-Vicente et al., 2008) modulation of LAMP2A dynamics at the lysosomal membrane may also represent a fruitful strategy. CMA activity is regulated by the lysosomal mTORC2/PHLPP1/Akt axis (Arias et al., 2015), suggesting that available drugs acting as inhibitors of mTORC2 or Akt, or as activators of PHLPP1 that can modulate the assembly/disassembly rate of the LAMP2A translocation complex could become attractive targets for selective modulation of CMA.

\section{INHIBITING $\alpha$-SYNUCLEIN AGGREGATION}

Prevention of $\alpha$-synuclein aggregation and misfolding is a key player in disease confronting (Figure 3). The selective specificity of intrabodies/nanobodies allows them to bind to specific regions of different $\alpha$-synuclein species (monomers, oligomers, fibrils)

\footnotetext{
${ }^{1}$ https://lti-staging.squarespace.com/our-science/\#lti-291
} 
and modulate aggregation, therefore attenuating the disease pathology (Bhatt et al., 2013). The nanobodies VH14*PEST and NbSyn $87^{*}$ PEST target the NAC and the C-terminal regions of $\alpha$ synuclein, respectively, and have been efficiently used against the formation of pathological pSer129 $\alpha$-synuclein species following their delivery using viral vectors in the rat substantia nigra (Chatterjee et al., 2018). Three small molecules, NPT200-11, NPT100-18A and NPT088 have been reported as inhibitors of either oligomeric or proteinase K-resistant $\alpha$-synuclein aggregates, both in vitro and in vivo (Krishnan et al., 2014; Wrasidlo et al., 2016; Price et al., 2018). Moreover, an emerging number of compounds tested in cellular and mouse models of PD exerted a protective role against $\alpha$-synuclein pathology. Specifically, polyphenol (-)-epi-gallocatechin-3-gallate (EGCG) is used in both $\mathrm{AD}$ and PD cases and acts as an inhibitor of $\alpha$ synuclein and amyloid beta fibril-maturation, by converting large amyloid fibrils into smaller non-toxic aggregates (Bieschke et al., 2010). Anle138b [3-(1,3-benzodioxol-5-yl)-5-(3-bromophenyl)$1 \mathrm{H}$-pyrazole] is an oligomer modulator shown to prevent the formation of pathological aggregates in vitro and in vivo of both prion protein $\operatorname{PrP}(\mathrm{Sc})$ and $\alpha$-synuclein (Wagner et al, 2013; Levin et al., 2014). Behavioral and histological analysis of the PLP- $\alpha$-synuclein transgenic mice treated with anle138b revealed that this aggregation inhibitor effectively attenuated the progression of the MSA-like pathology (Fellner et al., 2016; Heras-Garvin et al., 2019). Interestingly, this compound has gained attention as a promising fluorescent biomarker for the detection of aggregation-related epitopes (Deeg et al., 2015).

CLR01, another aggregation-inhibitor, prevented the formation of $\beta$-sheet-rich fibrils and had beneficial effects on the health and survival of a zebrafish model of $\alpha$-synuclein toxicity (Prabhudesai et al., 2012). Moreover, when PLP- or Thy1- $\alpha$-synuclein transgenic mice received treatment with CLR01, they displayed amelioration of the $\alpha$-synuclein-related brain pathology and behavioral deficits (Richter et al., 2017; Herrera-Vaquero et al., 2019). Furthermore, KYP-2047, a prolyl oligopeptidase inhibitor, has also been effectively used against $\alpha$-synuclein aggregation in both cellular and mouse models of PD (Myohanen et al., 2012), whereas porphyrin phthalocyanine tetrasulfonate, an inhibitor of protein aggregation through binding to vesicle-associated $\alpha$-synuclein, is suggested to modulate $\alpha$-synuclein misfolding and toxicity (Fonseca-Ornelas et al., 2014). There are also numerous chemical compounds belonging to polyphenols, phenothiazines, polyene macrolides, porphyrins, rifamycins, Congo red (and its derivatives) and terpenoids, that have been shown to decrease $\alpha$-synuclein fibrillization (Masuda et al,, 2006). Baicalein (flavone), delphinidin (anthocyanidin) and methylthioninium (monoamine oxidase inhibitor) are chemical molecules with inhibitory properties against $\alpha$-synuclein filament formation (Zhu et al., 2004; Hung et al., 2016; Schwab et al., 2017; Javed et al., 2018) as proposed by in vitro and in vivo experiments. Similarly, mannitol, catechol-o-methyltransferase inhibitors, cinnamon extract, and ring-fused pyridones have anti-aggregatory properties and provide protection against $\alpha$-synuclein toxicity (Di Giovanni et al., 2010; Shaltiel-Karyo et al., 2012, 2013; Horvath et al., 2013).
Synthetic peptides are also another therapeutic approach developed for $\beta$-sheet structure disruption and inhibition of $\alpha$-synuclein accumulation (El-Agnaf et al., 2004; Kim et al., 2009; Shaltiel-Karyo et al., 2010). Moreover, the antibiotic rifampicin has been used as a destabilizer of $\alpha$-synuclein fibrils (Li et al., 2004) and a reduction in monomeric, oligomeric and pathological pSer129 $\alpha$-synuclein has been reported in a rifampicin-treated transgenic MSA mouse model (Ubhi et al., 2008). Rifampicin has been also tested in a clinical trial where 50 participants received a 12 -month treatment with rifampicin (600 mg/day), with however, negative results (Low et al., 2014). Another anti-aggregation therapeutic strategy in the context of MSA would be the inhibition of $\beta$-III tubulin and the oligodendroglial-specific phosphoprotein TPPP/p25 $\alpha$, since both proteins are implicated in $\alpha$-synuclein accumulation (Lindersson et al., 2005; Nakayama et al., 2012; Mavroeidi et al., 2019). Nocodazole, a synthetic tubulin-binding agent that inhibits tubulin polymerization, prevented $\alpha$-synuclein accumulation in primary neuronal and glial cultures, pinpointing the crucial role of $\beta$-III tubulin/ $\alpha$-synuclein interaction in MSA pathogenesis (Nakayama et al., 2012). Unfortunately, up-to-date there are no available p25 $\alpha$ inhibitors, although such an approach may exert beneficial effects against MSA.

\section{TARGETING $\alpha$-SYNUCLEIN POST-TRANSLATIONAL MODIFICATIONS}

Taking into account that post-translational modifications of $\alpha$-synuclein, such as phosphorylation, truncation or oxidation/nitration, are tightly associated with the development of neuropathology (Oueslati et al., 2010; Barrett and Timothy Greenamyre, 2015), modulating these modifications is another viable approach. Although the majority of studies link pSer129$\alpha$-synuclein with neuropathology (Smith et al., 2005; Chau et al., 2009; Ma et al., 2016; Grassi et al., 2018), others support that $\alpha$-synuclein phosphorylation and the subsequent inclusion formation protects cells from toxicity (Chen and Feany, 2005; Paleologou et al., 2008; Wu B.et al., 2011; Kuwahara et al., 2012). Therefore, regulation of the expression and/or activity of kinases and phosphatases responsible for phosphorylation and de-phosphorylation of $\alpha$-synuclein at Ser129 represent a main target. Specifically, overexpression of G-protein-coupled receptor kinase 6 (GRK6) proposed to phosphorylate $\alpha$-synuclein via AAVs in the rat substantia nigra, led to extensive degeneration of dopaminergic neurons (Sato et al., 2011). Towards the same direction, mutation of Ser129 to alanine inhibited the G proteincoupled receptor kinase 2 (Gprk2)-mediated phosphorylation of $\alpha$-synuclein and attenuated $\alpha$-synuclein toxicity in a PD transgenic fly model (Chen and Feany, 2005). Moreover, in vitro and in vivo enhancement of $\alpha$-synuclein de-phosphorylation via the phosphoprotein phosphatase-2A (PP2A) protected neurons against $\alpha$-synuclein pathology (Lee et al., 2011).

Many studies have also proposed that both $C$ - and $\mathrm{N}$-terminal truncations of $\alpha$-synuclein facilitate $\alpha$-synuclein aggregation and misfolding and exhibit pathological properties 
(Ulusoy et al., 2010; Hall et al., 2015; Wang et al., 2016; Iyer et al., 2017; Ma et al., 2018; Terada et al., 2018). Monoclonal antibodies against the C-terminal truncation $(1 \mathrm{H} 7,5 \mathrm{C} 1$, and 5D12) have been tested in a PD mouse model and the results showed reduced aggregation of $\alpha$-synuclein and improved neurotoxic and behavioral deficits upon immunotherapy (Games et al., 2014). Other studies focused on calpain targeting by using specific calpain inhibitors in vivo, a strategy that resulted in amelioration of $\alpha$-synuclein pathology (Diepenbroek et al., 2014; Hassen et al., 2018). However, enhancement of calpain activity did not result in the expected exacerbation of $\alpha$-synuclein pathology (Diepenbroek et al., 2014).

\section{REDUCING UPTAKE AND CELL-TO-CELL TRANSMISSION OF $\alpha$-SYNUCLEIN}

As mentioned above, one proposed mechanism for $\alpha$-synuclein uptake is endocytosis and inhibiting the protein endocytosis represents another strategy against $\alpha$-synuclein propagation and spread (Figure 3). For example, experiments in $\alpha$-synucleintreated cells have shown that deletion of LAG3 or use of antibodies raised against this neuronal receptor effectively inhibits $\alpha$-synuclein cell-to-cell transfer (Anderson et al., 2016; Mao et al., 2016). Moreover, heparin or chloral hydrate can also act as $\alpha$-synuclein fibril uptake inhibitors, via disruption of heparan sulphate proteoglycans that normally bind amyloid proteins (Holmes et al., 2013; Karpowicz et al., 2017). Taking into consideration the fact that prion protein (PrPC) is suggested to be implicated in amyloid $\alpha$-synuclein uptake and neurotoxicity, genetic knockout of PrPC in primary neurons and mice effectively reduced the uptake and aggregation of $\alpha$-synuclein (Aulic et al., 2017; Ferreira et al., 2017).

Another therapeutic approach to combat $\alpha$-synuclein cell-tocell transmission is to target the signaling pathway downstream of the receptor responsible for $\alpha$-synuclein uptake. For example, the inflammatory response of microglial cells to pathological $\alpha$ synuclein via TLR signaling can be ameliorated by using TLR4 signaling inhibitors, such as resatorvid (TAK242) (Ii et al., 2006; Kawamoto et al., 2008). In another study, treatment of cells with TAK242 or RSLA (another TLR4 inhibitor) resulted in reduction of TNF $\alpha$ secretion from microglial cells and protection of neuronal cells against $\alpha$-synuclein neurotoxicity (Hughes et al., 2019). However, when TAK242 was tested in a clinical trial, it failed to reduce serum cytokine levels in patients with severe sepsis and shock or respiratory failure (Rice et al., 2010). Finally, CU-CPT22 (another selective inhibitor for TLR1/2) also reduced TNF $\alpha$ production in primary microglia cells treated with oligomeric $\alpha$-synuclein and blocked NF- $\kappa$ B nuclear translocation (Daniele et al., 2015). Although most of the existing therapeutic approaches target $\mathrm{PD}$, one of the most promising strategies against MSA is the use of sertraline, a second-generation selective serotonin reuptake inhibitor (SSRI). Sertraline inhibits dynamin 1 and 2 thus blocking the endocytic pathway and it has been shown to inhibit $\alpha$-synuclein uptake by oligodendrocytes and to prevent pathological $\alpha$-synuclein spread (Konno et al., 2012).
Another SSRI, paroxetine, has already been clinically tested at doses of $30 \mathrm{mg}$ for 2 weeks in 20 patients with MSA and resulted into statistically significant motor improvement (Friess et al., 2006).

\section{IMMUNOTHERAPY}

The role of the immune system and neuroinflammation in the pathophysiology of PD and related synucleinopathies, along with the specificity of antigen-antibody binding, render immunotherapy (active and passive) one of the most promising therapeutic approaches (Figure 4). The first study of active immunization against $\alpha$-synuclein utilized full-length $\alpha$ synuclein vaccination in the PDGF transgenic $\alpha$-synuclein mice and resulted in decreased $\alpha$-synuclein accumulation in neuronal cell bodies and synapses (Masliah et al., 2005). Active vaccination of the PDGF and the Thyl transgenic $\alpha$-synuclein mice with the PD01A and PD03A vaccines (also known as AFFITOPE) reduced $\alpha$-synuclein oligomers in axons and synapses, decreased caudo-putamen nucleus degeneration and memory deficits in both mouse models (Mandler et al., 2014). The same results, along with reduced demyelination were observed in an MSA transgenic mouse model (Mandler et al., 2015). Recently, the AFFITOPE was tested and successfully passed into the Phase 1 clinical trial in MSA patients, whereas the clinical trial for PD patients is ongoing ${ }^{2}$. More recently, it was shown that a novel vaccination modality combining an antigen-presenting cell-targeting glucan particle (GP) vaccine delivery system with encapsulated antigen ( $\alpha$-synuclein) plus rapamycin induced both strong anti- $\alpha$-synuclein antibody titers and neuroprotective $\mathrm{T}$ regulatory (Tregs) responses in synucleinopathy models, being more effective than the humoral or cellular immunization alone (Rockenstein et al., 2018). In the same concept, prophylactic vaccinations with full-length recombinant $\alpha$-synuclein in rats, which subsequent receive AAV- $\alpha$-synuclein, prevented the accumulation of $\alpha$-synuclein through the induction of Tregs and microglia activation (Christiansen et al., 2016).

Passive immunization with monoclonal antibodies targeting mostly the $\mathrm{C}$ - and $\mathrm{N}$-terminal region of $\alpha$-synuclein have been also used as means to sequester the extracellular protein, thus inhibiting the propagation of the disease (Masliah et al., 2011; Games et al., 2014; Tran et al., 2014; Shahaduzzaman et al., 2015). The first passive immunotherapy using the PRX002 or 9E4 antibody was tested in 2011, in the PDGF- $\alpha$-synuclein transgenic mice, and resulted in reduced $\alpha$-synuclein accumulation in axons and synapses, enhanced lysosomal degradation and improved behavioral and motor defects (Masliah et al., 2011). The promising preclinical results of two antibodies, the PRX002 and the BIIB054 (Weihofen et al., 2019), led to their testing in clinical trials where both of them were found safe and effective in preventing $\alpha$-synuclein spread. Specifically, PRX002 (PRX002, initially developed by Perrigo, Allegan, MI, United States; patent number US7910333; NCT02157714 and NCT02095171) is a humanized IgG1 monoclonal antibody that resulted in $96.5 \%$

\footnotetext{
${ }^{2}$ http://sympath-project.eu/wp-content/uploads/PR_AFF009_V1.pdf
} 


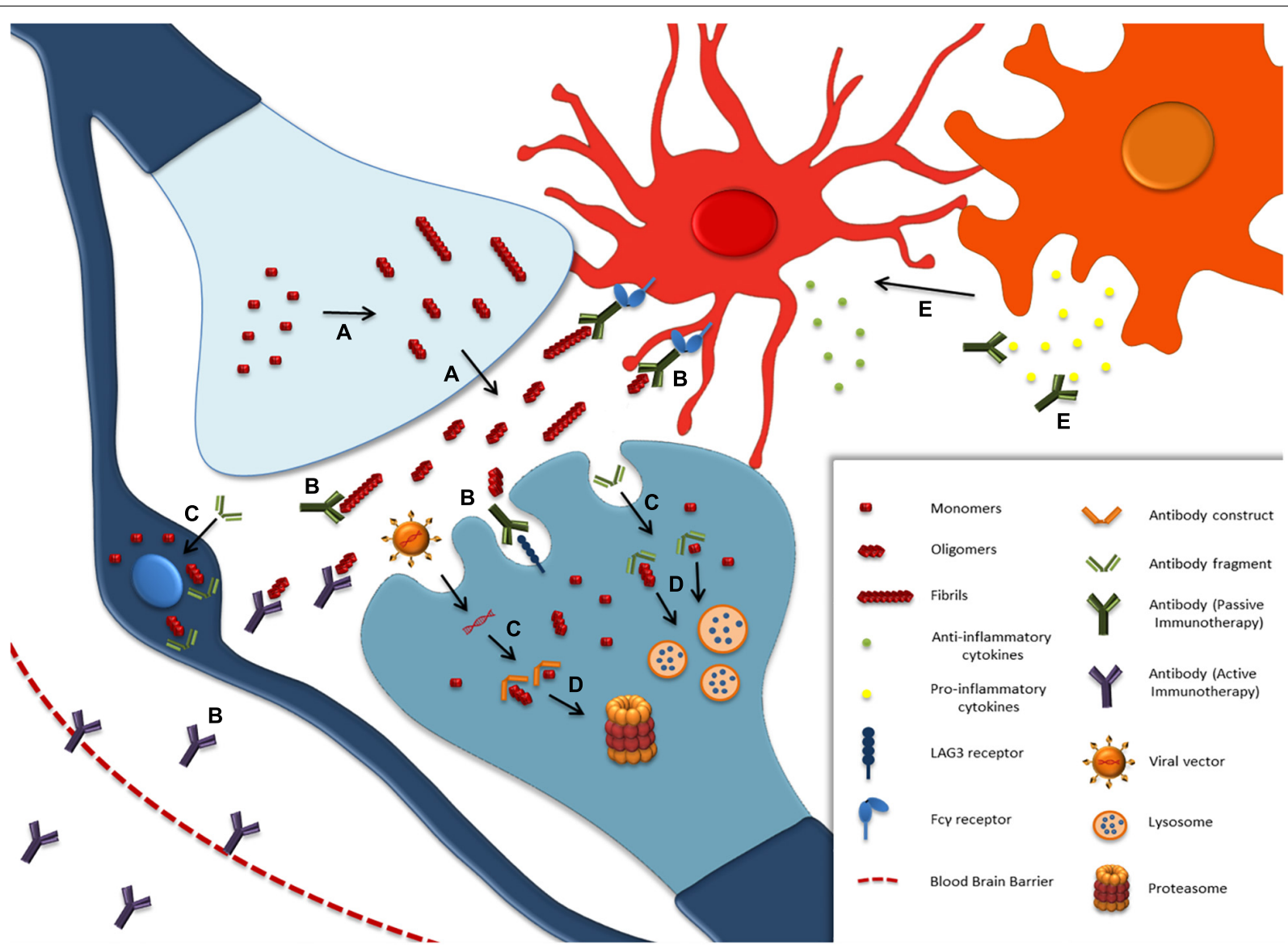

FIGURE 4 | Immunotherapy approaches against $\alpha$-synuclein. (A) Thermodynamically unstable monomers of $\alpha$-synuclein misfold and aggregate into pathological species. The release of oligomeric and fibrillar $\alpha$-synuclein into the extracellular space triggers $\alpha$-synuclein propagation into non-affected cells, microglial activation and neuroinflammation. (B) Active or passive immunization mainly aims to lower the extracellular $\alpha$-synuclein by microglial-mediated degradation and to prevent pathology propagation via antibody binding on receptors facilitating $\alpha$-synuclein endocytosis. (C) The effective targeting of intracellular $\alpha$-synuclein is achieved by antibody fragments paired with signaling peptides for endocytosis, or viral vector-derived antibody constructs, which are expressed within the cells. (D) The engineered intrabodies bind to $\alpha$-synuclein toxic species and lead them to degradation through proteasomal or autophagic pathways. (E) Antibodies against immune system activation is another immunotherapy approach, which aims to reduce pro-inflammatory cytokine release, enhance anti-inflammatory microglial activity and, by that, prevent $\alpha$-synuclein pathology progression.

decrease of free serum $\alpha$-synuclein in phase 1a clinical trial (Schenk et al., 2017) and 97\% decrease following a single intravenous infusion of the highest dose $(60 \mathrm{mg} / \mathrm{kg})$ in phase $1 \mathrm{~b}$ and these findings prompted the design of an ongoing phase 2 clinical trial (NCT03100149) (Jankovic et al., 2018). BIIB054 (licensed by Biogen) is a fully human-derived monoclonal antibody specifically raised against aggregated and fibrillar $\alpha$ synuclein that displayed beneficial effects regarding $\alpha$-synuclein aggregation in the PFF-inoculated PD mouse model (Weihofen et al., 2019). The results from phase 1 clinical trial in PD and healthy patients revealed that BIIB054 is safe and tolerable and have allowed the initiation of phase 2 trial (NCT03318523) (Brys et al., 2019). Finally, other monoclonal antibodies raised against misfolded $\alpha$-synuclein (Syn211 and Syn303) have been efficiently used in vivo and inhibited $\alpha$-synuclein uptake and pathology transmission (Tran et al., 2014). Other C-terminal targeting $\alpha$-synuclein antibodies, such as $1 \mathrm{H} 7,5 \mathrm{C} 1, \mathrm{~A} 1-\mathrm{A} 6$ and ab274 antibodies, were efficiently shown to decrease protein aggregation and exert neuroprotective effects (Bae et al., 2012; Games et al., 2014; Sahin et al., 2017).

The first reported N-terminal targeting antibody, AB1, prevented dopaminergic neuron loss and microgliosis in an AAV- $\alpha$-synuclein rat model of PD (Shahaduzzaman et al., 2015). Subsequently, the aggregate-selective BIIB054 human $\alpha-$ synuclein antibody was reported to attenuate the spreading of $\alpha$ synuclein pathology, to rescue motor impairments and to reduce the loss of dopamine transporter density in the nigrostriatal terminals in three different PFF-inoculated mouse models (Weihofen et al., 2019). BIIB054 was originally licensed by Biogen in 2010 and it was first tested in healthy volunteers in 2015. Since then, BIIB054 successfully passed through Phase 1 clinical testing for safety and tolerability and a Phase 2 clinical trial in 311 PD patients is ongoing 3 (Brys et al., 2019). The aggregated forms of $\alpha$-synuclein are also the target of the monoclonal

\footnotetext{
${ }^{3}$ https://www.alzforum.org/therapeutics/biib054
} 
antibodies Syn211 and Syn303, with promising reported results in cellular and animal $\alpha$-synuclein PFF-models (Tran et al., 2014). Antibody targeting of the NAC region is another approach. As such, administration of the NAC32 antibody decreased formation of aberrant species and mitigated $\alpha$-synuclein-related toxicity by $75 \%$ in an A53T mutant $\alpha$-synuclein neuronal cell line. Importantly, the NAC32 established the prime basis of intrabodies manufacture, and open up new opportunities for intracellular $\alpha$-synuclein targeting (Lynch et al., 2008). Direct targeting of oligomers is another way to inhibit further the aggregation process and promote the clearance of pathological $\alpha$ synuclein assemblies. In vitro [D5 antibody, (Emadi et al., 2007)] and in vivo [Syn-10H antibody, (Emadi et al., 2009)] studies using such oligomer-specific antibodies reported promising antiaggregation effects. In addition, the D5 antibody paired with the LDL receptor-binding domain of apolipoprotein B resulted in increased penetration of the construct intrabody through the endosomal sorting complex required for transport (ESCRT) and resulted in enhanced $\alpha$-synuclein oligomer degradation in vivo (Spencer et al., 2014). Based on this, the combined administration of a CD5-D5 single-chain antibody prevented astrogliosis, microgliosis and $\alpha$-synuclein aggregation in a mouse model of MSA (Valera et al., 2017).

Likewise, in the PLP- $\alpha$-synuclein MSA mouse model, administration of the Rec47 antibody led to enhanced $\alpha$ synuclein clearance, reduced intracellular seeding of the protein and limited microglial activation (Kallab et al., 2018). Furthermore, the oligomer-specific mAb47 antibody successfully prevented $\alpha$-synuclein assembly formation in murine co-cultures of astrocytes, oligodendrocytes and neurons and, interestingly, protected astroglia from an oligomeric $\alpha$-synuclein-mediated mitochondrial dysfunction (Gustafsson et al., 2017). Moreover, MEDI1341, a high affinity $\alpha$-synuclein antibody that crosses the $\mathrm{BBB}$ and binds monomeric and aggregated $\alpha$-synuclein, prevented cell-to-cell transmission of $\alpha$-synuclein in PFF-treated neuronal cells and is currently tested in a Phase 1 clinical trial for $\alpha$-synucleinopathies (ClinicalTrials.gov identifier NCT03272165) (Schofield et al., 2019). A phase 1 clinical study with the monoclonal antibody ABBV-0805 (or BAN0805) that selectively targets oligomeric and protofibrilar forms of $\alpha$-synuclein has initiated, however no results have been published yet. A variety of antibodies against oligomeric and fibrillar forms of $\alpha$-synuclein were recently reported. Syn-O1, Syn-O2 and Syn-O4 target oligomers and Syn-F1 and Syn-F2 recognize the fibrillar assemblies. Syn-O1, Syn-O4 and Syn-F1 antibodies limited $\alpha$-synuclein aggregation with higher efficacy than the other constructs when tested in the PDGF $\alpha$-synuclein mouse model (El-Agnaf et al., 2017).

Finally, many current immunotherapeutic approaches aim to modulate the immune system imbalance evoked by misfolded $\alpha$-synuclein accumulation by promoting anti-inflammatory and neuroprotective conditions (Reynolds et al., 2010). Therapies, including administration of the granulocyte macrophage-colony stimulating factor (GM-CSF) and the vasoactive intestinal peptide (VIP), avert the inflammatory role of effector $\mathrm{T}$ cells (Teff) by inducing $\mathrm{T}$ regulatory cells (Tregs), which are severely diminished in PD patients (Saunders et al., 2012). The GMCSF stimulating factor, sargramostim, is already in clinical trial phase 1 for PD providing promising results in motor defects improvement (Gendelman et al., 2017). Unfortunately, VIP is rapidly metabolized; hence a VIPR2 agonist, LBT3627, has been designed and used in $\alpha$-synuclein overexpression rats and MPTPintoxicated mice with beneficial results (Olson et al., 2015, 2016; Mosley et al., 2019). Therefore, its promising outcome in animal models renders VIP agonist as a therapeutic candidate for clinical testing in the future.

\section{TARGETING THE GUT}

$\alpha$-synuclein spread via the gut-brain axis has gained attention in the last years as a potential therapeutic target against $\alpha$ synucleinopathies (Holmqvist et al., 2014; Lee et al., 2018; Manfredsson et al., 2018). Many studies have focused on gut microbiota as a regulator of $\alpha$-synuclein misfolding and transmission towards the brain via the vagus nerve (Sampson et al., 2016; Bhattacharyya et al., 2019; Chiang and Lin, 2019) and results have revealed differences in gut microbiota between PD patients and healthy controls suggesting a role of the gut microbiome in PD pathogenesis (Scheperjans et al., 2015; Unger et al., 2016; Lin A.et al., 2018). To this end, the generation of a germfree $\alpha$-synuclein PD mouse model resulted in decreased $\alpha$-synuclein toxicity and neuroinflammation; however when the same mice received gut microbiota from PD patients, they exhibited motor impairment (Sampson et al., 2016). Gastrointestinal dysfunction is connected to PD and several approaches have been developed to alleviate $\alpha$-synuclein pathological effects, such as therapeutic strategies to stimulate gastric motility (Moore et al., 2018), use of antibiotics and microbiota replacement (Fasano et al., 2015; Felice et al., 2016).

\section{CONCLUDING REMARKS AND FUTURE PERSPECTIVES}

Undoubtedly, $\alpha$-synuclein plays a crucial role in the initiation and progression of the neurodegenerative cascade characterizing PD and related synucleinopathies. Candidate attractive options for therapy aim to reduce protein production or enhance protein degradation, to inhibit protein aggregation and misfolding, to alter $\alpha$-synuclein post-translational modifications or to target the extracellular levels of the protein with antibodies, thus intervening in the protein uptake and cell-cell propagation mechanisms. All approaches should be handled with caution, since uncontrolled manipulation of the global $\alpha$-synuclein levels may lead to neurotoxicity, due to the prevailing role of the protein in synaptic neurotransmission. Regarding the degradation strategies, experimental findings surmise that such strategies imply extensive knowledge about dosage and timing of application, a fact that may limit their current therapeutic applicability. Others and we have found that under specific circumstances induction of macroautophagy can have detrimental effects, thus the therapeutic utility of chemical 
modulators of macroautophagy or even CMA should be examined with caution given that they may be involved in diverse range of processes. Our experience in regards to CMA enhancement showed that this approach represents a fruitful strategy for synucleinopathies, at least in rodent cellular and animal models. This therapeutic modality is currently being tested in a non-human primate model of $\alpha$-synucleinopathy and if proven successful it may pave the way for its possible clinical utility for the treatment of PD and related synucleinopathies. In regards to the approaches targeting extracellular $\alpha$-synuclein, they seem to represent a compelling strategy to slow or halt disease progression, by interfering to the cell-cell transmission mechanisms. However, it still remains to be elucidated whether this transmission involves only the neuronal connectome and, most importantly, which species or strains of the protein are the main culprits for the pathology transmission.

In addition, a growing body of evidence suggests that an underlying cause of the heterogeneity characterizing synucleinopathies is the presence of distinct $\alpha$-synuclein strains in patient samples. As such, PD- and MSA- derived patient $\alpha$-synuclein strains exhibit different biophysical/biochemical properties and evoke different responses in cultured cells and animal models. Furthermore, the cellular milieu seems to affect the pathogenetic properties of the engendered strains, suggesting that other co-factors may alter disease initiation and progression. Hence, the aforementioned therapeutic strategies targeting the degradation, modification, secretion and seeding of the distinct strains may result in different outcomes in neurons and oligodendrocytes, raising the possibility of the application of a precision medicine in synucleinopathies in

\section{REFERENCES}

Aarsland, D., Laake, K., Larsen, J. P., and Janvin, C. (2002). Donepezil for cognitive impairment in Parkinson's disease: a randomised controlled study. J. Neurol. Neurosurg. Psychiatry 72, 708-712. doi: 10.1136/jnnp.72. 6.708

Abdelmotilib, H., Maltbie, T., Delic, V., Liu, Z., Hu, X., Fraser, K. B., et al. (2017). alpha-Synuclein fibril-induced inclusion spread in rats and mice correlates with dopaminergic Neurodegeneration. Neurobiol. Dis. 105, 84-98. doi: 10.1016/j. nbd.2017.05.014

Abounit, S., Bousset, L., Loria, F., Zhu, S., de Chaumont, F., Pieri, L., et al. (2016). Tunneling nanotubes spread fibrillar alpha-synuclein by intercellular trafficking of lysosomes. EMBO J. 35, 2120-2138. doi: 10.15252/embj.20159 3411

Afitska, K., Fucikova, A., Shvadchak, V. V., and Yushchenko, D. A. (2019). alphaSynuclein aggregation at low concentrations. Biochim. Biophys. Acta Proteins Proteom. 1867, 701-709. doi: 10.1016/j.bbapap.2019.05.003

Ahn, K. J., Paik, S. R., Chung, K. C., and Kim, J. (2006). Amino acid sequence motifs and mechanistic features of the membrane translocation of alpha-synuclein. J. Neurochem. 97, 265-279. doi: 10.1111/j.1471-4159.2006.03 731.x

Alarcon-Aris, D., Recasens, A., Galofre, M., Carballo-Carbajal, I., Zacchi, N., Ruiz-Bronchal, E., et al. (2018). Selective alpha-synuclein knockdown in monoamine neurons by intranasal oligonucleotide delivery: potential therapy for Parkinson's disease. Mol. Ther. 26, 550-567. doi: 10.1016/j.ymthe.2017. 11.015

Alvarez-Erviti, L., Rodriguez-Oroz, M. C., Cooper, J. M., Caballero, C., Ferrer, I., Obeso, J. A., et al. (2010). Chaperone-mediated autophagy markers in Parkinson disease brains. Arch. Neurol. 67, 1464-1472. doi: 10.1001/archneurol. 2010.198 the near future. By utilizing advanced structural biology techniques and cryo-electron microscopy we may attain a better understanding of the clinical heterogeneity amongst $\alpha$-synucleinopathies, thus offering the opportunity for the future development of strain-specific therapies to halt or delay disease progression.

Collectively, we believe that further research is needed to better understand the precise mechanisms underlying the $\alpha$ synuclein pathology enigma and to pinpoint the factors that differentiate the pathology observed in synucleinopathies.

\section{AUTHOR CONTRIBUTIONS}

MF, PM, and GT wrote the initial draft. MX revised and generated the final version of the manuscript. All authors contributed to the article and approved the submitted version.

\section{FUNDING}

Work in Dr. Xilouri's lab is supported by a Michael J. Fox Foundation for Parkinson's research grant (Grant ID 16887). This research is co-financed by Greece and the European Union (European Social Fund - ESF) through the Operational Programme "Human Resources Development, Education and Lifelong Learning" in the context of the project "Strengthening Human Resources Research Potential via Doctorate Research" (MIS-5000432), implemented by the State Scholarships Foundation (IKY).

Alvarez-Erviti, L., Seow, Y., Schapira, A. H., Gardiner, C., Sargent, I. L., Wood, M. J., et al. (2011). Lysosomal dysfunction increases exosome-mediated alphasynuclein release and transmission. Neurobiol. Dis. 42, 360-367. doi: 10.1016/j. nbd.2011.01.029

Ambrosi, G., Ghezzi, C., Zangaglia, R., Levandis, G., Pacchetti, C., and Blandini, F. (2015). Ambroxol-induced rescue of defective glucocerebrosidase is associated with increased LIMP-2 and saposin C levels in GBA1 mutant Parkinson's disease cells. Neurobiol. Dis. 82, 235-242. doi: 10.1016/j.nbd.2015.06.008

Anderson, A. C., Joller, N., and Kuchroo, V. K. (2016). Lag-3, Tim-3, and TIGIT: co-inhibitory receptors with specialized functions in immune regulation. Immunity 44, 989-1004. doi: 10.1016/j.immuni.2016.05.001

Anglade, P., Vyas, S., Javoy-Agid, F., Herrero, M. T., Michel, P. P., Marquez, J., et al. (1997). Apoptosis and autophagy in nigral neurons of patients with Parkinson's disease. Histol. Histopathol. 12, 25-31.

Angot, E., Steiner, J. A., Lema Tome, C. M., Ekstrom, P., Mattsson, B., Bjorklund, A., et al. (2012). Alpha-synuclein cell-to-cell transfer and seeding in grafted dopaminergic neurons in vivo. PLoS One 7:e39465. doi: 10.1371/journal.pone. 0039465

Arias, E., Koga, H., Diaz, A., Mocholi, E., Patel, B., and Cuervo, A. M. (2015). Lysosomal mTORC2/PHLPP1/Akt regulate chaperone-mediated autophagy. Mol. Cell 59, 270-284. doi: 10.1016/j.molcel.2015.05.030

Arotcarena, M. L., Bourdenx, M., Dutheil, N., Thiolat, M. L., Doudnikoff, E., Dovero, S., et al. (2019). Transcription factor EB overexpression prevents neurodegeneration in experimental synucleinopathies. JCI Insight 4:e129719. doi: $10.1172 /$ jci.insight.129719

Asi, Y. T., Simpson, J. E., Heath, P. R., Wharton, S. B., Lees, A. J., Revesz, T., et al. (2014). Alpha-synuclein mRNA expression in oligodendrocytes in MSA. Glia 62, 964-970. doi: 10.1002/glia.22653

Aulic, S., Masperone, L., Narkiewicz, J., Isopi, E., Bistaffa, E., Ambrosetti, E., et al. (2017). alpha-Synuclein Amyloids Hijack Prion Protein to Gain Cell Entry, 
Facilitate Cell-to-Cell Spreading and Block Prion Replication. Sci. Rep. 7:10050. doi: 10.1038/s41598-017-10236-x

Badiola, N., de Oliveira, R. M., Herrera, F., Guardia-Laguarta, C., Goncalves, S. A., Pera, M., et al. (2011). Tau enhances alpha-synuclein aggregation and toxicity in cellular models of synucleinopathy. PLoS One 6:e26609. doi: 10.1371/journal. pone.0026609

Bae, E. J., Lee, H. J., Rockenstein, E., Ho, D. H., Park, E. B., Yang, N. Y., et al. (2012). Antibody-aided clearance of extracellular alpha-synuclein prevents cellto-cell aggregate transmission. J. Neurosci. 32, 13454-13469. doi: 10.1523/ JNEUROSCI.1292-12.2012

Bai, X., Wey, M. C., Fernandez, E., Hart, M. J., Gelfond, J., Bokov, A. F., et al. (2015). Rapamycin improves motor function, reduces 4-hydroxynonenal adducted protein in brain, and attenuates synaptic injury in a mouse model of synucleinopathy. Pathobiol. Aging Age Relat. Dis. 5:28743. doi: 10.3402/pba.v5. 28743

Barkholt, P., Sanchez-Guajardo, V., Kirik, D., and Romero-Ramos, M. (2012). Long-term polarization of microglia upon alpha-synuclein overexpression in nonhuman primates. Neuroscience 208, 85-96. doi: 10.1016/j.neuroscience. 2012.02.004

Barrett, P. J., and Timothy Greenamyre, J. (2015). Post-translational modification of alpha-synuclein in Parkinson's disease. Brain Res. 1628(Pt B), 247-253. doi: 10.1016/j.brainres.2015.06.002

Bartels, T., Choi, J. G., and Selkoe, D. J. (2011). alpha-Synuclein occurs physiologically as a helically folded tetramer that resists aggregation. Nature 477, 107-110. doi: 10.1038/nature10324

Bennett, M. C., Bishop, J. F., Leng, Y., Chock, P. B., Chase, T. N., and Mouradian, M. M. (1999). Degradation of alpha-synuclein by proteasome. J. Biol. Chem. 274, 33855-33858. doi: 10.1074/jbc.274.48.33855

Benskey, M. J., Sellnow, R. C., Sandoval, I. M., Sortwell, C. E., Lipton, J. W., and Manfredsson, F. P. (2018). Silencing alpha synuclein in mature Nigral neurons results in rapid neuroinflammation and subsequent toxicity. Front. Mol. Neurosci. 11:36. doi: 10.3389/fnmol.2018.00036

Bentea, E., Verbruggen, L., and Massie, A. (2017). The proteasome inhibition model of Parkinson's disease. J. Parkinsons Dis. 7, 31-63. doi: 10.3233/JPD160921

Bernis, M. E., Babila, J. T., Breid, S., Wusten, K. A., Wullner, U., and Tamguney, G. (2015). Prion-like propagation of human brain-derived alphasynuclein in transgenic mice expressing human wild-type alpha-synuclein. Acta Neuropathol. Commun. 3:75. doi: 10.1186/s40478-015-0254-7

Bhatt, M. A., Messer, A., and Kordower, J. H. (2013). Can intrabodies serve as neuroprotective therapies for Parkinson's disease? Beginning thoughts. J. Parkinsons Dis. 3, 581-591. doi: 10.3233/JPD- 130252

Bhattacharyya, D., Mohite, G. M., Krishnamoorthy, J., Gayen, N., Mehra, S., Navalkar, A., et al. (2019). Lipopolysaccharide from gut microbiota modulates alpha-synuclein aggregation and alters its biological function. ACS Chem. Neurosci. 10, 2229-2236. doi: 10.1021/acschemneuro.8b00733

Bieschke, J., Russ, J., Friedrich, R. P., Ehrnhoefer, D. E., Wobst, H., Neugebauer, K., et al. (2010). EGCG remodels mature alpha-synuclein and amyloid-beta fibrils and reduces cellular toxicity. Proc. Natl. Acad. Sci. U.S.A. 107, 7710-7715. doi: 10.1073/pnas.0910723107

Birol, M., Wojcik, S. P., Miranker, A. D., and Rhoades, E. (2019). Identification of N-linked glycans as specific mediators of neuronal uptake of acetylated alpha-Synuclein. PLoS Biol. 17:e3000318. doi: 10.1371/journal.pbio.3000318

Blanz, J., and Saftig, P. (2016). Parkinson's disease: acid-glucocerebrosidase activity and alpha-synuclein clearance. J. Neurochem. 139(Suppl. 1), 198-215. doi: 10. 1111/jnc. 13517

Bose, A., and Beal, M. F. (2016). Mitochondrial dysfunction in Parkinson's disease. J. Neurochem. 139(Suppl. 1), 216-231. doi: 10.1111/jnc.13731

Bousset, L., Pieri, L., Ruiz-Arlandis, G., Gath, J., Jensen, P. H., Habenstein, B., et al. (2013). Structural and functional characterization of two alpha-synuclein strains. Nat. Commun. 4:2575. doi: 10.1038/ncomms3575

Braak, H., de Vos, R. A., Bohl, J., and Del Tredici, K. (2006). Gastric alphasynuclein immunoreactive inclusions in Meissner's and Auerbach's plexuses in cases staged for Parkinson's disease-related brain pathology. Neurosci. Lett. 396, 67-72. doi: 10.1016/j.neulet.2005.11.012

Braak, H., Del Tredici, K., Rub, U., de Vos, R. A., Jansen Steur, E. N., and Braak, E. (2003). Staging of brain pathology related to sporadic Parkinson's disease. Neurobiol. Aging 24, 197-211. doi: 10.1016/s0197-4580(02)00065-9
Brahmachari, S., Ge, P., Lee, S. H., Kim, D., Karuppagounder, S. S., Kumar, M., et al. (2016). Activation of tyrosine kinase c-Abl contributes to alphasynuclein-induced neurodegeneration. J. Clin. Invest. 126, 2970-2988. doi: 10. 1172/JCI85456

Brenner, S., Wersinger, C., and Gasser, T. (2015). Transcriptional regulation of the alpha-synuclein gene in human brain tissue. Neurosci. Lett. 599, 140-145. doi: 10.1016/j.neulet.2015.05.029

Bruening, W., Giasson, B. I., Klein-Szanto, A. J., Lee, V. M., Trojanowski, J. Q., and Godwin, A. K. (2000). Synucleins are expressed in the majority of breast and ovarian carcinomas and in preneoplastic lesions of the ovary. Cancer 88 , 2154-2163. doi: 10.1002/(sici)1097-0142(20000501)88:9<2154::aid-cncr23>3. $0 . \operatorname{co} ; 2-9$

Brys, M., Fanning, L., Hung, S., Ellenbogen, A., Penner, N., Yang, M., et al. (2019). Randomized phase I clinical trial of anti-alpha-synuclein antibody BIIB054. Mov. Disord. 34, 1154-1163. doi: 10.1002/mds.27738

Burn, D., Emre, M., McKeith, I., De Deyn, P. P., Aarsland, D., Hsu, C., et al. (2006). Effects of rivastigmine in patients with and without visual hallucinations in dementia associated with Parkinson's disease. Mov. Disord. 21, 1899-1907. doi: $10.1002 / \mathrm{mds} .21077$

Burre, J., Sharma, M., and Sudhof, T. C. (2014). alpha-Synuclein assembles into higher-order multimers upon membrane binding to promote SNARE complex formation. Proc. Natl. Acad. Sci. U.S.A. 111, E4274-E4283. doi: 10.1073/pnas. 1416598111

Burre, J., Sharma, M., Tsetsenis, T., Buchman, V., Etherton, M. R., and Sudhof, T. C. (2010). Alpha-synuclein promotes SNARE-complex assembly in vivo and in vitro. Science 329, 1663-1667. doi: 10.1126/science.1195227

Busch, D. J., Oliphint, P. A., Walsh, R. B., Banks, S. M., Woods, W. S., George, J. M., et al. (2014). Acute increase of alpha-synuclein inhibits synaptic vesicle recycling evoked during intense stimulation. Mol. Biol. Cell 25, 3926-3941. doi: $10.1091 / \mathrm{mbc} . \mathrm{E} 14-02-0708$

Bussell, R. Jr., and Eliezer, D. (2001). Residual structure and dynamics in Parkinson's disease-associated mutants of alpha-synuclein. J. Biol. Chem. 276, 45996-46003. doi: 10.1074/jbc.M106777200

Butler, B., Saha, K., Rana, T., Becker, J. P., Sambo, D., Davari, P., et al. (2015). Dopamine transporter activity is modulated by alpha-Synuclein. J. Biol. Chem. 290, 29542-29554. doi: 10.1074/jbc.M115.691592

Butler, B., Sambo, D., and Khoshbouei, H. (2017). Alpha-synuclein modulates dopamine neurotransmission. J. Chem. Neuroanat. 83-84, 41-49. doi: 10.1016/ j.jchemneu.2016.06.001

Candelise, N., Schmitz, M., Llorens, F., Villar-Pique, A., Cramm, M., Thom, T., et al. (2019). Seeding variability of different alpha synuclein strains in synucleinopathies. Ann. Neurol. 85, 691-703. doi: 10.1002/ana.25446

Casarejos, M. J., Solano, R. M., Gomez, A., Perucho, J., de Yebenes, J. G., and Mena, M. A. (2011). The accumulation of neurotoxic proteins, induced by proteasome inhibition, is reverted by trehalose, an enhancer of autophagy, in human neuroblastoma cells. Neurochem. Int. 58, 512-520. doi: 10.1016/j.neuint. 2011.01.008

Chandra, S., Chen, X., Rizo, J., Jahn, R., and Sudhof, T. C. (2003). A broken alpha -helix in folded alpha -Synuclein. J. Biol. Chem. 278, 15313-15318. doi: $10.1074 /$ jbc.M213128200

Chandra, S., Gallardo, G., Fernandez-Chacon, R., Schluter, O. M., and Sudhof, T. C. (2005). Alpha-synuclein cooperates with CSPalpha in preventing neurodegeneration. Cell 123, 383-396. doi: 10.1016/j.cell.2005.09.028

Charles, V., Mezey, E., Reddy, P. H., Dehejia, A., Young, T. A., Polymeropoulos, M. H., et al. (2000). Alpha-synuclein immunoreactivity of huntingtin polyglutamine aggregates in striatum and cortex of Huntington's disease patients and transgenic mouse models. Neurosci. Lett. 289, 29-32. doi: 10.1016/ s0304-3940(00)01247-7

Chartier-Harlin, M. C., Kachergus, J., Roumier, C., Mouroux, V., Douay, X., Lincoln, S., et al. (2004). Alpha-synuclein locus duplication as a cause of familial Parkinson's disease. Lancet 364, 1167-1169. doi: 10.1016/S01406736(04)17103-1

Chatterjee, D., Bhatt, M., Butler, D., De Genst, E., Dobson, C. M., Messer, A., et al. (2018). Proteasome-targeted nanobodies alleviate pathology and functional decline in an alpha-synuclein-based Parkinson's disease model. NPJ Parkinsons Dis. 4:25. doi: 10.1038/s41531-018-0062-4

Chau, K. Y., Ching, H. L., Schapira, A. H., and Cooper, J. M. (2009). Relationship between alpha synuclein phosphorylation, proteasomal inhibition and cell 
death: relevance to Parkinson's disease pathogenesis. J. Neurochem. 110, 10051013. doi: $10.1111 / j .1471-4159.2009 .06191 . x$

Chen, H., and Chan, D. C. (2009). Mitochondrial dynamics-fusion, fission, movement, and mitophagy-in neurodegenerative diseases. Hum. Mol. Genet. 18, R169-R176. doi: 10.1093/hmg/ddp326

Chen, J., Ren, Y., Gui, C., Zhao, M., Wu, X., Mao, K., et al. (2018). Phosphorylation of Parkin at serine 131 by p38 MAPK promotes mitochondrial dysfunction and neuronal death in mutant A53T alpha-synuclein model of Parkinson's disease. Cell Death Dis. 9:700. doi: 10.1038/s41419-018-0722-7

Chen, L., and Feany, M. B. (2005). Alpha-synuclein phosphorylation controls neurotoxicity and inclusion formation in a Drosophila model of Parkinson disease. Nat. Neurosci. 8, 657-663. doi: 10.1038/nn1443

Chen, M., Yang, W., Li, X., Wang, P., Yue, F., Yang, H., et al. (2016). Ageand brain region-dependent alpha-synuclein oligomerization is attributed to alterations in intrinsic enzymes regulating alpha-synuclein phosphorylation in aging monkey brains. Oncotarget 7, 8466-8480. doi: 10.18632/oncotarget.6445

Chen, Q. Q., Haikal, C., Li, W., and Li, J. Y. (2019). Gut inflammation in association with pathogenesis of Parkinson's disease. Front. Mol. Neurosci. 12:218. doi: 10.3389/fnmol.2019.00218

Chen, S. G., Stribinskis, V., Rane, M. J., Demuth, D. R., Gozal, E., Roberts, A. M., et al. (2016). Exposure to the functional bacterial amyloid protein Curli enhances Alpha-synuclein aggregation in aged Fischer 344 Rats and Caenorhabditis elegans. Sci. Rep. 6:34477. doi: 10.1038/srep34477

Chen, Y., Wei, Q. Q., Ou, R., Cao, B., Chen, X., Zhao, B., et al. (2015). Genetic Variants of SNCA are associated with susceptibility to Parkinson's disease but not amyotrophic lateral sclerosis or multiple system atrophy in a Chinese population. PLoS One 10:e0133776. doi: 10.1371/journal.pone.0133776

Chiang, H. L., and Lin, C. H. (2019). Altered gut microbiome and intestinal pathology in Parkinson's disease. J. Mov. Disord. 12, 67-83. doi: 10.14802/jmd. 18067

Chiba, Y., Takei, S., Kawamura, N., Kawaguchi, Y., Sasaki, K., Hasegawa-Ishii, S., et al. (2012). Immunohistochemical localization of aggresomal proteins in glial cytoplasmic inclusions in multiple system atrophy. Neuropathol. Appl. Neurobiol. 38, 559-571. doi: 10.1111/j.1365-2990.2011.01229.x

Choi, B. K., Choi, M. G., Kim, J. Y., Yang, Y., Lai, Y., Kweon, D. H., et al. (2013). Large alpha-synuclein oligomers inhibit neuronal SNARE-mediated vesicle docking. Proc. Natl. Acad. Sci. U.S.A. 110, 4087-4092. doi: 10.1073/pnas. 1218424110

Choi, D. C., Yoo, M., Kabaria, S., and Junn, E. (2018). MicroRNA-7 facilitates the degradation of alpha-synuclein and its aggregates by promoting autophagy. Neurosci. Lett. 678, 118-123. doi: 10.1016/j.neulet.2018.05.009

Choi, J. G., Kim, N., Ju, I. G., Eo, H., Lim, S. M., Jang, S. E., et al. (2018). Oral administration of Proteus mirabilis damages dopaminergic neurons and motor functions in mice. Sci. Rep. 8:1275. doi: 10.1038/s41598-018-19646-x

Choi, K. C., Kim, S. H., Ha, J. Y., Kim, S. T., and Son, J. H. (2010). A novel mTOR activating protein protects dopamine neurons against oxidative stress by repressing autophagy related cell death. J. Neurochem. 112, 366-376. doi: 10.1111/j.1471-4159.2009.06463.x

Choi, Y. R., Cha, S. H., Kang, S. J., Kim, J. B., Jou, I., and Park, S. M. (2018). Prionlike propagation of alpha-synuclein is regulated by the FcgammaRIIB-SHP-1/2 signaling pathway in neurons. Cell Rep. 22, 136-148. doi: 10.1016/j.celrep.2017. 12.009

Choubey, V., Safiulina, D., Vaarmann, A., Cagalinec, M., Wareski, P., Kuum, M., et al. (2011). Mutant A53T alpha-synuclein induces neuronal death by increasing mitochondrial autophagy. J. Biol. Chem. 286, 10814-10824. doi: 10.1074/jbc.M110.132514

Christiansen, J. R., Olesen, M. N., Otzen, D. E., Romero-Ramos, M., and Sanchez-Guajardo, V. (2016). alpha-Synuclein vaccination modulates regulatory $\mathrm{T}$ cell activation and microglia in the absence of brain pathology. J. Neuroinflammation 13:74. doi: 10.1186/s12974-016-0532-8

Clark, L. N., Kartsaklis, L. A., Wolf Gilbert, R., Dorado, B., Ross, B. M., Kisselev, S., et al. (2009). Association of glucocerebrosidase mutations with dementia with lewy bodies. Arch. Neurol. 66, 578-583. doi: 10.1001/archneurol.20 09.54

Clough, R. L., Dermentzaki, G., and Stefanis, L. (2009). Functional dissection of the alpha-synuclein promoter: transcriptional regulation by ZSCAN21 and ZNF219. J. Neurochem. 110, 1479-1490. doi: 10.1111/j.1471-4159.2009.06 250.x
Clough, R. L., and Stefanis, L. (2007). A novel pathway for transcriptional regulation of alpha-synuclein. FASEB J. 21, 596-607. doi: 10.1096/fj.06$7111 \mathrm{com}$

Colla, E. (2019). Linking the endoplasmic reticulum to Parkinson's disease and Alpha-Synucleinopathy. Front. Neurosci. 13:560. doi: 10.3389/fnins.2019.00560

Colla, E., Coune, P., Liu, Y., Pletnikova, O., Troncoso, J. C., Iwatsubo, T., et al. (2012). Endoplasmic reticulum stress is important for the manifestations of alpha-synucleinopathy in vivo. J. Neurosci. 32, 3306-3320. doi: 10.1523/ JNEUROSCI.5367-11.2012

Collier, T. J., Redmond, D. E. Jr., Steece-Collier, K., Lipton, J. W., and Manfredsson, F. P. (2016). Is Alpha-synuclein loss-of-function a contributor to Parkinsonian pathology? Evidence from Non-human Primates. Front. Neurosci. 10:12. doi: 10.3389/fnins.2016.00012

Conway, K. A., Harper, J. D., and Lansbury, P. T. (1998). Accelerated in vitro fibril formation by a mutant alpha-synuclein linked to early-onset Parkinson disease. Nat. Med. 4, 1318-1320. doi: 10.1038/3311

Conway, K. A., Lee, S. J., Rochet, J. C., Ding, T. T., Williamson, R. E., and Lansbury, P. T. Jr. (2000). Acceleration of oligomerization, not fibrillization, is a shared property of both alpha-synuclein mutations linked to early-onset Parkinson's disease: implications for pathogenesis and therapy. Proc. Natl. Acad. Sci. U.S.A. 97, 571-576. doi: 10.1073/pnas.97.2.571

Conway, K. A., Rochet, J. C., Bieganski, R. M., and Lansbury, P. T. Jr. (2001). Kinetic stabilization of the alpha-synuclein protofibril by a dopamine-alphasynuclein adduct. Science 294, 1346-1349. doi: 10.1126/science.1063522

Cooper, J. M., Wiklander, P. B., Nordin, J. Z., Al-Shawi, R., Wood, M. J., Vithlani, M., et al. (2014). Systemic exosomal siRNA delivery reduced alpha-synuclein aggregates in brains of transgenic mice. Mov. Disord. 29, 1476-1485. doi: 10. $1002 /$ mds. 25978

Couch, Y., Alvarez-Erviti, L., Sibson, N. R., Wood, M. J., and Anthony, D. C. (2011). The acute inflammatory response to intranigral alpha-synuclein differs significantly from intranigral lipopolysaccharide and is exacerbated by peripheral inflammation. J. Neuroinflammation 8:166. doi: 10.1186/1742-20948-166

Cremades, N., Cohen, S. I., Deas, E., Abramov, A. Y., Chen, A. Y., Orte, A., et al. (2012). Direct observation of the interconversion of normal and toxic forms of alpha-synuclein. Cell 149, 1048-1059. doi: 10.1016/j.cell.2012.03.037

Crews, L., Spencer, B., Desplats, P., Patrick, C., Paulino, A., Rockenstein, E., et al. (2010). Selective molecular alterations in the autophagy pathway in patients with Lewy body disease and in models of alpha-synucleinopathy. PLoS One 5:e9313. doi: 10.1371/journal.pone.0009313

Cuervo, A. M., Stefanis, L., Fredenburg, R., Lansbury, P. T., and Sulzer, D. (2004). Impaired degradation of mutant alpha-synuclein by chaperone-mediated autophagy. Science 305, 1292-1295. doi: 10.1126/science.1101738

Dalfo, E., Barrachina, M., Rosa, J. L., Ambrosio, S., and Ferrer, I. (2004). Abnormal alpha-synuclein interactions with rab3a and rabphilin in diffuse Lewy body disease. Neurobiol. Dis. 16, 92-97. doi: 10.1016/j.nbd.2004.01.001

Daniele, S. G., Beraud, D., Davenport, C., Cheng, K., Yin, H., and Maguire-Zeiss, K. A. (2015). Activation of MyD88-dependent TLR1/2 signaling by misfolded alpha-synuclein, a protein linked to neurodegenerative disorders. Sci. Signal. 8:ra45. doi: 10.1126/scisignal.2005965

Danzer, K. M., Haasen, D., Karow, A. R., Moussaud, S., Habeck, M., Giese, A., et al. (2007). Different species of alpha-synuclein oligomers induce calcium influx and seeding. J. Neurosci. 27, 9220-9232. doi: 10.1523/JNEUROSCI.261707.2007

Danzer, K. M., Kranich, L. R., Ruf, W. P., Cagsal-Getkin, O., Winslow, A. R., Zhu, L., et al. (2012). Exosomal cell-to-cell transmission of alpha synuclein oligomers. Mol. Neurodegener. 7:42. doi: 10.1186/1750-1326-7-42

Davidson, W. S., Jonas, A., Clayton, D. F., and George, J. M. (1998). Stabilization of alpha-synuclein secondary structure upon binding to synthetic membranes. J. Biol. Chem. 273, 9443-9449. doi: 10.1074/jbc.273.16.9443

Decressac, M., Mattsson, B., Weikop, P., Lundblad, M., Jakobsson, J., and Bjorklund, A. (2013). TFEB-mediated autophagy rescues midbrain dopamine neurons from alpha-synuclein toxicity. Proc. Natl. Acad. Sci. U.S.A. 110, E1817E1826. doi: 10.1073/pnas.1305623110

Deeg, A. A., Reiner, A. M., Schmidt, F., Schueder, F., Ryazanov, S., Ruf, V. C., et al. (2015). Anle138b and related compounds are aggregation specific fluorescence markers and reveal high affinity binding to alpha-synuclein aggregates. Biochim. Biophys. Acta 1850, 1884-1890. doi: 10.1016/j.bbagen.2015.05.021 
Dehay, B., Bove, J., Rodriguez-Muela, N., Perier, C., Recasens, A., Boya, P., et al. (2010). Pathogenic lysosomal depletion in Parkinson's disease. J. Neurosci. 30, 12535-12544. doi: 10.1523/JNEUROSCI.1920-10.2010

Delenclos, M., Trendafilova, T., Mahesh, D., Baine, A. M., Moussaud, S., Yan, I. K., et al. (2017). Investigation of endocytic pathways for the internalization of exosome-associated oligomeric Alpha-Synuclein. Front. Neurosci. 11:172. doi: 10.3389/fnins.2017.00172

Dermentzaki, G., Paschalidis, N., Politis, P. K., and Stefanis, L. (2016). Complex Effects of the ZSCAN21 transcription factor on transcriptional regulation of alpha-synuclein in primary neuronal cultures and in vivo. J. Biol. Chem. 291, 8756-8772. doi: 10.1074/jbc.M115.704973

Desplats, P., Lee, H. J., Bae, E. J., Patrick, C., Rockenstein, E., Crews, L., et al. (2009). Inclusion formation and neuronal cell death through neuron-to-neuron transmission of alpha-synuclein. Proc. Natl. Acad. Sci. U.S.A. 106, 13010-13015. doi: 10.1073/pnas.0903691106

Dettmer, U., Newman, A. J., Soldner, F., Luth, E. S., Kim, N. C., von Saucken, V. E., et al. (2015). Parkinson-causing alpha-synuclein missense mutations shift native tetramers to monomers as a mechanism for disease initiation. Nat. Commun. 6:7314. doi: 10.1038/ncomms8314

Di Giovanni, S., Eleuteri, S., Paleologou, K. E., Yin, G., Zweckstetter, M., Carrupt, P. A., et al. (2010). Entacapone and tolcapone, two catechol O-methyltransferase inhibitors, block fibril formation of alpha-synuclein and beta-amyloid and protect against amyloid-induced toxicity. J. Biol. Chem. 285, 14941-14954. doi: 10.1074/jbc.M109.080390

Di Maio, R., Hoffman, E. K., Rocha, E. M., Keeney, M. T., Sanders, L. H., De Miranda, B. R., et al. (2018). LRRK2 activation in idiopathic Parkinson's disease. Sci. Transl. Med. 10:eaar5429. doi: 10.1126/scitranslmed.aar5429

Diao, J., Burre, J., Vivona, S., Cipriano, D. J., Sharma, M., Kyoung, M., et al. (2013). Native alpha-synuclein induces clustering of synaptic-vesicle mimics via binding to phospholipids and synaptobrevin-2/VAMP2. eLife 2:e00592. doi: 10.7554/eLife.00592

Diaz, E. F., Labra, V. C., Alvear, T. F., Mellado, L. A., Inostroza, C. A., Oyarzun, J. E., et al. (2019). Connexin 43 hemichannels and pannexin-1 channels contribute to the alpha-synuclein-induced dysfunction and death of astrocytes. Glia 67, 1598-1619. doi: 10.1002/glia.23631

Diepenbroek, M., Casadei, N., Esmer, H., Saido, T. C., Takano, J., Kahle, P. J., et al. (2014). Overexpression of the calpain-specific inhibitor calpastatin reduces human alpha-Synuclein processing, aggregation and synaptic impairment in [A30P] alphaSyn transgenic mice. Hum. Mol. Genet. 23, 3975-3989. doi: 10. 1093/hmg/ddu112

Dikiy, I., and Eliezer, D. (2014). N-terminal acetylation stabilizes N-terminal helicity in lipid- and micelle-bound alpha-synuclein and increases its affinity for physiological membranes. J. Biol. Chem. 289, 3652-3665. doi: 10.1074/jbc. M113.512459

Doxakis, E. (2010). Post-transcriptional regulation of alpha-synuclein expression by mir-7 and mir-153. J. Biol. Chem. 285, 12726-12734. doi: 10.1074/jbc.M109. 086827

Du, T. T., Wang, L., Duan, C. L., Lu, L. L., Zhang, J. L., Gao, G., et al. (2015). GBA deficiency promotes SNCA/alpha-synuclein accumulation through autophagic inhibition by inactivated PPP2A. Autophagy 11, 1803-1820. doi: 10.1080/ 15548627.2015.1086055

Dulovic, M., Jovanovic, M., Xilouri, M., Stefanis, L., Harhaji-Trajkovic, L., KravicStevovic, T., et al. (2014). The protective role of AMP-activated protein kinase in alpha-synuclein neurotoxicity in vitro. Neurobiol. Dis. 63, 1-11. doi: 10.1016/ j.nbd.2013.11.002

Ebrahimi-Fakhari, D., Cantuti-Castelvetri, I., Fan, Z., Rockenstein, E., Masliah, E., Hyman, B. T., et al. (2011). Distinct roles in vivo for the ubiquitin-proteasome system and the autophagy-lysosomal pathway in the degradation of alphasynuclein. J. Neurosci. 31, 14508-14520. doi: 10.1523/JNEUROSCI.1560-11. 2011

El Turk, F., De Genst, E., Guilliams, T., Fauvet, B., Hejjaoui, M., Di Trani, J., et al. (2018). Exploring the role of post-translational modifications in regulating alpha-synuclein interactions by studying the effects of phosphorylation on nanobody binding. Protein Sci. 27, 1262-1274. doi: 10.1002/pro.3412

El-Agnaf, O., Overk, C., Rockenstein, E., Mante, M., Florio, J., Adame, A., et al. (2017). Differential effects of immunotherapy with antibodies targeting alphasynuclein oligomers and fibrils in a transgenic model of synucleinopathy. Neurobiol. Dis. 104, 85-96. doi: 10.1016/j.nbd.2017.05.002
El-Agnaf, O. M., Jakes, R., Curran, M. D., Middleton, D., Ingenito, R., Bianchi, E., et al. (1998). Aggregates from mutant and wild-type alpha-synuclein proteins and NAC peptide induce apoptotic cell death in human neuroblastoma cells by formation of beta-sheet and amyloid-like filaments. FEBS Lett. 440, 71-75. doi: 10.1016/s0014-5793(98)01418-5

El-Agnaf, O. M., Paleologou, K. E., Greer, B., Abogrein, A. M., King, J. E., Salem, S. A., et al. (2004). A strategy for designing inhibitors of alpha-synuclein aggregation and toxicity as a novel treatment for Parkinson's disease and related disorders. FASEB J. 18, 1315-1317. doi: 10.1096/fj.03-1346fje

El-Agnaf, O. M., Salem, S. A., Paleologou, K. E., Cooper, L. J., Fullwood, N. J., Gibson, M. J., et al. (2003). Alpha-synuclein implicated in Parkinson's disease is present in extracellular biological fluids, including human plasma. FASEB J. 17, 1945-1947. doi: 10.1096/fj.03-0098fje

Elkouris, M., Kouroupi, G., Vourvoukelis, A., Papagiannakis, N., Kaltezioti, V., Matsas, R., et al. (2019). Long non-coding RNAs associated with neurodegeneration-linked genes are reduced in Parkinson's disease patients. Front. Cell. Neurosci. 13:58. doi: 10.3389/fncel.2019.00058

Emadi, S., Barkhordarian, H., Wang, M. S., Schulz, P., and Sierks, M. R. (2007). Isolation of a human single chain antibody fragment against oligomeric alpha-synuclein that inhibits aggregation and prevents alpha-synucleininduced toxicity. J. Mol. Biol. 368, 1132-1144. doi: 10.1016/j.jmb.2007. 02.089

Emadi, S., Kasturirangan, S., Wang, M. S., Schulz, P., and Sierks, M. R. (2009). Detecting morphologically distinct oligomeric forms of alpha-synuclein. J. Biol. Chem. 284, 11048-11058. doi: 10.1074/jbc.M806559200

Emmanouilidou, E., Melachroinou, K., Roumeliotis, T., Garbis, S. D., Ntzouni, M., Margaritis, L. H., et al. (2010a). Cell-produced alpha-synuclein is secreted in a calcium-dependent manner by exosomes and impacts neuronal survival. J. Neurosci. 30, 6838-6851. doi: 10.1523/JNEUROSCI.5699-09. 2010

Emmanouilidou, E., Stefanis, L., and Vekrellis, K. (2010b). Cell-produced alphasynuclein oligomers are targeted to, and impair, the 26S proteasome. Neurobiol. Aging 31, 953-968. doi: 10.1016/j.neurobiolaging.2008.07.008

Ettle, B., Reiprich, S., Deusser, J., Schlachetzki, J. C., Xiang, W., Prots, I., et al. (2014). Intracellular alpha-synuclein affects early maturation of primary oligodendrocyte progenitor cells. Mol. Cell. Neurosci. 62, 68-78. doi: 10.1016/j. mcn.2014.06.012

Fahn, S., Oakes, D., Shoulson, I., Kieburtz, K., Rudolph, A., Lang, A., et al. (2004). Levodopa and the progression of Parkinson's disease. N. Engl. J. Med. 351, 2498-2508. doi: 10.1056/NEJMoa033447

Fanciulli, A., and Wenning, G. K. (2015). Multiple-system atrophy. N. Engl. J. Med. 372, 249-263. doi: 10.1056/NEJMra1311488

Fasano, A., Visanji, N. P., Liu, L. W., Lang, A. E., and Pfeiffer, R. F. (2015). Gastrointestinal dysfunction in Parkinson's disease. Parkinsonism Relat. Disord. 14, 625-639. doi: 10.1016/S1474-4422(15)00007-1

Fauvet, B., Mbefo, M. K., Fares, M. B., Desobry, C., Michael, S., Ardah, M. T., et al. (2012). alpha-Synuclein in central nervous system and from erythrocytes, mammalian cells, and Escherichia coli exists predominantly as disordered monomer. J. Biol. Chem. 287, 15345-15364. doi: 10.1074/jbc.M111.318949

Felice, V. D., Quigley, E. M., Sullivan, A. M., O’Keeffe, G. W., and O'Mahony, S. M. (2016). Microbiota-gut-brain signalling in Parkinson's disease: implications for non-motor symptoms. Parkinsonism Relat. Disord. 27, 1-8. doi: 10.1016/j. parkreldis.2016.03.012

Fellner, L., Buchinger, E., Brueck, D., Irschick, R., Wenning, G. K., and Stefanova, N. (2018). Limited effects of dysfunctional macroautophagy on the accumulation of extracellularly derived alpha-synuclein in oligodendroglia: implications for MSA pathogenesis. BMC Neurosci. 19:32. doi: 10.1186/s12868018-0431-2

Fellner, L., Kuzdas-Wood, D., Levin, J., Ryazanov, S., Leonov, A., Griesinger, C., et al. (2016). Anle138b partly ameliorates motor deficits despite failure of neuroprotection in a model of advanced multiple system atrophy. Front. Neurosci. 10:99. doi: 10.3389/fnins.2016.00099

Fellner, L., and Stefanova, N. (2013). The role of glia in alpha-synucleinopathies. Mol. Neurobiol. 47, 575-586. doi: 10.1007/s12035-012-8340-3

Ferreira, D. G., Temido-Ferreira, M., Vicente Miranda, H., Batalha, V. L., Coelho, J. E., Szego, E. M., et al. (2017). alpha-synuclein interacts with $\operatorname{PrP}(C)$ to induce cognitive impairment through mGluR5 and NMDAR2B. Nat. Neurosci. 20, 1569-1579. doi: 10.1038/nn.4648 
Ferreon, A. C., and Deniz, A. A. (2007). Alpha-synuclein multistate folding thermodynamics: implications for protein misfolding and aggregation. Biochemistry 46, 4499-4509. doi: 10.1021/bi602461y

Ferretta, A., Gaballo, A., Tanzarella, P., Piccoli, C., Capitanio, N., Nico, B., et al. (2014). Effect of resveratrol on mitochondrial function: implications in parkinassociated familiar Parkinson's disease. Biochim. Biophys. Acta 1842, 902-915. doi: 10.1016/j.bbadis.2014.02.010

Fonseca-Ornelas, L., Eisbach, S. E., Paulat, M., Giller, K., Fernandez, C. O., Outeiro, T. F., et al. (2014). Small molecule-mediated stabilization of vesicle-associated helical alpha-synuclein inhibits pathogenic misfolding and aggregation. Nat. Commun. 5:5857. doi: 10.1038/ncomms6857

Fountaine, T. M., and Wade-Martins, R. (2007). RNA interference-mediated knockdown of alpha-synuclein protects human dopaminergic neuroblastoma cells from $\mathrm{MPP}(+)$ toxicity and reduces dopamine transport. J. Neurosci. Res. 85, 351-363. doi: 10.1002/jnr.21125

Fredenburg, R. A., Rospigliosi, C., Meray, R. K., Kessler, J. C., Lashuel, H. A., Eliezer, D., et al. (2007). The impact of the E46K mutation on the properties of alpha-synuclein in its monomeric and oligomeric states. Biochemistry 46, 7107-7118. doi: 10.1021/bi7000246

Friess, E., Kuempfel, T., Modell, S., Winkelmann, J., Holsboer, F., Ising, M., et al. (2006). Paroxetine treatment improves motor symptoms in patients with multiple system atrophy. Parkinsonism Relat. Disord. 12, 432-437. doi: 10.1016/ j.parkreldis.2006.04.002

Fu, H., Subramanian, R. R., and Masters, S. C. (2000). 14-3-3 proteins: structure, function, and regulation. Annu. Rev. Pharmacol. Toxicol. 40, 617-647. doi: 10.1146/annurev.pharmtox.40.1.617

Fujiwara, H., Hasegawa, M., Dohmae, N., Kawashima, A., Masliah, E., Goldberg, M. S., et al. (2002). alpha-Synuclein is phosphorylated in synucleinopathy lesions. Nat. Cell Biol. 4, 160-164. doi: 10.1038/ncb748

Fusco, G., Chen, S. W., Williamson, P. T. F., Cascella, R., Perni, M., Jarvis, J. A., et al. (2017). Structural basis of membrane disruption and cellular toxicity by alpha-synuclein oligomers. Science 358, 1440-1443. doi: 10.1126/science. aan6160

Fussi, N., Hollerhage, M., Chakroun, T., Nykanen, N. P., Rosler, T. W., Koeglsperger, T., et al. (2018). Exosomal secretion of alpha-synuclein as protective mechanism after upstream blockage of macroautophagy. Cell Death Dis. 9:757. doi: 10.1038/s41419-018-0816-2

Games, D., Valera, E., Spencer, B., Rockenstein, E., Mante, M., Adame, A., et al. (2014). Reducing C-terminal-truncated alpha-synuclein by immunotherapy attenuates neurodegeneration and propagation in Parkinson's disease-like models. J. Neurosci. 34, 9441-9454. doi: 10.1523/JNEUROSCI.5314-13.2014

Ganjam, G. K., Bolte, K., Matschke, L. A., Neitemeier, S., Dolga, A. M., Hollerhage, M., et al. (2019). Mitochondrial damage by alpha-synuclein causes cell death in human dopaminergic neurons. Cell Death Dis. 10:865. doi: 10.1038/s41419019-2091-2

Garcia-Reitbock, P., Anichtchik, O., Bellucci, A., Iovino, M., Ballini, C., Fineberg, E., et al. (2010). SNARE protein redistribution and synaptic failure in a transgenic mouse model of Parkinson's disease. Brain 133(Pt 7), 2032-2044. doi: $10.1093 /$ brain/awq132

Gendelman, H. E., Zhang, Y., Santamaria, P., Olson, K. E., Schutt, C. R., Bhatti, D., et al. (2017). Evaluation of the safety and immunomodulatory effects of sargramostim in a randomized, double-blind phase 1 clinical Parkinson's disease trial. NPJ Parkinsons Dis. 3:10. doi: 10.1038/s41531-017-0013-5

George, S., Rey, N. L., Tyson, T., Esquibel, C., Meyerdirk, L., Schulz, E., et al. (2019). Microglia affect alpha-synuclein cell-to-cell transfer in a mouse model of Parkinson's disease. Mol. Neurodegener. 14:34. doi: 10.1186/s13024-0190335-3

Giasson, B. I., Duda, J. E., Quinn, S. M., Zhang, B., Trojanowski, J. Q., and Lee, V. M. (2002). Neuronal alpha-synucleinopathy with severe movement disorder in mice expressing A53T human alpha-synuclein. Neuron 34, 521-533. doi: 10.1016/s0896-6273(02)00682-7

Giasson, B. I., Forman, M. S., Higuchi, M., Golbe, L. I., Graves, C. L., Kotzbauer, P. T., et al. (2003). Initiation and synergistic fibrillization of tau and alphasynuclein. Science 300, 636-640. doi: 10.1126/science.1082324

Giasson, B. I., Murray, I. V., Trojanowski, J. Q., and Lee, V. M. (2001). A hydrophobic stretch of 12 amino acid residues in the middle of alpha-synuclein is essential for filament assembly. J. Biol. Chem. 276, 2380-2386. doi: 10.1074/ jbc.M008919200
Gitler, A. D., Bevis, B. J., Shorter, J., Strathearn, K. E., Hamamichi, S., Su, L. J., et al. (2008). The Parkinson's disease protein alpha-synuclein disrupts cellular Rab homeostasis. Proc. Natl. Acad. Sci. U.S.A. 105, 145-150. doi: 10.1073/pnas. 0710685105

Gonzalez, N., Arcos-Lopez, T., Konig, A., Quintanar, L., Menacho Marquez, M., Outeiro, T. F., et al. (2019). Effects of alpha-synuclein post-translational modifications on metal binding. J. Neurochem. 150, 507-521. doi: 10.1111/jnc. 14721

Gorbatyuk, O. S., Li, S., Nash, K., Gorbatyuk, M., Lewin, A. S., Sullivan, L. F., et al. (2010). In vivo RNAi-mediated alpha-synuclein silencing induces nigrostriatal degeneration. Mol. Ther. 18, 1450-1457. doi: 10.1038/mt.2010.115

Gould, N., Mor, D. E., Lightfoot, R., Malkus, K., Giasson, B., and Ischiropoulos, H. (2014). Evidence of native alpha-synuclein conformers in the human brain. J. Biol. Chem. 289, 7929-7934. doi: 10.1074/jbc.C113.538249

Grassi, D., Howard, S., Zhou, M., Diaz-Perez, N., Urban, N. T., Guerrero-Given, D., et al. (2018). Identification of a highly neurotoxic alpha-synuclein species inducing mitochondrial damage and mitophagy in Parkinson's disease. Proc. Natl. Acad. Sci. U.S.A. 115, E2634-E2643. doi: 10.1073/pnas.1713849115

Grathwohl, S. A., Steiner, J. A., Britschgi, M., and Brundin, P. (2013). Mind the gut: secretion of alpha-synuclein by enteric neurons. J. Neurochem. 125, 487-490. doi: 10.1111/jnc. 12191

Guardia-Laguarta, C., Area-Gomez, E., Rub, C., Liu, Y., Magrane, J., Becker, D., et al. (2014). alpha-Synuclein is localized to mitochondria-associated ER membranes. J. Neurosci. 34, 249-259. doi: 10.1523/JNEUROSCI.2507-13.2014

Guo, J. L., Covell, D. J., Daniels, J. P., Iba, M., Stieber, A., Zhang, B., et al. (2013). Distinct alpha-synuclein strains differentially promote tau inclusions in neurons. Cell 154, 103-117. doi: 10.1016/j.cell.2013.05.057

Guo, Y. J., Dong, S. Y., Cui, X. X., Feng, Y., Liu, T., Yin, M., et al. (2016). Resveratrol alleviates MPTP-induced motor impairments and pathological changes by autophagic degradation of alpha-synuclein via SIRT1-deacetylated LC3. Mol. Nutr. Food Res. 60, 2161-2175. doi: 10.1002/mnfr.201600111

Gustafsson, G., Lindstrom, V., Rostami, J., Nordstrom, E., Lannfelt, L., Bergstrom, J., et al. (2017). Alpha-synuclein oligomer-selective antibodies reduce intracellular accumulation and mitochondrial impairment in alphasynuclein exposed astrocytes. J. Neuroinflammation 14:241. doi: 10.1186/ s12974-017-1018-z

Gustafsson, G., Loov, C., Persson, E., Lazaro, D. F., Takeda, S., Bergstrom, J., et al. (2018). Secretion and uptake of alpha-synuclein via extracellular vesicles in cultured cells. Cell. Mol. Neurobiol. 38, 1539-1550. doi: 10.1007/s10571-0180622-5

Haj-Yahya, M., Fauvet, B., Herman-Bachinsky, Y., Hejjaoui, M., Bavikar, S. N., Karthikeyan, S. V., et al. (2013). Synthetic polyubiquitinated alpha-Synuclein reveals important insights into the roles of the ubiquitin chain in regulating its pathophysiology. Proc. Natl. Acad. Sci. U.S.A. 110, 17726-17731. doi: 10.1073/ pnas. 1315654110

Hall, K., Yang, S., Sauchanka, O., Spillantini, M. G., and Anichtchik, O. (2015). Behavioural deficits in transgenic mice expressing human truncated (1-120 amino acid) alpha-synuclein. Exp. Neurol. 264, 8-13. doi: 10.1016/j.expneurol. 2014.11.003

Han, Y., Khodr, C. E., Sapru, M. K., Pedapati, J., and Bohn, M. C. (2011). A microRNA embedded AAV alpha-synuclein gene silencing vector for dopaminergic neurons. Brain Res. 1386, 15-24. doi: 10.1016/j.brainres.2011.02. 041

Hansen, C., Angot, E., Bergstrom, A. L., Steiner, J. A., Pieri, L., Paul, G., et al. (2011). alpha-Synuclein propagates from mouse brain to grafted dopaminergic neurons and seeds aggregation in cultured human cells. J. Clin. Invest. 121, 715-725. doi: 10.1172/JCI43366

Hassen, G. W., Kesner, L., Stracher, A., Shulman, A., Rockenstein, E., Mante, M., et al. (2018). Effects of novel calpain inhibitors in transgenic animal model of Parkinson's disease/dementia with Lewy bodies. Sci. Rep. 8:18083. doi: 10.1038/ s41598-018-35729-1

Hayashita-Kinoh, H., Yamada, M., Yokota, T., Mizuno, Y., and Mochizuki, H. (2006). Down-regulation of alpha-synuclein expression can rescue dopaminergic cells from cell death in the substantia nigra of Parkinson's disease rat model. Biochem. Biophys. Res. Commun. 341, 1088-1095. doi: 10.1016/j. bbrc.2006.01.057

He, Q., Koprich, J. B., Wang, Y., Yu, W. B., Xiao, B. G., Brotchie, J. M., et al. (2016). Treatment with trehalose prevents behavioral and neurochemical 
deficits produced in an AAV alpha-synuclein rat model of Parkinson's disease. Mol. Neurobiol. 53, 2258-2268. doi: 10.1007/s12035-015-9173-7

Hebron, M. L., Lonskaya, I., and Moussa, C. E. (2013). Nilotinib reverses loss of dopamine neurons and improves motor behavior via autophagic degradation of alpha-synuclein in Parkinson's disease models. Hum. Mol. Genet. 22, 33153328. doi: $10.1093 / \mathrm{hmg} / \mathrm{ddt} 192$

Hellstrand, E., Nowacka, A., Topgaard, D., Linse, S., and Sparr, E. (2013). Membrane lipid co-aggregation with alpha-synuclein fibrils. PLoS One 8:e77235. doi: 10.1371/journal.pone.0077235

Heras-Garvin, A., Weckbecker, D., Ryazanov, S., Leonov, A., Griesinger, C., Giese, A., et al. (2019). Anle138b modulates alpha-synuclein oligomerization and prevents motor decline and neurodegeneration in a mouse model of multiple system atrophy. Mov. Disord. 34, 255-263. doi: 10.1002/mds. 27562

Herrera-Vaquero, M., Bouquio, D., Kallab, M., Biggs, K., Nair, G., Ochoa, J., et al. (2019). The molecular tweezer CLR01 reduces aggregated, pathologic, and seeding-competent alpha-synuclein in experimental multiple system atrophy. Biochim. Biophys. Acta Mol. Basis Dis. 1865:165513. doi: 10.1016/j.bbadis.2019. 07.007

Ho, P. W., Leung, C. T., Liu, H., Pang, S. Y., Lam, C. S., Xian, J., et al. (2020). Agedependent accumulation of oligomeric SNCA/alpha-synuclein from impaired degradation in mutant LRRK2 knockin mouse model of Parkinson disease: role for therapeutic activation of chaperone-mediated autophagy (CMA). Autophagy 16, 347-370. doi: 10.1080/15548627.2019.1603545

Holmes, B. B., DeVos, S. L., Kfoury, N., Li, M., Jacks, R., Yanamandra, K., et al. (2013). Heparan sulfate proteoglycans mediate internalization and propagation of specific proteopathic seeds. Proc. Natl. Acad. Sci. U.S.A. 110, E3138-E3147. doi: $10.1073 /$ pnas. 1301440110

Holmqvist, S., Chutna, O., Bousset, L., Aldrin-Kirk, P., Li, W., Bjorklund, T., et al. (2014). Direct evidence of Parkinson pathology spread from the gastrointestinal tract to the brain in rats. Acta Neuropathol. 128, 805-820. doi: 10.1007/s00401014-1343-6

Horvath, I., Sellstedt, M., Weise, C., Nordvall, L. M., Krishna Prasad, G., Olofsson, A., et al. (2013). Modulation of alpha-synuclein fibrillization by ring-fused 2pyridones: templation and inhibition involve oligomers with different structure. Arch. Biochem. Biophys. 532, 84-90. doi: 10.1016/j.abb.2013.01.012

Houser, M. C., and Tansey, M. G. (2017). The gut-brain axis: is intestinal inflammation a silent driver of Parkinson's disease pathogenesis? NPJ. Parkinsons Dis. 3:3. doi: 10.1038/s41531-016-0002-0

Hughes, C. D., Choi, M. L., Ryten, M., Hopkins, L., Drews, A., Botia, J. A., et al. (2019). Picomolar concentrations of oligomeric alpha-synuclein sensitizes TLR4 to play an initiating role in Parkinson's disease pathogenesis. Acta Neuropathol. 137, 103-120. doi: 10.1007/s00401-018-1907-y

Hung, K. C., Huang, H. J., Wang, Y. T., and Lin, A. M. (2016). Baicalein attenuates alpha-synuclein aggregation, inflammasome activation and autophagy in the $\mathrm{MPP}(+)$-treated nigrostriatal dopaminergic system in vivo. J. Ethnopharmacol. 194, 522-529. doi: 10.1016/j.jep.2016.10.040

Ihse, E., Yamakado, H., van Wijk, X. M., Lawrence, R., Esko, J. D., and Masliah, E. (2017). Cellular internalization of alpha-synuclein aggregates by cell surface heparan sulfate depends on aggregate conformation and cell type. Sci. Rep. 7:9008. doi: 10.1038/s41598-017-08720-5

Ii, M., Matsunaga, N., Hazeki, K., Nakamura, K., Takashima, K., Seya, T., et al. (2006). A novel cyclohexene derivative, ethyl (6R)-6-[N-(2-Chloro4-fluorophenyl)sulfamoyl]cyclohex-1-ene-1-carboxylate (TAK-242), selectively inhibits toll-like receptor 4-mediated cytokine production through suppression of intracellular signaling. Mol. Pharmacol. 69, 1288-1295. doi: 10.1124/mol.105. 019695

Ishizawa, K., Komori, T., Sasaki, S., Arai, N., Mizutani, T., and Hirose, T. (2004). Microglial activation parallels system degeneration in multiple system atrophy. J. Neuropathol. Exp. Neurol. 63, 43-52. doi: 10.1093/jnen/63.1.43

Issa, A. R., Sun, J., Petitgas, C., Mesquita, A., Dulac, A., Robin, M., et al. (2018). The lysosomal membrane protein LAMP2A promotes autophagic flux and prevents SNCA-induced Parkinson disease-like symptoms in the Drosophila brain. Autophagy 14, 1898-1910. doi: 10.1080/15548627.2018.149 1489

Iyer, A., Roeters, S. J., Kogan, V., Woutersen, S., Claessens, M., and Subramaniam, V. (2017). C-terminal truncated alpha-synuclein fibrils contain strongly twisted beta-Sheets. J. Am. Chem. Soc. 139, 15392-15400. doi: 10.1021/jacs.7b07403
Jakes, R., Spillantini, M. G., and Goedert, M. (1994). Identification of two distinct synucleins from human brain. FEBS Lett. 345, 27-32. doi: 10.1016/00145793(94)00395-5

Jang, A., Lee, H. J., Suk, J. E., Jung, J. W., Kim, K. P., and Lee, S. J. (2010), Non-classical exocytosis of alpha-synuclein is sensitive to folding states and promoted under stress conditions. J. Neurochem. 113, 1263-1274. doi: 10.1111/ j.1471-4159.2010.06695.x

Jankovic, J., Goodman, I., Safirstein, B., Marmon, T. K., Schenk, D. B., Koller, M., et al. (2018). Safety and tolerability of multiple ascending doses of PRX002/RG7935, an anti-alpha-synuclein monoclonal antibody, in patients with Parkinson disease: a randomized clinical trial. JAMA Neurol. 75, 12061214. doi: 10.1001/jamaneurol.2018.1487

Jao, C. C., Hegde, B. G., Chen, J., Haworth, I. S., and Langen, R. (2008). Structure of membrane-bound alpha-synuclein from site-directed spin labeling and computational refinement. Proc. Natl. Acad. Sci. U.S.A. 105, 19666-19671. doi: $10.1073 /$ pnas. 0807826105

Javed, H., Nagoor Meeran, M. F., Azimullah, S., Adem, A., Sadek, B., and Ojha, S. K. (2018). Plant extracts and phytochemicals targeting alpha-synuclein aggregation in Parkinson's disease models. Front. Pharmacol. 9:1555. doi: 10. 3389/fphar.2018.01555

Jeannotte, A. M., and Sidhu, A. (2007). Regulation of the norepinephrine transporter by alpha-synuclein-mediated interactions with microtubules. Eur. J. Neurosci. 26, 1509-1520. doi: 10.1111/j.1460-9568.2007.05757.x

Jensen, P. H., Nielsen, M. S., Jakes, R., Dotti, C. G., and Goedert, M. (1998). Binding of alpha-synuclein to brain vesicles is abolished by familial Parkinson's disease mutation. J. Biol. Chem. 273, 26292-26294. doi: 10.1074/jbc.273.41.26292

Ji, H., Liu, Y. E., Jia, T., Wang, M., Liu, J., Xiao, G., et al. (1997). Identification of a breast cancer-specific gene. BCSG1, by direct differential cDNA sequencing. Cancer Res. 57, 759-764.

Jiang, P., Gan, M., Yen, S. H., McLean, P. J., and Dickson, D. W. (2017). Impaired endo-lysosomal membrane integrity accelerates the seeding progression of alpha-synuclein aggregates. Sci. Rep. 7:7690. doi: 10.1038/s41598-017-08149-w

Jiang, T. F., Zhang, Y. J., Zhou, H. Y., Wang, H. M., Tian, L. P., Liu, J., et al. (2013). Curcumin ameliorates the neurodegenerative pathology in A53T alphasynuclein cell model of Parkinson's disease through the downregulation of mTOR/p70S6K signaling and the recovery of macroautophagy. J. Neuroimmune Pharmacol. 8, 356-369. doi: 10.1007/s11481-012-9431-7

Jin, H., Kanthasamy, A., Ghosh, A., Yang, Y., Anantharam, V., and Kanthasamy, A. G. (2011). alpha-Synuclein negatively regulates protein kinase Cdelta expression to suppress apoptosis in dopaminergic neurons by reducing p300 histone acetyltransferase activity. J. Neurosci. 31, 2035-2051. doi: 10.1523/ JNEUROSCI.5634-10.2011

Judith Peterschmitt, M., Gasser, T., Isaacson, S., Kulisevsky, J., Mir, P., Simuni, T., et al. (2019). Safety, tolerability and pharmacokinetics of oral venglustat in Parkinson disease patients with a GBA mutation. Mol. Genet. Metab. 126:S117.

Junn, E., Lee, K. W., Jeong, B. S., Chan, T. W., Im, J. Y., and Mouradian, M. M. (2009). Repression of alpha-synuclein expression and toxicity by microRNA-7. Proc. Natl. Acad. Sci. U.S.A. 106, 13052-13057. doi: 10.1073/pnas.0906277106

Kahle, P. J., Neumann, M., Ozmen, L., Muller, V., Jacobsen, H., Spooren, W., et al. (2002). Hyperphosphorylation and insolubility of alpha-synuclein in transgenic mouse oligodendrocytes. EMBO Rep. 3, 583-588. doi: 10.1093/embo-reports/ kvf109

Kaji, S., Maki, T., Kinoshita, H., Uemura, N., Ayaki, T., Kawamoto, Y., et al. (2018). Pathological endogenous alpha-synuclein accumulation in oligodendrocyte precursor cells potentially induces inclusions in multiple system atrophy. Stem Cell Rep. 10, 356-365. doi: 10.1016/j.stemcr.2017.12.001

Kallab, M., Herrera-Vaquero, M., Johannesson, M., Eriksson, F., Sigvardson, J., Poewe, W., et al. (2018). Region-specific effects of immunotherapy with antibodies targeting alpha-synuclein in a transgenic model of synucleinopathy. Front. Neurosci. 12:452. doi: 10.3389/fnins.2018.00452

Kamp, F., Exner, N., Lutz, A. K., Wender, N., Hegermann, J., Brunner, B., et al. (2010). Inhibition of mitochondrial fusion by alpha-synuclein is rescued by PINK1, Parkin and DJ-1. EMBO J. 29, 3571-3589. doi: 10.1038/emboj.2010.223

Kanaan, N. M., and Manfredsson, F. P. (2012). Loss of functional alpha-synuclein: A toxic event in Parkinson's disease? J. Parkinsons Dis. 2, 249-267. doi: 10.3233/ JPD-012138

Karampetsou, M., Ardah, M. T., Semitekolou, M., Polissidis, A., Samiotaki, M., Kalomoiri, M., et al. (2017). Phosphorylated exogenous alpha-synuclein fibrils 
exacerbate pathology and induce neuronal dysfunction in mice. Sci. Rep. 7:16533. doi: 10.1038/s41598-017-15813-8

Karpinar, D. P., Balija, M. B., Kugler, S., Opazo, F., Rezaei-Ghaleh, N., Wender, N., et al. (2009). Pre-fibrillar alpha-synuclein variants with impaired beta-structure increase neurotoxicity in Parkinson's disease models. EMBO J. 28, 3256-3268. doi: 10.1038/emboj.2009.257

Karpowicz, R. J. Jr., Haney, C. M., Mihaila, T. S., Sandler, R. M., Petersson, E. J., and Lee, V. M. (2017). Selective imaging of internalized proteopathic alpha-synuclein seeds in primary neurons reveals mechanistic insight into transmission of synucleinopathies. J. Biol. Chem. 292, 13482-13497. doi: 10. 1074/jbc.M117.780296

Karuppagounder, S. S., Brahmachari, S., Lee, Y., Dawson, V. L., Dawson, T. M., and Ko, H. S. (2014). The c-Abl inhibitor, nilotinib, protects dopaminergic neurons in a preclinical animal model of Parkinson's disease. Sci. Rep. 4:4874. doi: 10.1038/srep04874

Kaufman, E., Hall, S., Surova, Y., Widner, H., Hansson, O., and Lindqvist, D. (2013). Proinflammatory cytokines are elevated in serum of patients with multiple system atrophy. PLoS One 8:e62354. doi: 10.1371/journal.pone.0062354

Kawamoto, T., Ii, M., Kitazaki, T., Iizawa, Y., and Kimura, H. (2008). TAK242 selectively suppresses Toll-like receptor 4-signaling mediated by the intracellular domain. Eur. J. Pharmacol. 584, 40-48. doi: 10.1016/j.ejphar.2008. 01.026

Kayed, R., Sokolov, Y., Edmonds, B., McIntire, T. M., Milton, S. C., Hall, J. E., et al. (2004). Permeabilization of lipid bilayers is a common conformationdependent activity of soluble amyloid oligomers in protein misfolding diseases. J. Biol. Chem. 279, 46363-46366. doi: 10.1074/jbc.C400260200

Kellie, J. F., Higgs, R. E., Ryder, J. W., Major, A., Beach, T. G., Adler, C. H., et al. (2014). Quantitative measurement of intact alpha-synuclein proteoforms from post-mortem control and Parkinson's disease brain tissue by intact protein mass spectrometry. Sci. Rep. 4:5797. doi: 10.1038/srep05797

Khalaf, O., Fauvet, B., Oueslati, A., Dikiy, I., Mahul-Mellier, A. L., Ruggeri, F. S., et al. (2014). The H50Q mutation enhances alpha-synuclein aggregation, secretion, and toxicity. J. Biol. Chem. 289, 21856-21876. doi: 10.1074/jbc.M114. 553297

Khodr, C. E., Becerra, A., Han, Y., and Bohn, M. C. (2014). Targeting alphasynuclein with a microRNA-embedded silencing vector in the rat substantia nigra: positive and negative effects. Brain Res. 1550, 47-60. doi: 10.1016/j. brainres.2014.01.010

Khodr, C. E., Sapru, M. K., Pedapati, J., Han, Y., West, N. C., Kells, A. P., et al. (2011). An alpha-synuclein AAV gene silencing vector ameliorates a behavioral deficit in a rat model of Parkinson's disease, but displays toxicity in dopamine neurons. Brain Res. 1395, 94-107. doi: 10.1016/j.brainres.2011.04.036

Kiely, A. P., Asi, Y. T., Kara, E., Limousin, P., Ling, H., Lewis, P., et al. (2013). alpha-Synucleinopathy associated with G51D SNCA mutation: a link between Parkinson's disease and multiple system atrophy? Acta Neuropathol. 125, 753769. doi: 10.1007/s00401-013-1096-7

Kiely, A. P., Ling, H., Asi, Y. T., Kara, E., Proukakis, C., Schapira, A. H., et al. (2015). Distinct clinical and neuropathological features of G51D SNCA mutation cases compared with SNCA duplication and H50Q mutation. Mol. Neurodegener. 10:41. doi: 10.1186/s13024-015-0038-3

Kim, C., Ho, D. H., Suk, J. E., You, S., Michael, S., Kang, J., et al. (2013). Neuron-released oligomeric alpha-synuclein is an endogenous agonist of TLR2 for paracrine activation of microglia. Nat. Commun. 4:1562. doi: 10.1038/ ncomms 2534

Kim, C., Lv, G., Lee, J. S., Jung, B. C., Masuda-Suzukake, M., Hong, C. S., et al. (2016). Exposure to bacterial endotoxin generates a distinct strain of alpha-synuclein fibril. Sci. Rep. 6:30891. doi: 10.1038/srep30891

Kim, S., Kwon, S. H., Kam, T. I., Panicker, N., Karuppagounder, S. S., Lee, S., et al. (2019). Transneuronal propagation of pathologic alpha-synuclein from the gut to the brain models Parkinson's disease. Neuron 103, 627-641.e7. doi: 10.1016/j.neuron.2019.05.035

Kim, T., Mehta, S. L., Morris-Blanco, K. C., Chokkalla, A. K., Chelluboina, B., Lopez, M., et al. (2018). The microRNA miR-7a-5p ameliorates ischemic brain damage by repressing alpha-synuclein. Sci. Signal. 11:eaat4285. doi: 10.1126/ scisignal.aat 4285

Kim, T. D., Paik, S. R., and Yang, C. H. (2002). Structural and functional implications of C-terminal regions of alpha-synuclein. Biochemistry 41, 1378213790. doi: $10.1021 / \mathrm{bi026284c}$
Kim, Y. S., Lim, D., Kim, J. Y., Kang, S. J., Kim, Y. H., and Im, H. (2009). beta-Sheetbreaking peptides inhibit the fibrillation of human alpha-synuclein. Biochem. Biophys. Res. Commun. 387, 682-687. doi: 10.1016/j.bbrc.2009.07.083

Kirik, D., Rosenblad, C., Burger, C., Lundberg, C., Johansen, T. E., Muzyczka, N., et al. (2002). Parkinson-like neurodegeneration induced by targeted overexpression of alpha-synuclein in the nigrostriatal system. J. Neurosci. 22, 2780-2791. doi: 10.1523/jneurosci.22-07-02780.2002

Kisos, H., Pukass, K., Ben-Hur, T., Richter-Landsberg, C., and Sharon, R. (2012). Increased neuronal alpha-synuclein pathology associates with its accumulation in oligodendrocytes in mice modeling alpha-synucleinopathies. PLoS One 7:e46817. doi: 10.1371/journal.pone.0046817

Klegeris, A., Pelech, S., Giasson, B. I., Maguire, J., Zhang, H., McGeer, E. G., et al. (2008). Alpha-synuclein activates stress signaling protein kinases in THP-1 cells and microglia. Neurobiol. Aging 29, 739-752. doi: 10.1016/j.neurobiolaging. 2006.11.013

Klein, A. D., and Mazzulli, J. R. (2018). Is Parkinson's disease a lysosomal disorder? Brain 141, 2255-2262. doi: 10.1093/brain/awy147

Kleinknecht, A., Popova, B., Lazaro, D. F., Pinho, R., Valerius, O., Outeiro, T. F., et al. (2016). C-Terminal tyrosine residue modifications modulate the protective phosphorylation of serine 129 of alpha-synuclein in a yeast model of Parkinson's disease. PLoS Genet. 12:e1006098. doi: 10.1371/journal.pgen.100 6098

Konno, M., Hasegawa, T., Baba, T., Miura, E., Sugeno, N., Kikuchi, A., et al. (2012). Suppression of dynamin GTPase decreases alpha-synuclein uptake by neuronal and oligodendroglial cells: a potent therapeutic target for synucleinopathy. Mol. Neurodegener. 7:38. doi: 10.1186/1750-1326-7-38

Kordower, J. H., Chu, Y., Hauser, R. A., Freeman, T. B., and Olanow, C. W. (2008). Lewy body-like pathology in long-term embryonic nigral transplants in Parkinson's disease. Nat. Med. 14, 504-506. doi: 10.1038/nm1747

Kordower, J. H., Dodiya, H. B., Kordower, A. M., Terpstra, B., Paumier, K., Madhavan, L., et al. (2011). Transfer of host-derived alpha synuclein to grafted dopaminergic neurons in rat. Neurobiol. Dis. 43, 552-557. doi: 10.1016/j.nbd. 2011.05.001

Kragh, C. L., Lund, L. B., Febbraro, F., Hansen, H. D., Gai, W. P., El-Agnaf, O., et al. (2009). Alpha-synuclein aggregation and Ser-129 phosphorylationdependent cell death in oligodendroglial cells. J. Biol. Chem. 284, 10211-10222. doi: 10.1074/jbc.M809671200

Krishnan, R., Tsubery, H., Proschitsky, M. Y., Asp, E., Lulu, M., Gilead, S., et al. (2014). A bacteriophage capsid protein provides a general amyloid interaction motif (GAIM) that binds and remodels misfolded protein assemblies. J. Mol. Biol. 426, 2500-2519. doi: 10.1016/j.jmb.2014.04.015

Kruger, R., Kuhn, W., Muller, T., Woitalla, D., Graeber, M., Kosel, S., et al. (1998). Ala30Pro mutation in the gene encoding alpha-synuclein in Parkinson's disease. Nat. Genet. 18, 106-108. doi: 10.1038/ng0298-106

Krumova, P., Meulmeester, E., Garrido, M., Tirard, M., Hsiao, H. H., Bossis, G., et al. (2011). Sumoylation inhibits alpha-synuclein aggregation and toxicity. J. Cell Biol. 194, 49-60. doi: 10.1083/jcb.201010117

Kurowska, Z., Englund, E., Widner, H., Lindvall, O., Li, J. Y., and Brundin, P. (2011). Signs of degeneration in 12-22-year old grafts of mesencephalic dopamine neurons in patients with Parkinson's disease. J. Parkinsons Dis. 1, 83-92. doi: 10.3233/JPD-2011-11004

Kuwahara, T., Tonegawa, R., Ito, G., Mitani, S., and Iwatsubo, T. (2012). Phosphorylation of alpha-synuclein protein at Ser-129 reduces neuronal dysfunction by lowering its membrane binding property in Caenorhabditis elegans. J. Biol. Chem. 287, 7098-7109. doi: 10.1074/jbc.M111.237131

Lan, D. M., Liu, F. T., Zhao, J., Chen, Y., Wu, J. J., Ding, Z. T., et al. (2012). Effect of trehalose on PC12 cells overexpressing wild-type or A53T mutant alpha-synuclein. Neurochem. Res. 37, 2025-2032. doi: 10.1007/s11064-0120823-0

Lassot, I., Mora, S., Lesage, S., Zieba, B. A., Coque, E., Condroyer, C., et al. (2018). The E3 Ubiquitin Ligases TRIM17 and TRIM41 modulate alpha-synuclein expression by regulating ZSCAN21. Cell Rep. 25, 2484-2496.e9. doi: 10.1016/ j.celrep.2018.11.002

Lau, A., So, R. W. L., Lau, H. H. C., Sang, J. C., Ruiz-Riquelme, A., Fleck, S. C., et al. (2020). alpha-Synuclein strains target distinct brain regions and cell types. Nat. Neurosci. 23, 21-31. doi: 10.1038/s41593-019-0541-x

Lautenschlager, J., Stephens, A. D., Fusco, G., Strohl, F., Curry, N., Zacharopoulou, M., et al. (2018). C-terminal calcium binding of alpha-synuclein modulates 
synaptic vesicle interaction. Nat. Commun. 9:712. doi: 10.1038/s41467-01803111-4

Lazaro, D. F., Rodrigues, E. F., Langohr, R., Shahpasandzadeh, H., Ribeiro, T., Guerreiro, P., et al. (2014). Systematic comparison of the effects of alphasynuclein mutations on its oligomerization and aggregation. PLoS Genet. 10:e1004741. doi: 10.1371/journal.pgen.1004741

Lebouvier, T., Neunlist, M., Bruley des Varannes, S., Coron, E., Drouard, A., N'Guyen, J. M., et al. (2010). Colonic biopsies to assess the neuropathology of Parkinson's disease and its relationship with symptoms. PLoS One 5:e12728. doi: 10.1371/journal.pone.0012728

Lee, H. J., Cho, E. D., Lee, K. W., Kim, J. H., Cho, S. G., and Lee, S. J. (2013). Autophagic failure promotes the exocytosis and intercellular transfer of alphasynuclein. Exp. Mol. Med. 45:e22. doi: 10.1038/emm.2013.45

Lee, H. J., Jung, K. W., Chung, S. J., Hong, S. M., Kim, J., Lee, J. H., et al. (2018). Relation of enteric alpha-synuclein to gastrointestinal dysfunction in patients with Parkinson's Disease and in neurologically intact subjects. J. Neurogastroenterol. Motil. 24, 469-478. doi: 10.5056/jnm1 7141

Lee, H. J., Patel, S., and Lee, S. J. (2005). Intravesicular localization and exocytosis of alpha-synuclein and its aggregates. J. Neurosci. 25, 6016-6024. doi: 10.1523/ JNEUROSCI.0692-05.2005

Lee, H. J., Suk, J. E., Bae, E. J., Lee, J. H., Paik, S. R., and Lee, S. J. (2008a). Assembly-dependent endocytosis and clearance of extracellular alphasynuclein. Int. J. Biochem. Cell Biol. 40, 1835-1849. doi: 10.1016/j.biocel.2008. 01.017

Lee, H. J., Suk, J. E., Bae, E. J., and Lee, S. J. (2008b). Clearance and deposition of extracellular alpha-synuclein aggregates in microglia. Biochem. Biophys. Res. Commun. 372, 423-428. doi: 10.1016/j.bbrc.2008.05.045

Lee, H. J., Suk, J. E., Patrick, C., Bae, E. J., Cho, J. H., Rho, S., et al. (2010). Direct transfer of alpha-synuclein from neuron to astroglia causes inflammatory responses in synucleinopathies. J. Biol. Chem. 285, 9262-9272. doi: 10.1074/jbc. M109.081125

Lee, K. W., Chen, W., Junn, E., Im, J. Y., Grosso, H., Sonsalla, P. K., et al. (2011). Enhanced phosphatase activity attenuates alpha-synucleinopathy in a mouse model. J. Neurosci. 31, 6963-6971. doi: 10.1523/JNEUROSCI.6513-10.2011

Lei, Z., Cao, G., and Wei, G. (2019). A30P mutant alpha-synuclein impairs autophagic flux by inactivating JNK signaling to enhance ZKSCAN3 activity in midbrain dopaminergic neurons. Cell Death Dis. 10:133. doi: 10.1038/s41419019-1364-0

Levin, J., Schmidt, F., Boehm, C., Prix, C., Botzel, K., Ryazanov, S., et al. (2014). The oligomer modulator anle138b inhibits disease progression in a Parkinson mouse model even with treatment started after disease onset. Acta Neuropathol. 127, 779-780. doi: 10.1007/s00401-014-1265-3

Lewis, J., Melrose, H., Bumcrot, D., Hope, A., Zehr, C., Lincoln, S., et al. (2008). In vivo silencing of alpha-synuclein using naked siRNA. Mol. Neurodegener. 3:19. doi: 10.1186/1750-1326-3-19

Li, J., Zhu, M., Rajamani, S., Uversky, V. N., and Fink, A. L. (2004). Rifampicin inhibits alpha-synuclein fibrillation and disaggregates fibrils. Chem. Biol. 11, 1513-1521. doi: 10.1016/j.chembiol.2004.08.025

Li, J. Y., Englund, E., Holton, J. L., Soulet, D., Hagell, P., Lees, A. J., et al. (2008). Lewy bodies in grafted neurons in subjects with Parkinson's disease suggest host-to-graft disease propagation. Nat. Med. 14, 501-503. doi: 10.1038/nm1746

Li, J. Y., Englund, E., Widner, H., Rehncrona, S., Bjorklund, A., Lindvall, O., et al. (2010). Characterization of Lewy body pathology in 12- and 16-yearold intrastriatal mesencephalic grafts surviving in a patient with Parkinson's disease. Mov. Disord. 25, 1091-1096. doi: 10.1002/mds.23012

Lin, A., Zheng, W., He, Y., Tang, W., Wei, X., He, R., et al. (2018). Gut microbiota in patients with Parkinson's disease in southern China. Parkinsonism Relat. Disord. 53, 82-88. doi: 10.1016/j.parkreldis.2018.05.007

Lin, D., Liang, Y., Jing, X., Chen, Y., Lei, M., Zeng, Z., et al. (2018). Microarray analysis of an synthetic alpha-synuclein induced cellular model reveals the expression profile of long non-coding RNA in Parkinson's disease. Brain Res. 1678, 384-396. doi: 10.1016/j.brainres.2017.11.007

Lin, T. K., Chen, S. D., Chuang, Y. C., Lin, H. Y., Huang, C. R., Chuang, J. H., et al. (2014). Resveratrol partially prevents rotenone-induced neurotoxicity in dopaminergic SH-SY5Y cells through induction of heme oxygenase1 dependent autophagy. Int. J. Mol. Sci. 15, 1625-1646. doi: 10.3390/ ijms 15011625
Lindersson, E., Lundvig, D., Petersen, C., Madsen, P., Nyengaard, J. R., Hojrup, P., et al. (2005). p25alpha Stimulates alpha-synuclein aggregation and is colocalized with aggregated alpha-synuclein in alpha-synucleinopathies. J. Biol. Chem. 280, 5703-5715. doi: 10.1074/jbc.M410409200

Liu, C. W., Corboy, M. J., DeMartino, G. N., and Thomas, P. J. (2003). Endoproteolytic activity of the proteasome. Science 299, 408-411. doi: 10.1126/ science. 1079293

Liu, G., Chen, M., Mi, N., Yang, W., Li, X., Wang, P., et al. (2015). Increased oligomerization and phosphorylation of alpha-synuclein are associated with decreased activity of glucocerebrosidase and protein phosphatase $2 \mathrm{~A}$ in aging monkey brains. Neurobiol. Aging 36, 2649-2659. doi: 10.1016/j.neurobiolaging. 2015.06.004

Liu, K., Shi, N., Sun, Y., Zhang, T., and Sun, X. (2013). Therapeutic effects of rapamycin on MPTP-induced Parkinsonism in mice. Neurochem. Res. 38, 201-207. doi: 10.1007/s11064-012-0909-8

Lo Bianco, C., Ridet, J. L., Schneider, B. L., Deglon, N., and Aebischer, P. (2002). alpha -Synucleinopathy and selective dopaminergic neuron loss in a rat lentiviral-based model of Parkinson's disease. Proc. Natl. Acad. Sci. U.S.A. 99, 10813-10818. doi: 10.1073/pnas.152339799

Logan, T., Bendor, J., Toupin, C., Thorn, K., and Edwards, R. H. (2017). alphaSynuclein promotes dilation of the exocytotic fusion pore. Nat. Neurosci. 20, 681-689. doi: 10.1038/nn.4529

Longhena, F., Faustini, G., Spillantini, M. G., and Bellucci, A. (2019). Living in promiscuity: the multiple partners of Alpha-synuclein at the synapse in physiology and pathology. Int. J. Mol. Sci. 20:141. doi: 10.3390/ijms20010141

Loria, F., Vargas, J. Y., Bousset, L., Syan, S., Salles, A., Melki, R., et al. (2017). alphaSynuclein transfer between neurons and astrocytes indicates that astrocytes play a role in degradation rather than in spreading. Acta Neuropathol. 134, 789-808. doi: 10.1007/s00401-017-1746-2

Low, P. A., Robertson, D., Gilman, S., Kaufmann, H., Singer, W., Biaggioni, I., et al. (2014). Efficacy and safety of rifampicin for multiple system atrophy: a randomised, double-blind, placebo-controlled trial. Parkinsonism Relat. Disord. 13, 268-275. doi: 10.1016/S1474-4422(13)70301-6

Lu, M., Su, C., Qiao, C., Bian, Y., Ding, J., and Hu, G. (2016). Metformin prevents dopaminergic neuron death in MPTP/P-induced mouse model of Parkinson's disease via autophagy and mitochondrial ROS CLEARANCE. Int. J. Neuropsychopharmacol. 19:pyw047. doi: 10.1093/ijnp/pyw047

Luk, K. C., Kehm, V., Carroll, J., Zhang, B., O’Brien, P., Trojanowski, J. Q., et al. (2012a). Pathological alpha-synuclein transmission initiates Parkinsonlike neurodegeneration in nontransgenic mice. Science 338, 949-953. doi: 10. $1126 /$ science. 1227157

Luk, K. C., Kehm, V. M., Zhang, B., O’Brien, P., Trojanowski, J. Q., and Lee, V. M. (2012b). Intracerebral inoculation of pathological alpha-synuclein initiates a rapidly progressive neurodegenerative alpha-synucleinopathy in mice. J. Exp. Med. 209, 975-986. doi: 10.1084/jem.20112457

Luk, K. C., Song, C., O’Brien, P., Stieber, A., Branch, J. R., Brunden, K. R., et al. (2009). Exogenous alpha-synuclein fibrils seed the formation of Lewy bodylike intracellular inclusions in cultured cells. Proc. Natl. Acad. Sci. U.S.A. 106, 20051-20056. doi: 10.1073/pnas.0908005106

Luna, E., Decker, S. C., Riddle, D. M., Caputo, A., Zhang, B., Cole, T., et al. (2018). Differential alpha-synuclein expression contributes to selective vulnerability of hippocampal neuron subpopulations to fibril-induced toxicity. Acta Neuropathol. 135, 855-875. doi: 10.1007/s00401-018-1829-8

Ly, T., and Julian, R. R. (2008). Protein-metal interactions of calmodulin and alphasynuclein monitored by selective noncovalent adduct protein probing mass spectrometry. J. Am. Soc. Mass Spectrom. 19, 1663-1672. doi: 10.1016/j.jasms. 2008.07.006

Lynch, S. M., Zhou, C., and Messer, A. (2008). An scFv intrabody against the nonamyloid component of alpha-synuclein reduces intracellular aggregation and toxicity. J. Mol. Biol. 377, 136-147. doi: 10.1016/j.jmb.2007. 11.096

Ma, L., Yang, C., Zhang, X., Li, Y., Wang, S., Zheng, L., et al. (2018). C-terminal truncation exacerbates the aggregation and cytotoxicity of alpha-Synuclein: a vicious cycle in Parkinson's disease. Biochim. Biophys. Acta Mol. Basis Dis. 1864, 3714-3725. doi: 10.1016/j.bbadis.2018.10.003

Ma, M. R., Hu, Z. W., Zhao, Y. F., Chen, Y. X., and Li, Y. M. (2016). Phosphorylation induces distinct alpha-synuclein strain formation. Sci. Rep. 6:37130. doi: $10.1038 /$ srep 37130 
Mahul-Mellier, A. L., Fauvet, B., Gysbers, A., Dikiy, I., Oueslati, A., Georgeon, S., et al. (2014). c-Abl phosphorylates alpha-synuclein and regulates its degradation: implication for alpha-synuclein clearance and contribution to the pathogenesis of Parkinson's disease. Hum. Mol. Genet. 23, 2858-2879. doi: 10.1093/hmg/ddt674

Mak, S. K., McCormack, A. L., Manning-Bog, A. B., Cuervo, A. M., and Di Monte, D. A. (2010). Lysosomal degradation of alpha-synuclein in vivo. J. Biol. Chem. 285, 13621-13629. doi: 10.1074/jbc.M109.074617

Malagelada, C., Jin, Z. H., Jackson-Lewis, V., Przedborski, S., and Greene, L. A. (2010). Rapamycin protects against neuron death in in vitro and in vivo models of Parkinson's disease. J. Neurosci. 30, 1166-1175. doi: 10.1523/JNEUROSCI. 3944-09.2010

Malerba, M., and Ragnoli, B. (2008). Ambroxol in the 21st century: pharmacological and clinical update. Expert Opin. Drug Metab. Toxicol. 4, 1119-1129. doi: 10.1517/17425255.4.8.1119

Mandler, M., Valera, E., Rockenstein, E., Mante, M., Weninger, H., Patrick, C., et al. (2015). Active immunization against alpha-synuclein ameliorates the degenerative pathology and prevents demyelination in a model of multiple system atrophy. Mol. Neurodegener. 10:10. doi: 10.1186/s13024-015-0008-9

Mandler, M., Valera, E., Rockenstein, E., Weninger, H., Patrick, C., Adame, A., et al. (2014). Next-generation active immunization approach for synucleinopathies: implications for Parkinson's disease clinical trials. Acta Neuropathol. 127, 861879. doi: 10.1007/s00401-014-1256-4

Manfredsson, F. P., Luk, K. C., Benskey, M. J., Gezer, A., Garcia, J., Kuhn, N. C., et al. (2018). Induction of alpha-synuclein pathology in the enteric nervous system of the rat and non-human primate results in gastrointestinal dysmotility and transient CNS pathology. Neurobiol. Dis. 112, 106-118. doi: 10.1016/j.nbd. 2018.01.008

Mao, X., Ou, M. T., Karuppagounder, S. S., Kam, T. I., Yin, X., Xiong, Y., et al. (2016). Pathological alpha-synuclein transmission initiated by binding lymphocyte-activation gene 3. Science 353:aah3374. doi: 10.1126/science. aah3374

Maroteaux, L., Campanelli, J. T., and Scheller, R. H. (1988). Synuclein: a neuronspecific protein localized to the nucleus and presynaptic nerve terminal. J. Neurosci. 8, 2804-2815. doi: 10.1523/jneurosci.08-08-02804.1988

Martin-Clemente, B., Alvarez-Castelao, B., Mayo, I., Sierra, A. B., Diaz, V., Milan, M., et al. (2004). alpha-Synuclein expression levels do not significantly affect proteasome function and expression in mice and stably transfected PC12 cell lines. J. Biol. Chem. 279, 52984-52990. doi: 10.1074/jbc.M409028200

Martinez-Vicente, M., Talloczy, Z., Kaushik, S., Massey, A. C., Mazzulli, J., Mosharov, E. V., et al. (2008). Dopamine-modified alpha-synuclein blocks chaperone-mediated autophagy. J. Clin. Invest. 118, 777-788. doi: 10.1172/ JCI32806

Masliah, E., Rockenstein, E., Adame, A., Alford, M., Crews, L., Hashimoto, M., et al. (2005). Effects of alpha-synuclein immunization in a mouse model of Parkinson's disease. Neuron 46, 857-868. doi: 10.1016/j.neuron.2005.05.010

Masliah, E., Rockenstein, E., Mante, M., Crews, L., Spencer, B., Adame, A., et al. (2011). Passive immunization reduces behavioral and neuropathological deficits in an alpha-synuclein transgenic model of Lewy body disease. PLoS One 6:e19338. doi: 10.1371/journal.pone.0019338

Masliah, E., Rockenstein, E., Veinbergs, I., Sagara, Y., Mallory, M., Hashimoto, M., et al. (2001). beta-amyloid peptides enhance alpha-synuclein accumulation and neuronal deficits in a transgenic mouse model linking Alzheimer's disease and Parkinson's disease. Proc. Natl. Acad. Sci. U.S.A. 98, 12245-12250. doi: 10.1073/pnas.211412398

Masuda, M., Suzuki, N., Taniguchi, S., Oikawa, T., Nonaka, T., Iwatsubo, T., et al. (2006). Small molecule inhibitors of alpha-synuclein filament assembly. Biochemistry 45, 6085-6094. doi: 10.1021/bi0600749

Masuda-Suzukake, M., Nonaka, T., Hosokawa, M., Kubo, M., Shimozawa, A., Akiyama, H., et al. (2014). Pathological alpha-synuclein propagates through neural networks. Acta Neuropathol. Commun. 2:88. doi: 10.1186/s40478-0140088-8

Masuda-Suzukake, M., Nonaka, T., Hosokawa, M., Oikawa, T., Arai, T., Akiyama, H., et al. (2013). Prion-like spreading of pathological alpha-synuclein in brain. Brain 136(Pt 4), 1128-1138. doi: 10.1093/brain/awt037

Mata, I. F., Samii, A., Schneer, S. H., Roberts, J. W., Griffith, A., Leis, B. C., et al. (2008). Glucocerebrosidase gene mutations: a risk factor for Lewy body disorders. Arch. Neurol. 65, 379-382. doi: 10.1001/archneurol.2007.68
Mavroeidi, P., Arvanitaki, F., Karakitsou, A. K., Vetsi, M., Kloukina, I., Zweckstetter, M., et al. (2019). Endogenous oligodendroglial alpha-synuclein and TPPP/p25alpha orchestrate alpha-synuclein pathology in experimental multiple system atrophy models. Acta Neuropathol. 138, 415-441. doi: 10.1007/ s00401-019-02014-y

Mazzulli, J. R., Xu, Y. H., Sun, Y., Knight, A. L., McLean, P. J., Caldwell, G. A., et al. (2011). Gaucher disease glucocerebrosidase and alpha-synuclein form a bidirectional pathogenic loop in synucleinopathies. Cell 146, 37-52. doi: 10. 1016/j.cell.2011.06.001

McCormack, A. L., Mak, S. K., Henderson, J. M., Bumcrot, D., Farrer, M. J., and Di Monte, D. A. (2010). Alpha-synuclein suppression by targeted small interfering RNA in the primate substantia nigra. PLoS One 5:e12122. doi: 10.1371/journal. pone.0012122

McNeill, A., Magalhaes, J., Shen, C., Chau, K. Y., Hughes, D., Mehta, A., et al. (2014). Ambroxol improves lysosomal biochemistry in glucocerebrosidase mutation-linked Parkinson disease cells. Brain 137(Pt 5), 1481-1495. doi: 10. 1093/brain/awu020

Migdalska-Richards, A., Daly, L., Bezard, E., and Schapira, A. H. (2016). Ambroxol effects in glucocerebrosidase and alpha-synuclein transgenic mice. Ann. Neurol. 80, 766-775. doi: 10.1002/ana.24790

Migdalska-Richards, A., Ko, W. K. D., Li, Q., Bezard, E., and Schapira, A. H. V. (2017). Oral ambroxol increases brain glucocerebrosidase activity in a nonhuman primate. Synapse 71:e21967. doi: 10.1002/syn.21967

Minakaki, G., Menges, S., Kittel, A., Emmanouilidou, E., Schaeffner, I., Barkovits, K., et al. (2018). Autophagy inhibition promotes SNCA/alpha-synuclein release and transfer via extracellular vesicles with a hybrid autophagosome-exosomelike phenotype. Autophagy 14, 98-119. doi: 10.1080/15548627.2017.1395992

Mittal, S., Bjornevik, K., Im, D. S., Flierl, A., Dong, X., Locascio, J. J., et al. (2017). beta2-Adrenoreceptor is a regulator of the alpha-synuclein gene driving risk of Parkinson's disease. Science 357, 891-898. doi: 10.1126/science.aaf3934

Mogi, M., Harada, M., Kondo, T., Riederer, P., Inagaki, H., Minami, M., et al. (1994a). Interleukin-1 beta, interleukin-6, epidermal growth factor and transforming growth factor-alpha are elevated in the brain from parkinsonian patients. Neurosci. Lett. 180, 147-150. doi: 10.1016/0304-3940(94)90508-8

Mogi, M., Harada, M., Riederer, P., Narabayashi, H., Fujita, K., and Nagatsu, T. (1994b). Tumor necrosis factor-alpha (TNF-alpha) increases both in the brain and in the cerebrospinal fluid from parkinsonian patients. Neurosci. Lett. 165, 208-210. doi: 10.1016/0304-3940(94)90746-3

Monzio Compagnoni, G., and Di Fonzo, A. (2019). Understanding the pathogenesis of multiple system atrophy: state of the art and future perspectives. Acta Neuropathol. Commun. 7:113. doi: 10.1186/s40478-019-0730-6

Moore, J. S., Gibson, P. R., and Burgell, R. E. (2018). Neuromodulation via interferential electrical stimulation as a novel therapy in gastrointestinal motility disorders. J. Neurogastroenterol. Motil. 24, 19-29. doi: 10.5056/ jnm 17071

Mosley, R. L., Lu, Y., Olson, K. E., Machhi, J., Yan, W., Namminga, K. L., et al. (2019). A synthetic agonist to vasoactive intestinal peptide receptor-2 induces regulatory $\mathrm{T}$ cell neuroprotective activities in models of Parkinson's disease. Front. Cell. Neurosci. 13:421. doi: 10.3389/fncel.2019.00421

Mougenot, A. L., Nicot, S., Bencsik, A., Morignat, E., Verchere, J., Lakhdar, L., et al. (2012). Prion-like acceleration of a synucleinopathy in a transgenic mouse model. Neurobiol. Aging 33, 2225-2228. doi: 10.1016/j.neurobiolaging.2011. 06.022

Mullin, S., Smith, L., Lee, K., D’Souza, G., Woodgate, P., Elflein, J., et al. (2020). Ambroxol for the treatment of patients with Parkinson disease with and without glucocerebrosidase gene mutations: a nonrandomized, noncontrolled trial. JAMA Neurol. 77, 427-434. doi: 10.1001/jamaneurol.2019.4611

Murphy, K. E., Gysbers, A. M., Abbott, S. K., Spiro, A. S., Furuta, A., Cooper, A., et al. (2015). Lysosomal-associated membrane protein 2 isoforms are differentially affected in early Parkinson's disease. Mov. Disord. 30, 1639-1647. doi: $10.1002 / \mathrm{mds} .26141$

Murphy, K. E., Gysbers, A. M., Abbott, S. K., Tayebi, N., Kim, W. S., Sidransky, E., et al. (2014). Reduced glucocerebrosidase is associated with increased alphasynuclein in sporadic Parkinson's disease. Brain 137(Pt 3), 834-848. doi: 10. 1093/brain/awt367

Myohanen, T. T., Hannula, M. J., Van Elzen, R., Gerard, M., Van Der Veken, P., Garcia-Horsman, J. A., et al. (2012). A prolyl oligopeptidase inhibitor, KYP2047, reduces alpha-synuclein protein levels and aggregates in cellular and 
animal models of Parkinson's disease. Br. J. Pharmacol. 166, 1097-1113. doi: 10.1111/j.1476-5381.2012.01846.x

Nagatsu, T., Mogi, M., Ichinose, H., and Togari, A. (2000). "Cytokines in Parkinson's disease," in Advances in Research on Neurodegeneration, eds Y. Mizuno, D. B. Calne, R. Horowski, W. Poewe, P. Riederer, M. B. H. Youdim (Vienna: Springer).

Nagatsu, T., and Sawada, M. (2005). Inflammatory process in Parkinson's disease: role for cytokines. Curr. Pharm. Des. 11, 999-1016. doi: 10.2174/ 1381612053381620

Nakamura, K., Mori, F., Kon, T., Tanji, K., Miki, Y., Tomiyama, M., et al. (2015). Filamentous aggregations of phosphorylated alpha-synuclein in Schwann cells (Schwann cell cytoplasmic inclusions) in multiple system atrophy. Acta Neuropathol. Commun. 3:29. doi: 10.1186/s40478-015-0208-0

Nakamura, K., Nemani, V. M., Azarbal, F., Skibinski, G., Levy, J. M., Egami, K., et al. (2011). Direct membrane association drives mitochondrial fission by the Parkinson disease-associated protein alpha-synuclein. J. Biol. Chem. 286, 20710-20726. doi: 10.1074/jbc.M110.213538

Nakayama, K., Suzuki, Y., and Yazawa, I. (2012). Binding of neuronal alphasynuclein to beta-III tubulin and accumulation in a model of multiple system atrophy. Biochem. Biophys. Res. Commun. 417, 1170-1175. doi: 10.1016/j.bbrc. 2011.12.092

Nalls, M. A., Pankratz, N., Lill, C. M., Do, C. B., Hernandez, D. G., Saad, M., et al. (2014). Large-scale meta-analysis of genome-wide association data identifies six new risk loci for Parkinson's disease. Nat. Genet. 46, 989-993. doi: 10.1038/ng. 3043

Nemani, V. M., Lu, W., Berge, V., Nakamura, K., Onoa, B., Lee, M. K., et al. (2010). Increased expression of alpha-synuclein reduces neurotransmitter release by inhibiting synaptic vesicle reclustering after endocytosis. Neuron 65, 66-79. doi: 10.1016/j.neuron.2009.12.023

Ng, C. H., Guan, M. S., Koh, C., Ouyang, X., Yu, F., Tan, E. K., et al. (2012). AMP kinase activation mitigates dopaminergic dysfunction and mitochondrial abnormalities in Drosophila models of Parkinson's disease. J. Neurosci. 32, 14311-14317. doi: 10.1523/JNEUROSCI.0499- 12.2012

Nishie, M., Mori, F., Fujiwara, H., Hasegawa, M., Yoshimoto, M., Iwatsubo, T., et al. (2004). Accumulation of phosphorylated alpha-synuclein in the brain and peripheral ganglia of patients with multiple system atrophy. Acta Neuropathol. 107, 292-298. doi: 10.1007/s00401-003-0811-1

Norris, E. H., Giasson, B. I., Ischiropoulos, H., and Lee, V. M. (2003). Effects of oxidative and nitrative challenges on alpha-synuclein fibrillogenesis involve distinct mechanisms of protein modifications. J. Biol. Chem. 278, 27230-27240. doi: 10.1074/jbc.M212436200

Obergasteiger, J., Frapporti, G., Pramstaller, P. P., Hicks, A. A., and Volta, M. (2018). A new hypothesis for Parkinson's disease pathogenesis: GTPase-p38 MAPK signaling and autophagy as convergence points of etiology and genomics. Mol. Neurodegener. 13:40. doi: 10.1186/s13024-0180273-5

Odagiri, S., Tanji, K., Mori, F., Kakita, A., Takahashi, H., and Wakabayashi, K. (2012). Autophagic adapter protein NBR1 is localized in Lewy bodies and glial cytoplasmic inclusions and is involved in aggregate formation in alphasynucleinopathy. Acta Neuropathol. 124, 173-186. doi: 10.1007/s00401-0120975-7

Okun, M. S. (2012). Deep-brain stimulation for Parkinson's disease. N. Engl. J. Med. 367, 1529-1538. doi: 10.1056/NEJMct1208070

Olson, K. E., Bade, A. N., Schutt, C. R., Dong, J., Shandler, S. J., Boska, M. D., et al. (2016). Manganese-enhanced magnetic resonance imaging for detection of vasoactive intestinal peptide receptor 2 agonist therapy in a model of Parkinson's disease. Neurotherapeutics 13, 635-646. doi: 10.1007/s13311-0160449-z

Olson, K. E., Kosloski-Bilek, L. M., Anderson, K. M., Diggs, B. J., Clark, B. E., Gledhill, J. M., et al. (2015). Selective VIP receptor agonists facilitate immune transformation for dopaminergic neuroprotection in MPTP-intoxicated mice. J. Neurosci. 35, 16463-16478. doi: 10.1523/JNEUROSCI.2131-15.2015

Onfelt, B., Nedvetzki, S., Yanagi, K., and Davis, D. M. (2004). Cutting edge: membrane nanotubes connect immune cells. J. Immunol. 173, 1511-1513. doi: 10.4049/jimmunol.173.3.1511

Orme, T., Guerreiro, R., and Bras, J. (2018). The genetics of dementia with Lewy bodies: current understanding and future directions. Curr. Neurol. Neurosci. Rep. 18:67. doi: 10.1007/s11910-018-0874-y
Osellame, L. D., Rahim, A. A., Hargreaves, I. P., Gegg, M. E., Richard-Londt, A., Brandner, S., et al. (2013). Mitochondria and quality control defects in a mouse model of Gaucher disease-links to Parkinson's disease. Cell Metab. 17, 941-953. doi: 10.1016/j.cmet.2013.04.014

Oueslati, A. (2016). Implication of Alpha-synuclein phosphorylation at S129 in synucleinopathies: What have we learned in the last decade? J. Parkinsons Dis. 6, 39-51. doi: 10.3233/JPD- 160779

Oueslati, A., Fournier, M., and Lashuel, H. A. (2010). Role of post-translational modifications in modulating the structure, function and toxicity of alphasynuclein: implications for Parkinson's disease pathogenesis and therapies. Prog. Brain Res. 183, 115-145. doi: 10.1016/S0079-6123(10)83007-9

Paillusson, S., Clairembault, T., Biraud, M., Neunlist, M., and Derkinderen, P. (2013). Activity-dependent secretion of alpha-synuclein by enteric neurons. J. Neurochem. 125, 512-517. doi: 10.1111/jnc.12131

Paleologou, K. E., Oueslati, A., Shakked, G., Rospigliosi, C. C., Kim, H. Y., Lamberto, G. R., et al. (2010). Phosphorylation at $\mathrm{S} 87$ is enhanced in synucleinopathies, inhibits alpha-synuclein oligomerization, and influences synuclein-membrane interactions. J. Neurosci. 30, 3184-3198. doi: 10.1523/ JNEUROSCI.5922-09.2010

Paleologou, K. E., Schmid, A. W., Rospigliosi, C. C., Kim, H. Y., Lamberto, G. R., Fredenburg, R. A., et al. (2008). Phosphorylation at Ser-129 but not the phosphomimics S129E/D inhibits the fibrillation of alpha-synuclein. J. Biol. Chem. 283, 16895-16905. doi: 10.1074/jbc.M800747200

Pandey, N., Strider, J., Nolan, W. C., Yan, S. X., and Galvin, J. E. (2008). Curcumin inhibits aggregation of alpha-synuclein. Acta Neuropathol. 115, 479-489. doi: 10.1007/s00401-007-0332-4

Park, J. Y., Kim, K. S., Lee, S. B., Ryu, J. S., Chung, K. C., Choo, Y. K., et al. (2009). On the mechanism of internalization of alpha-synuclein into microglia: roles of ganglioside GM1 and lipid raft. J. Neurochem. 110, 400-411. doi: 10.1111/j. 1471-4159.2009.06150.x

Park, S. M., Jung, H. Y., Kim, T. D., Park, J. H., Yang, C. H., and Kim, J. (2002). Distinct roles of the N-terminal-binding domain and the C-terminalsolubilizing domain of alpha-synuclein, a molecular chaperone. J. Biol. Chem. 277, 28512-28520. doi: 10.1074/jbc.M111971200

Pasanen, P., Myllykangas, L., Siitonen, M., Raunio, A., Kaakkola, S., Lyytinen, J., et al. (2014). Novel alpha-synuclein mutation A53E associated with atypical multiple system atrophy and Parkinson's disease-type pathology. Neurobiol. Aging 35, 2180.e1-2180.e5. doi: 10.1016/j.neurobiolaging.2014. 03.024

Patil, S. P., Jain, P. D., Ghumatkar, P. J., Tambe, R., and Sathaye, S. (2014). Neuroprotective effect of metformin in MPTP-induced Parkinson's disease in mice. Neuroscience 277, 747-754. doi: 10.1016/j.neuroscience.2014.07.046

Paumier, K. L., Luk, K. C., Manfredsson, F. P., Kanaan, N. M., Lipton, J. W., Collier, T. J., et al. (2015). Intrastriatal injection of pre-formed mouse alpha-synuclein fibrils into rats triggers alpha-synuclein pathology and bilateral nigrostriatal degeneration. Neurobiol. Dis. 82, 185-199. doi: 10.1016/j.nbd.2015.06.003

Peelaerts, W., Bousset, L., Van der Perren, A., Moskalyuk, A., Pulizzi, R., Giugliano, M., et al. (2015). alpha-Synuclein strains cause distinct synucleinopathies after local and systemic administration. Nature 522, 340-344. doi: 10.1038/ nature 14547

Peng, C., Gathagan, R. J., Covell, D. J., Medellin, C., Stieber, A., Robinson, J. L., et al. (2018a). Cellular milieu imparts distinct pathological alpha-synuclein strains in alpha-synucleinopathies. Nature 557, 558-563. doi: 10.1038/s41586-0180104-4

Peng, C., Gathagan, R. J., and Lee, V. M. (2018b). Distinct alpha-Synuclein strains and implications for heterogeneity among alpha-Synucleinopathies. Neurobiol. Dis. 109(Pt B), 209-218. doi: 10.1016/j.nbd.2017.07.018

Peng, X., Tehranian, R., Dietrich, P., Stefanis, L., and Perez, R. G. (2005). Alphasynuclein activation of protein phosphatase $2 \mathrm{~A}$ reduces tyrosine hydroxylase phosphorylation in dopaminergic cells. J. Cell Sci. 118(Pt 15), 3523-3530. doi: $10.1242 /$ jcs. 02481

Pieri, L., Madiona, K., and Melki, R. (2016). Structural and functional properties of prefibrillar alpha-synuclein oligomers. Sci. Rep. 6:24526. doi: 10.1038/ srep24526

Pirc, K., and Ulrih, N. P. (2015). alpha-Synuclein interactions with phospholipid model membranes: key roles for electrostatic interactions and lipid-bilayer structure. Biochim. Biophys. Acta 1848(10 Pt A), 2002-2012. doi: 10.1016/j. bbamem.2015.06.021 
Pletnikova, O., West, N., Lee, M. K., Rudow, G. L., Skolasky, R. L., Dawson, T. M., et al. (2005). Abeta deposition is associated with enhanced cortical alpha-synuclein lesions in Lewy body diseases. Neurobiol. Aging 26, 1183-1192. doi: 10.1016/j.neurobiolaging.2004.10.006

Politis, M., Su, P., and Piccini, P. (2012). Imaging of microglia in patients with neurodegenerative disorders. Front. Pharmacol. 3:96. doi: 10.3389/fphar.2012. 00096

Polymeropoulos, M. H., Lavedan, C., Leroy, E., Ide, S. E., Dehejia, A., Dutra, A., et al. (1997). Mutation in the alpha-synuclein gene identified in families with Parkinson's disease. Science 276, 2045-2047. doi: 10.1126/science.276. 5321.2045

Pouclet, H., Lebouvier, T., Coron, E., Des Varannes, S. B., Neunlist, M., and Derkinderen, P. (2012). A comparison between colonic submucosa and mucosa to detect Lewy pathology in Parkinson's disease. Neurogastroenterol. Motil. 24, e202-e205. doi: 10.1111/j.1365-2982.2012.01887.x

Prabhudesai, S., Sinha, S., Attar, A., Kotagiri, A., Fitzmaurice, A. G., Lakshmanan, R., et al. (2012). A novel "molecular tweezer" inhibitor of alpha-synuclein neurotoxicity in vitro and in vivo. Neurotherapeutics 9, 464-476. doi: 10.1007/ s13311-012-0105-1

Price, D. L., Koike, M. A., Khan, A., Wrasidlo, W., Rockenstein, E., Masliah, E., et al. (2018). The small molecule alpha-synuclein misfolding inhibitor, NPT200-11, produces multiple benefits in an animal model of Parkinson's disease. Sci. Rep. 8:16165. doi: 10.1038/s41598-018-34490-9

Proukakis, C., Dudzik, C. G., Brier, T., MacKay, D. S., Cooper, J. M., Millhauser, G. L., et al. (2013). A novel alpha-synuclein missense mutation in Parkinson disease. Neurology 80, 1062-1064. doi: 10.1212/WNL.0b013e31828727ba

Prusiner, S. B., Woerman, A. L., Mordes, D. A., Watts, J. C., Rampersaud, R., Berry, D. B., et al. (2015). Evidence for alpha-synuclein prions causing multiple system atrophy in humans with parkinsonism. Proc. Natl. Acad. Sci. U.S.A. 112, E5308-E5317. doi: 10.1073/pnas.1514475112

Pukass, K., Goldbaum, O., and Richter-Landsberg, C. (2015). Mitochondrial impairment and oxidative stress compromise autophagosomal degradation of alpha-synuclein in oligodendroglial cells. J. Neurochem. 135, 194-205. doi: 10. $1111 /$ jnc. 13256

Pukass, K., and Richter-Landsberg, C. (2014). Oxidative stress promotes uptake, accumulation, and oligomerization of extracellular alpha-synuclein in oligodendrocytes. J. Mol. Neurosci. 52, 339-352. doi: 10.1007/s12031-013-0154-

$$
\mathrm{x}
$$

Ravina, B., Putt, M., Siderowf, A., Farrar, J. T., Gillespie, M., Crawley, A., et al. (2005). Donepezil for dementia in Parkinson's disease: a randomised, double blind, placebo controlled, crossover study. J. Neurol. Neurosurg. Psychiatry 76, 934-939. doi: 10.1136/jnnp.2004.050682

Recasens, A., Dehay, B., Bove, J., Carballo-Carbajal, I., Dovero, S., Perez-Villalba, A., et al. (2014). Lewy body extracts from Parkinson disease brains trigger alphasynuclein pathology and neurodegeneration in mice and monkeys. Ann. Neurol. 75, 351-362. doi: 10.1002/ana.24066

Rey, N. L., Petit, G. H., Bousset, L., Melki, R., and Brundin, P. (2013). Transfer of human alpha-synuclein from the olfactory bulb to interconnected brain regions in mice. Acta Neuropathol. 126, 555-573. doi: 10.1007/s00401-013-1160-3

Rey, N. L., Steiner, J. A., Maroof, N., Luk, K. C., Madaj, Z., Trojanowski, J. Q., et al. (2016). Widespread transneuronal propagation of alpha-synucleinopathy triggered in olfactory bulb mimics prodromal Parkinson's disease. J. Exp. Med. 213, 1759-1778. doi: 10.1084/jem.20160368

Reyes, J. F., Rey, N. L., Bousset, L., Melki, R., Brundin, P., and Angot, E. (2014). Alpha-synuclein transfers from neurons to oligodendrocytes. Glia 62, 387-398. doi: $10.1002 /$ glia.22611

Reyes, J. F., Sackmann, C., Hoffmann, A., Svenningsson, P., Winkler, J., Ingelsson, M., et al. (2019). Binding of alpha-synuclein oligomers to Cx32 facilitates protein uptake and transfer in neurons and oligodendrocytes. Acta Neuropathol. 138, 23-47. doi: 10.1007/s00401-019-02007-x

Reynolds, A. D., Stone, D. K., Hutter, J. A., Benner, E. J., Mosley, R. L., and Gendelman, H. E. (2010). Regulatory T cells attenuate Th17 cell-mediated nigrostriatal dopaminergic neurodegeneration in a model of Parkinson's disease. J. Immunol. 184, 2261-2271. doi: 10.4049/jimmunol.0901852

Rice, T. W., Wheeler, A. P., Bernard, G. R., Vincent, J. L., Angus, D. C., Aikawa, N., et al. (2010). A randomized, double-blind, placebo-controlled trial of TAK242 for the treatment of severe sepsis. Crit. Care Med. 38, 1685-1694. doi: 10.1097/CCM.0b013e3181e7c5c9
Richter, F., Subramaniam, S. R., Magen, I., Lee, P., Hayes, J., Attar, A., et al. (2017). A molecular Tweezer ameliorates motor deficits in mice overexpressing alpha-Synuclein. Neurotherapeutics 14, 1107-1119. doi: 10.1007/s13311-0170544-9

Rideout, H. J., Larsen, K. E., Sulzer, D., and Stefanis, L. (2001). Proteasomal inhibition leads to formation of ubiquitin/alpha-synuclein-immunoreactive inclusions in PC12 cells. J. Neurochem. 78, 899-908. doi: 10.1046/j.1471-4159. 2001.00474.x

Rideout, H. J., and Stefanis, L. (2002). Proteasomal inhibition-induced inclusion formation and death in cortical neurons require transcription and ubiquitination. Mol. Cell. Neurosci. 21, 223-238. doi: 10.1006/mcne.2002.1173

Rocha, E. M., De Miranda, B., and Sanders, L. H. (2018). Alpha-synuclein: pathology, mitochondrial dysfunction and neuroinflammation in Parkinson's disease. Neurobiol. Dis. 109(Pt B), 249-257. doi: 10.1016/j.nbd.2017.04.004

Rocha, E. M., Smith, G. A., Park, E., Cao, H., Graham, A. R., Brown, E., et al. (2015). Sustained systemic glucocerebrosidase inhibition induces brain alphasynuclein aggregation, microglia and complement C1q activation in Mice. Antioxid. Redox Signal. 23, 550-564. doi: 10.1089/ars.2015.6307

Rockenstein, E., Ostroff, G., Dikengil, F., Rus, F., Mante, M., Florio, J., et al. (2018). Combined active humoral and cellular immunization approaches for the treatment of synucleinopathies. J. Neurosci. 38, 1000-1014. doi: 10.1523/ JNEUROSCI.1170-17.2017

Rockenstein, E., Ubhi, K., Inglis, C., Mante, M., Patrick, C., Adame, A., et al. (2012). Neuronal to oligodendroglial alpha-synuclein redistribution in a double transgenic model of multiple system atrophy. Neuroreport 23, 259-264. doi: 10.1097/WNR.0b013e3283509842

Rodriguez, J. A., Ivanova, M. I., Sawaya, M. R., Cascio, D., Reyes, F. E., Shi, D., et al. (2015). Structure of the toxic core of alpha-synuclein from invisible crystals. Nature 525, 486-490. doi: 10.1038/nature15368

Roodveldt, C., Labrador-Garrido, A., Gonzalez-Rey, E., Lachaud, C. C., Guilliams, T., Fernandez-Montesinos, R., et al. (2013). Preconditioning of microglia by alpha-synuclein strongly affects the response induced by toll-like receptor (TLR) stimulation. PLoS One 8:e79160. doi: 10.1371/journal.pone.0079160

Rospigliosi, C. C., McClendon, S., Schmid, A. W., Ramlall, T. F., Barre, P., Lashuel, H. A., et al. (2009). E46K Parkinson's-linked mutation enhances C-terminalto-N-terminal contacts in alpha-synuclein. J. Mol. Biol. 388, 1022-1032. doi: 10.1016/j.jmb.2009.03.065

Rott, R., Szargel, R., Haskin, J., Bandopadhyay, R., Lees, A. J., Shani, V., et al. (2011). alpha-Synuclein fate is determined by USP9X-regulated monoubiquitination. Proc. Natl. Acad. Sci. U.S.A. 108, 18666-18671. doi: 10.1073/pnas.1105725108

Sacino, A. N., Brooks, M., McGarvey, N. H., McKinney, A. B., Thomas, M. A., Levites, Y., et al. (2013a). Induction of CNS alpha-synuclein pathology by fibrillar and non-amyloidogenic recombinant alpha-synuclein. Acta Neuropathol. Commun. 1:38. doi: 10.1186/2051-5960-1-38

Sacino, A. N., Brooks, M., McKinney, A. B., Thomas, M. A., Shaw, G., Golde, T. E., et al. (2014a). Brain injection of alpha-synuclein induces multiple proteinopathies, gliosis, and a neuronal injury marker. J. Neurosci. 34, 1236812378. doi: 10.1523/JNEUROSCI.2102-14.2014

Sacino, A. N., Brooks, M., Thomas, M. A., McKinney, A. B., Lee, S., Regenhardt, R. W., et al. (2014b). Intramuscular injection of alpha-synuclein induces CNS alpha-synuclein pathology and a rapid-onset motor phenotype in transgenic mice. Proc. Natl. Acad. Sci. U.S.A. 111, 10732-10737. doi: 10.1073/pnas. 1321785111

Sacino, A. N., Thomas, M. A., Ceballos-Diaz, C., Cruz, P. E., Rosario, A. M., Lewis, J., et al. (2013b). Conformational templating of alpha-synuclein aggregates in neuronal-glial cultures. Mol. Neurodegener. 8:17. doi: 10.1186/1750-1326-8-17

Sahin, C., Lorenzen, N., Lemminger, L., Christiansen, G., Moller, I. M., Vesterager, L. B., et al. (2017). Antibodies against the C-terminus of alpha-synuclein modulate its fibrillation. Biophys. Chem. 220, 34-41. doi: 10.1016/j.bpc.2016. 11.002

Sailer, A., Scholz, S. W., Nalls, M. A., Schulte, C., Federoff, M., Price, T. R., et al. (2016). A genome-wide association study in multiple system atrophy. Neurology 87, 1591-1598. doi: 10.1212/WNL.0000000000003221

Saito, Y., Kawashima, A., Ruberu, N. N., Fujiwara, H., Koyama, S., Sawabe, M., et al. (2003). Accumulation of phosphorylated alpha-synuclein in aging human brain. J. Neuropathol. Exp. Neurol. 62, 644-654. doi: 10.1093/jnen/62.6.644

Sampson, T. R., Debelius, J. W., Thron, T., Janssen, S., Shastri, G. G., Ilhan, Z. E., et al. (2016). Gut microbiota regulate motor deficits and neuroinflammation in 
a model of Parkinson's disease. Cell 167, 1469-1480.e12. doi: 10.1016/j.cell.2016. 11.018

Sanchez-Guajardo, V., Febbraro, F., Kirik, D., and Romero-Ramos, M. (2010). Microglia acquire distinct activation profiles depending on the degree of alphasynuclein neuropathology in a rAAV based model of Parkinson's disease. PLoS One 5:e8784. doi: 10.1371/journal.pone.0008784

Sapru, M. K., Yates, J. W., Hogan, S., Jiang, L., Halter, J., and Bohn, M. C. (2006). Silencing of human alpha-synuclein in vitro and in rat brain using lentiviralmediated RNAi. Exp. Neurol. 198, 382-390. doi: 10.1016/j.expneurol.2005. 12.024

Sardi, S. P., Cedarbaum, J. M., and Brundin, P. (2018). Targeted therapies for Parkinson's disease: from genetics to the clinic. Mov. Disord. 33, 684-696. doi: $10.1002 / \mathrm{mds} .27414$

Sardi, S. P., Clarke, J., Kinnecom, C., Tamsett, T. J., Li, L., Stanek, L. M., et al. (2011). CNS expression of glucocerebrosidase corrects alpha-synuclein pathology and memory in a mouse model of Gaucher-related synucleinopathy. Proc. Natl. Acad. Sci. U.S.A. 108, 12101-12106. doi: 10.1073/pnas.1108197108

Sardi, S. P., Clarke, J., Viel, C., Chan, M., Tamsett, T. J., Treleaven, C. M., et al. (2013). Augmenting CNS glucocerebrosidase activity as a therapeutic strategy for parkinsonism and other Gaucher-related synucleinopathies. Proc. Natl. Acad. Sci. U.S.A. 110, 3537-3542. doi: 10.1073/pnas.1220464110

Sardi, S. P., Viel, C., Clarke, J., Treleaven, C. M., Richards, A. M., Park, H., et al. (2017). Glucosylceramide synthase inhibition alleviates aberrations in synucleinopathy models. Proc. Natl. Acad. Sci. U.S.A. 114, 2699-2704. doi: 10.1073/pnas.1616152114

Sarkar, S., Chigurupati, S., Raymick, J., Mann, D., Bowyer, J. F., Schmitt, T., et al. (2014). Neuroprotective effect of the chemical chaperone, trehalose in a chronic MPTP-induced Parkinson's disease mouse model. Neurotoxicology 44, 250-262. doi: 10.1016/j.neuro.2014.07.006

Sarkar, S., Davies, J. E., Huang, Z., Tunnacliffe, A., and Rubinsztein, D. C. (2007). Trehalose, a novel mTOR-independent autophagy enhancer, accelerates the clearance of mutant huntingtin and alpha-synuclein. J. Biol. Chem. 282, 56415652. doi: 10.1074/jbc.M609532200

Satake, W., Nakabayashi, Y., Mizuta, I., Hirota, Y., Ito, C., Kubo, M., et al. (2009). Genome-wide association study identifies common variants at four loci as genetic risk factors for Parkinson's disease. Nat. Genet. 41, 1303-1307. doi: 10.1038/ng.485

Satish Bollimpelli, V., and Kondapi, A. K. (2015). Differential sensitivity of immature and mature ventral mesencephalic neurons to rotenone induced neurotoxicity in vitro. Toxicol In Vitro 30(1 Pt B), 545-551. doi: 10.1016/j.tiv. 2015.09.006

Sato, H., Arawaka, S., Hara, S., Fukushima, S., Koga, K., Koyama, S., et al. (2011). Authentically phosphorylated alpha-synuclein at Ser129 accelerates neurodegeneration in a rat model of familial Parkinson's disease. J. Neurosci. 31, 16884-16894. doi: 10.1523/JNEUROSCI.3967-11.2011

Saunders, J. A., Estes, K. A., Kosloski, L. M., Allen, H. E., Dempsey, K. M., Torres-Russotto, D. R., et al. (2012). CD4+ regulatory and effector/memory T cell subsets profile motor dysfunction in Parkinson's disease. J. Neuroimmune Pharmacol. 7, 927-938. doi: 10.1007/s11481-012-9402-z

Schapira, A. H., and Gegg, M. E. (2013). Glucocerebrosidase in the pathogenesis and treatment of Parkinson disease. Proc. Natl. Acad. Sci. U.S.A. 110, 32143215. doi: 10.1073/pnas.1300822110

Schenk, D. B., Koller, M., Ness, D. K., Griffith, S. G., Grundman, M., Zago, W., et al. (2017). First-in-human assessment of PRX002, an anti-alpha-synuclein monoclonal antibody, in healthy volunteers. Mov. Disord. 32, 211-218. doi: $10.1002 / \mathrm{mds} .26878$

Scheperjans, F., Aho, V., Pereira, P. A., Koskinen, K., Paulin, L., Pekkonen, E., et al. (2015). Gut microbiota are related to Parkinson's disease and clinical phenotype. Mov. Disord. 30, 350-358. doi: 10.1002/mds.26069

Scherzer, C. R., Grass, J. A., Liao, Z., Pepivani, I., Zheng, B., Eklund, A. C., et al. (2008). GATA transcription factors directly regulate the Parkinson's diseaselinked gene alpha-synuclein. Proc. Natl. Acad. Sci. U.S.A. 105, 10907-10912. doi: 10.1073/pnas.0802437105

Schofield, D. J., Irving, L., Calo, L., Bogstedt, A., Rees, G., Nuccitelli, A., et al. (2019). Preclinical development of a high affinity alpha-synuclein antibody, MEDI1341, that can enter the brain, sequester extracellular alpha-synuclein and attenuate alpha-synuclein spreading in vivo. Neurobiol. Dis. 132:104582. doi: 10.1016/j.nbd.2019.104582
Scholz, S. W., Houlden, H., Schulte, C., Sharma, M., Li, A., Berg, D., et al. (2009). SNCA variants are associated with increased risk for multiple system atrophy. Ann. Neurol. 65, 610-614. doi: 10.1002/ana.21685

Schreiber, K. H., Ortiz, D., Academia, E. C., Anies, A. C., Liao, C. Y., and Kennedy, B. K. (2015). Rapamycin-mediated mTORC2 inhibition is determined by the relative expression of FK506-binding proteins. Aging Cell 14, 265-273. doi: 10.1111/acel.12313

Schwab, K., Frahm, S., Horsley, D., Rickard, J. E., Melis, V., Goatman, E. A., et al. (2017). A protein aggregation inhibitor, Leuco-Methylthioninium Bis(Hydromethanesulfonate), decreases alpha-synuclein inclusions in a transgenic mouse model of synucleinopathy. Front. Mol. Neurosci. 10:447. doi: 10.3389/fnmol.2017.00447

Schwarz, L., Goldbaum, O., Bergmann, M., Probst-Cousin, S., and RichterLandsberg, C. (2012). Involvement of macroautophagy in multiple system atrophy and protein aggregate formation in oligodendrocytes. J. Mol. Neurosci. 47, 256-266. doi: 10.1007/s12031-012-9733-5

Schweighauser, M., Bacioglu, M., Fritschi, S. K., Shimshek, D. R., Kahle, P. J., Eisele, Y. S., et al. (2015). Formaldehyde-fixed brain tissue from spontaneously ill alpha-synuclein transgenic mice induces fatal alpha-synucleinopathy in transgenic hosts. Acta Neuropathol. 129, 157-159. doi: 10.1007/s00401-0141360-5

Shahaduzzaman, M., Nash, K., Hudson, C., Sharif, M., Grimmig, B., Lin, X., et al. (2015). Anti-human alpha-synuclein N-terminal peptide antibody protects against dopaminergic cell death and ameliorates behavioral deficits in an AAValpha-synuclein rat model of Parkinson's disease. PLoS One 10:e0116841. doi: 10.1371/journal.pone.0116841

Shahnawaz, M., Mukherjee, A., Pritzkow, S., Mendez, N., Rabadia, P., Liu, X., et al. (2020). Discriminating alpha-synuclein strains in Parkinson's disease and multiple system atrophy. Nature 578, 273-277. doi: 10.1038/s41586-0201984-7

Shahpasandzadeh, H., Popova, B., Kleinknecht, A., Fraser, P. E., Outeiro, T. F., and Braus, G. H. (2014). Interplay between sumoylation and phosphorylation for protection against alpha-synuclein inclusions. J. Biol. Chem. 289, 31224-31240. doi: 10.1074/jbc.M114.559237

Shaltiel-Karyo, R., Davidi, D., Frenkel-Pinter, M., Ovadia, M., Segal, D., and Gazit, E. (2012). Differential inhibition of alpha-synuclein oligomeric and fibrillar assembly in parkinson's disease model by cinnamon extract. Biochim. Biophys. Acta 1820, 1628-1635. doi: 10.1016/j.bbagen.2012.04.021

Shaltiel-Karyo, R., Frenkel-Pinter, M., Egoz-Matia, N., Frydman-Marom, A., Shalev, D. E., Segal, D., et al. (2010). Inhibiting alpha-synuclein oligomerization by stable cell-penetrating beta-synuclein fragments recovers phenotype of Parkinson's disease model flies. PLoS One 5:e13863. doi: 10.1371/journal.pone. 0013863

Shaltiel-Karyo, R., Frenkel-Pinter, M., Rockenstein, E., Patrick, C., Levy-Sakin, M., Schiller, A., et al. (2013). A blood-brain barrier (BBB) disrupter is also a potent alpha-synuclein (alpha-syn) aggregation inhibitor: a novel dual mechanism of mannitol for the treatment of Parkinson disease (PD). J. Biol. Chem. 288, 17579-17588. doi: 10.1074/jbc.M112.434787

Shrivastava, A. N., Redeker, V., Fritz, N., Pieri, L., Almeida, L. G., Spolidoro, M., et al. (2015). alpha-synuclein assemblies sequester neuronal alpha3-Na+/K+ATPase and impair Na+ gradient. EMBO J. 34, 2408-2423. doi: 10.15252/embj. 201591397

Shults, C. W., Rockenstein, E., Crews, L., Adame, A., Mante, M., Larrea, G., et al. (2005). Neurological and neurodegenerative alterations in a transgenic mouse model expressing human alpha-synuclein under oligodendrocyte promoter: implications for multiple system atrophy. J. Neurosci. 25, 10689-10699. doi: 10.1523/JNEUROSCI.3527-05.2005

Silveira, C. R. A., MacKinley, J., Coleman, K., Li, Z., Finger, E., Bartha, R., et al. (2019). Ambroxol as a novel disease-modifying treatment for Parkinson's disease dementia: protocol for a single-centre, randomized, doubleblind, placebo-controlled trial. BMC Neurol. 19:20. doi: 10.1186/s12883-019$1252-3$

Simon-Sanchez, J., Schulte, C., Bras, J. M., Sharma, M., Gibbs, J. R., Berg, D., et al. (2009). Genome-wide association study reveals genetic risk underlying Parkinson's disease. Nat. Genet. 41, 1308-1312. doi: 10.1038/ng.487

Singleton, A. B., Farrer, M., Johnson, J., Singleton, A., Hague, S., Kachergus, J., et al. (2003). alpha-Synuclein locus triplication causes Parkinson's disease. Science 302:841. doi: $10.1126 /$ science. 1090278 
Smith, W. W., Margolis, R. L., Li, X., Troncoso, J. C., Lee, M. K., Dawson, V. L., et al. (2005). Alpha-synuclein phosphorylation enhances eosinophilic cytoplasmic inclusion formation in SH-SY5Y cells. J. Neurosci. 25, 5544-5552. doi: 10.1523/JNEUROSCI.0482-05.2005

Sode, K., Ochiai, S., Kobayashi, N., and Usuzaka, E. (2006). Effect of reparation of repeat sequences in the human alpha-synuclein on fibrillation ability. Int. J. Biol. Sci. 3, 1-7. doi: 10.7150/ijbs.3.1

Song, J. X., Sun, Y. R., Peluso, I., Zeng, Y., Yu, X., Lu, J. H., et al. (2016). A novel curcumin analog binds to and activates TFEB in vitro and in vivo independent of MTOR inhibition. Autophagy 12, 1372-1389. doi: 10.1080/15548627.2016. 1179404

Spencer, B., Emadi, S., Desplats, P., Eleuteri, S., Michael, S., Kosberg, K., et al. (2014). ESCRT-mediated uptake and degradation of brain-targeted alphasynuclein single chain antibody attenuates neuronal degeneration in vivo. Mol. Ther. 22, 1753-1767. doi: 10.1038/mt.2014.129

Spillantini, M. G., Crowther, R. A., Jakes, R., Hasegawa, M., and Goedert, M. (1998). alpha-Synuclein in filamentous inclusions of Lewy bodies from Parkinson's disease and dementia with lewy bodies. Proc. Natl. Acad. Sci. U.S.A. 95, 64696473. doi: 10.1073/pnas.95.11.6469

Spillantini, M. G., and Goedert, M. (2000). The alpha-synucleinopathies: Parkinson's disease, dementia with Lewy bodies, and multiple system atrophy. Ann. N. Y. Acad. Sci. 920, 16-27. doi: 10.1111/j.1749-6632.2000.tb06900.x

Spillantini, M. G., Schmidt, M. L., Lee, V. M., Trojanowski, J. Q., Jakes, R., and Goedert, M. (1997). Alpha-synuclein in Lewy bodies. Nature 388, 839-840. doi: $10.1038 / 42166$

Staats, K. A., Hernandez, S., Schonefeldt, S., Bento-Abreu, A., Dooley, J., Van Damme, P., et al. (2013). Rapamycin increases survival in ALS mice lacking mature lymphocytes. Mol. Neurodegener. 8:31. doi: 10.1186/1750-1326-8-31

Stefanis, L., Larsen, K. E., Rideout, H. J., Sulzer, D., and Greene, L. A. (2001). Expression of A53T mutant but not wild-type alpha-synuclein in PC12 cells induces alterations of the ubiquitin-dependent degradation system, loss of dopamine release, and autophagic cell death. J. Neurosci. 21, 9549-9560. doi: 10.1523/jneurosci.21-24-09549.2001

Stefanova, N., Fellner, L., Reindl, M., Masliah, E., Poewe, W., and Wenning, G. K. (2011). Toll-like receptor 4 promotes alpha-synuclein clearance and survival of nigral dopaminergic neurons. Am. J. Pathol. 179, 954-963. doi: 10.1016/j.ajpath. 2011.04.013

Stefanova, N., Reindl, M., Neumann, M., Kahle, P. J., Poewe, W., and Wenning, G. K. (2007). Microglial activation mediates neurodegeneration related to oligodendroglial alpha-synucleinopathy: implications for multiple system atrophy. Mov. Disord. 22, 2196-2203. doi: 10.1002/mds.21671

Stefanova, N., Reindl, M., Poewe, W., and Wenning, G. K. (2005). In vitro models of multiple system atrophy. Mov. Disord. 20(Suppl. 12), S53-S56. doi: 10.1002/ mds. 20540

Stefanova, N., and Wenning, G. K. (2016). Review: multiple system atrophy: emerging targets for interventional therapies. Neuropathol. Appl. Neurobiol. 42, 20-32. doi: $10.1111 /$ nan.12304

Stemberger, S., Poewe, W., Wenning, G. K., and Stefanova, N. (2010). Targeted overexpression of human alpha-synuclein in oligodendroglia induces lesions linked to MSA-like progressive autonomic failure. Exp. Neurol. 224, 459-464. doi: 10.1016/j.expneurol.2010.05.008

Strohaker, T., Jung, B. C., Liou, S. H., Fernandez, C. O., Riedel, D., Becker, S., et al. (2019). Structural heterogeneity of alpha-synuclein fibrils amplified from patient brain extracts. Nat. Commun. 10:5535. doi: 10.1038/s41467-019-13 564-w

Stuendl, A., Kunadt, M., Kruse, N., Bartels, C., Moebius, W., Danzer, K. M., et al. (2016). Induction of alpha-synuclein aggregate formation by CSF exosomes from patients with Parkinson's disease and dementia with Lewy bodies. Brain 139(Pt 2), 481-494. doi: 10.1093/brain/awv346

Su, X., Maguire-Zeiss, K. A., Giuliano, R., Prifti, L., Venkatesh, K., and Federoff, H. J. (2008). Synuclein activates microglia in a model of Parkinson's disease. Neurobiol. Aging 29, 1690-1701. doi: 10.1016/j.neurobiolaging.2007.04.006

Sung, J. Y., Kim, J., Paik, S. R., Park, J. H., Ahn, Y. S., and Chung, K. C. (2001). Induction of neuronal cell death by Rab5A-dependent endocytosis of alphasynuclein. J. Biol. Chem. 276, 27441-27448. doi: 10.1074/jbc.M101318200

Surgucheva, I., Gunewardena, S., Rao, H. S., and Surguchov, A. (2013). Cell-specific post-transcriptional regulation of gamma-synuclein gene by micro-RNAs. PLoS One 8:e73786. doi: 10.1371/journal.pone.0073786
Svensson, E., Horvath-Puho, E., Thomsen, R. W., Djurhuus, J. C., Pedersen, L., Borghammer, P., et al. (2015). Vagotomy and subsequent risk of Parkinson's disease. Ann. Neurol. 78, 522-529. doi: 10.1002/ana.24448

Swant, J., Goodwin, J. S., North, A., Ali, A. A., Gamble-George, J., Chirwa, S., et al. (2011). alpha-Synuclein stimulates a dopamine transporter-dependent chloride current and modulates the activity of the transporter. J. Biol. Chem. 286, 43933-43943. doi: 10.1074/jbc.M111.241232

Tan, S., Yu, C. Y., Sim, Z. W., Low, Z. S., Lee, B., See, F., et al. (2019). Pomegranate activates TFEB to promote autophagy-lysosomal fitness and mitophagy. Sci. Rep. 9:727. doi: 10.1038/s41598-018-37400-1

Tanaka, Y., Engelender, S., Igarashi, S., Rao, R. K., Wanner, T., Tanzi, R. E., et al. (2001). Inducible expression of mutant alpha-synuclein decreases proteasome activity and increases sensitivity to mitochondria-dependent apoptosis. Hum. Mol. Genet. 10, 919-926. doi: 10.1093/hmg/10.9.919

Tang, Y., and Le, W. (2016). Differential roles of M1 and M2 microglia in neurodegenerative diseases. Mol. Neurobiol. 53, 1181-1194. doi: 10.1007/ s12035-014-9070-5

Tanji, K., Miki, Y., Maruyama, A., Mimura, J., Matsumiya, T., Mori, F., et al. (2015). Trehalose intake induces chaperone molecules along with autophagy in a mouse model of Lewy body disease. Biochem. Biophys. Res. Commun. 465, 746-752. doi: 10.1016/j.bbrc.2015.08.076

Tanji, K., Odagiri, S., Maruyama, A., Mori, F., Kakita, A., Takahashi, H., et al. (2013). Alteration of autophagosomal proteins in the brain of multiple system atrophy. Neurobiol. Dis. 49, 190-198. doi: 10.1016/j.nbd.2012.08.017

Tansey, M. G., and Romero-Ramos, M. (2019). Immune system responses in Parkinson's disease: early and dynamic. Eur. J. Neurosci. 49, 364-383. doi: 10.1111/ejn. 14290

Teki, S., and Griffiths, T. D. (2016). Brain bases of working memory for time intervals in rhythmic sequences. Front. Neurosci. 10:239. doi: 10.3389/fnins. 2016.00239

Tenreiro, S., Reimao-Pinto, M. M., Antas, P., Rino, J., Wawrzycka, D., Macedo, D., et al. (2014). Phosphorylation modulates clearance of alpha-synuclein inclusions in a yeast model of Parkinson's disease. PLoS Genet. 10:e1004302. doi: 10.1371/journal.pgen.1004302

Terada, M., Suzuki, G., Nonaka, T., Kametani, F., Tamaoka, A., and Hasegawa, M. (2018). The effect of truncation on prion-like properties of alpha-synuclein. J. Biol. Chem. 293, 13910-13920. doi: 10.1074/jbc.RA118.001862

Thayanidhi, N., Helm, J. R., Nycz, D. C., Bentley, M., Liang, Y., and Hay, J. C. (2010). Alpha-synuclein delays endoplasmic reticulum (ER)-to-Golgi transport in mammalian cells by antagonizing ER/Golgi SNAREs. Mol. Biol. Cell 21, 1850-1863. doi: 10.1091/mbc.E09-09-0801

Tofaris, G. K., Layfield, R., and Spillantini, M. G. (2001). alpha-synuclein metabolism and aggregation is linked to ubiquitin-independent degradation by the proteasome. FEBS Lett. 509, 22-26. doi: 10.1016/s0014-5793(01)03115-5

Tomas-Zapico, C., Diez-Zaera, M., Ferrer, I., Gomez-Ramos, P., Moran, M. A., Miras-Portugal, M. T., et al. (2012). alpha-Synuclein accumulates in huntingtin inclusions but forms independent filaments and its deficiency attenuates early phenotype in a mouse model of Huntington's disease. Hum. Mol. Genet. 21, 495-510. doi: 10.1093/hmg/ddr507

Tran, H. T., Chung, C. H., Iba, M., Zhang, B., Trojanowski, J. Q., Luk, K. C., et al. (2014). Alpha-synuclein immunotherapy blocks uptake and templated propagation of misfolded alpha-synuclein and neurodegeneration. Cell Rep. 7, 2054-2065. doi: 10.1016/j.celrep.2014.05.033

Tsigelny, I. F., Sharikov, Y., Wrasidlo, W., Gonzalez, T., Desplats, P. A., Crews, L., et al. (2012). Role of alpha-synuclein penetration into the membrane in the mechanisms of oligomer pore formation. FEBS J. 279, 1000-1013. doi: 10.1111/j.1742-4658.2012.08489.x

Tufekci, K. U., Meuwissen, R., Genc, S., and Genc, K. (2012). Inflammation in Parkinson's disease. Adv. Protein Chem. Struct. Biol. 88, 69-132. doi: 10.1016/ B978-0-12-398314-5.00004-0

Ubhi, K., Rockenstein, E., Mante, M., Inglis, C., Adame, A., Patrick, C., et al. (2010). Neurodegeneration in a transgenic mouse model of multiple system atrophy is associated with altered expression of oligodendroglial-derived neurotrophic factors. J. Neurosci. 30, 6236-6246. doi: 10.1523/JNEUROSCI.0567-10.2010

Ubhi, K., Rockenstein, E., Mante, M., Patrick, C., Adame, A., Thukral, M., et al. (2008). Rifampicin reduces alpha-synuclein in a transgenic mouse model of multiple system atrophy. Neuroreport 19, 1271-1276. doi: 10.1097/WNR. 0b013e32830b3661 
Ueda, K., Fukushima, H., Masliah, E., Xia, Y., Iwai, A., Yoshimoto, M., et al. (1993). Molecular cloning of cDNA encoding an unrecognized component of amyloid in Alzheimer disease. Proc. Natl. Acad. Sci. U.S.A. 90, 11282-11286. doi: 10.1073/pnas.90.23.11282

Uehara, T., Choong, C. J., Nakamori, M., Hayakawa, H., Nishiyama, K., Kasahara, Y., et al. (2019). Amido-bridged nucleic acid (AmNA)-modified antisense oligonucleotides targeting alpha-synuclein as a novel therapy for Parkinson's disease. Sci. Rep. 9:7567. doi: 10.1038/s41598-019-43772-9

Uemura, N., Yagi, H., Uemura, M. T., Hatanaka, Y., Yamakado, H., and Takahashi, R. (2018). Inoculation of alpha-synuclein preformed fibrils into the mouse gastrointestinal tract induces Lewy body-like aggregates in the brainstem via the vagus nerve. Mol. Neurodegener. 13:21. doi: 10.1186/s13024-018-0257-5

Ulmer, T. S., Bax, A., Cole, N. B., and Nussbaum, R. L. (2005). Structure and dynamics of micelle-bound human alpha-synuclein. J. Biol. Chem. 280, 95959603. doi: 10.1074/jbc.M411805200

Ulusoy, A., Febbraro, F., Jensen, P. H., Kirik, D., and Romero-Ramos, M. (2010). Co-expression of C-terminal truncated alpha-synuclein enhances full-length alpha-synuclein-induced pathology. Eur J. Neurosci. 32, 409-422. doi: 10.1111/ j.1460-9568.2010.07284.x

Ulusoy, A., Musgrove, R. E., Rusconi, R., Klinkenberg, M., Helwig, M., Schneider, A., et al. (2015). Neuron-to-neuron alpha-synuclein propagation in vivo is independent of neuronal injury. Acta Neuropathol. Commun. 3:13. doi: 10.1186/ s40478-015-0198-y

Unger, M. M., Spiegel, J., Dillmann, K. U., Grundmann, D., Philippeit, H., Burmann, J., et al. (2016). Short chain fatty acids and gut microbiota differ between patients with Parkinson's disease and age-matched controls. Parkinsonism Relat. Disord. 32, 66-72. doi: 10.1016/j.parkreldis.2016.08.019

Ur Rasheed, M. S., Tripathi, M. K., Mishra, A. K., Shukla, S., and Singh, M. P. (2016). Resveratrol protects from toxin-induced parkinsonism: plethora of proofs hitherto petty translational value. Mol. Neurobiol. 53, 2751-2760. doi: 10.1007/s12035-015-9124-3

Uversky, V. N., Li, J., and Fink, A. L. (2001). Evidence for a partially folded intermediate in alpha-synuclein fibril formation. J. Biol. Chem. 276, $10737-$ 10744. doi: 10.1074/jbc.M010907200

Valente, T., Dentesano, G., Ezquerra, M., Fernandez-Santiago, R., MartinezMartin, J., Gallastegui, E., et al. (2020). CCAAT/enhancer binding protein delta is a transcriptional repressor of alpha-synuclein. Cell Death Differ. 27, 509-524. doi: 10.1038/s41418-019-0368-8

Valera, E., Spencer, B., Fields, J. A., Trinh, I., Adame, A., Mante, M., et al. (2017). Combination of alpha-synuclein immunotherapy with anti-inflammatory treatment in a transgenic mouse model of multiple system atrophy. Acta Neuropathol. Commun. 5:2. doi: 10.1186/s40478-016-0409-1

Van Den Berge, N., Ferreira, N., Gram, H., Mikkelsen, T. W., Alstrup, A. K. O., Casadei, N., et al. (2019). Evidence for bidirectional and trans-synaptic parasympathetic and sympathetic propagation of alpha-synuclein in rats. Acta Neuropathol. 138, 535-550. doi: 10.1007/s00401-019-02040-w

Van der Perren, A., Gelders, G., Fenyi, A., Bousset, L., Brito, F., Peelaerts, W., et al. (2020). The structural differences between patient-derived alpha-synuclein strains dictate characteristics of Parkinson's disease, multiple system atrophy and dementia with Lewy bodies. Acta Neuropathol. 139, 977-1000. doi: 10.1007/ s00401-020-02157-3

Vawter, M. P., Dillon-Carter, O., Tourtellotte, W. W., Carvey, P., and Freed, W. J. (1996). TGFbeta1 and TGFbeta2 concentrations are elevated in Parkinson's disease in ventricular cerebrospinal fluid. Exp. Neurol. 142, 313-322. doi: 10. 1006/exnr.1996.0200

Vekrellis, K., and Stefanis, L. (2012). Targeting intracellular and extracellular alpha-synuclein as a therapeutic strategy in Parkinson's disease and other synucleinopathies. Expert Opin. Ther. Targets 16, 421-432. doi: 10.1517/ 14728222.2012.674111

Vekrellis, K., Xilouri, M., Emmanouilidou, E., Rideout, H. J., and Stefanis, L. (2011). Pathological roles of alpha-synuclein in neurological disorders. Parkinsonism Relat. Disord. 10, 1015-1025. doi: 10.1016/S1474-4422(11)70213-7

Vekrellis, K., Xilouri, M., Emmanouilidou, E., and Stefanis, L. (2009). Inducible over-expression of wild type alpha-synuclein in human neuronal cells leads to caspase-dependent non-apoptotic death. J. Neurochem. 109, 1348-1362. doi: 10.1111/j.1471-4159.2009.06054.x

Vieira, B. D., Radford, R. A., Chung, R. S., Guillemin, G. J., and Pountney, D. L. (2015). Neuroinflammation in multiple system atrophy: response to and cause of alpha-synuclein aggregation. Front. Cell. Neurosci. 9:437. doi: 10.3389/fncel. 2015.00437

Vilarino-Guell, C., Soto-Ortolaza, A. I., Rajput, A., Mash, D. C., Papapetropoulos, S., Pahwa, R., et al. (2011). MAPT H1 haplotype is a risk factor for essential tremor and multiple system atrophy. Neurology 76, 670-672. doi: 10.1212/ WNL.0b013e31820c30c1

Vinueza-Gavilanes, R., Inigo-Marco, I., Larrea, L., Lasa, M., Carte, B., Santamaria, E., et al. (2020). N-terminal acetylation mutants affect alpha-synuclein stability, protein levels and neuronal toxicity. Neurobiol. Dis. 137:104781. doi: 10.1016/j. nbd.2020.104781

Vogiatzi, T., Xilouri, M., Vekrellis, K., and Stefanis, L. (2008). Wild type alphasynuclein is degraded by chaperone-mediated autophagy and macroautophagy in neuronal cells. J. Biol. Chem. 283, 23542-23556. doi: 10.1074/jbc.M80199 2200

Volles, M. J., and Lansbury, P. T. Jr. (2002). Vesicle permeabilization by protofibrillar alpha-synuclein is sensitive to Parkinson's disease-linked mutations and occurs by a pore-like mechanism. Biochemistry 41, 4595-4602. doi: 10.1021/bi0121353

Volpicelli-Daley, L. A., Luk, K. C., and Lee, V. M. (2014). Addition of exogenous alpha-synuclein preformed fibrils to primary neuronal cultures to seed recruitment of endogenous alpha-synuclein to Lewy body and Lewy neurite-like aggregates. Nat. Protoc. 9, 2135-2146. doi: 10.1038/nprot.20 14.143

Volpicelli-Daley, L. A., Luk, K. C., Patel, T. P., Tanik, S. A., Riddle, D. M., Stieber, A., et al. (2011). Exogenous alpha-synuclein fibrils induce Lewy body pathology leading to synaptic dysfunction and neuron death. Neuron 72, 57-71. doi: 10.1016/j.neuron.2011.08.033

Wagner, J., Ryazanov, S., Leonov, A., Levin, J., Shi, S., Schmidt, F., et al. (2013). Anle138b: a novel oligomer modulator for disease-modifying therapy of neurodegenerative diseases such as prion and Parkinson's disease. Acta Neuropathol. 125, 795-813. doi: 10.1007/s00401-013-1114-9

Wakabayashi, K., Hayashi, S., Kakita, A., Yamada, M., Toyoshima, Y., Yoshimoto, M., et al. (1998a). Accumulation of alpha-synuclein/NACP is a cytopathological feature common to Lewy body disease and multiple system atrophy. Acta Neuropathol. 96, 445-452. doi: 10.1007/s004010050918

Wakabayashi, K., Yoshimoto, M., Tsuji, S., and Takahashi, H. (1998b). Alphasynuclein immunoreactivity in glial cytoplasmic inclusions in multiple system atrophy. Neurosci. Lett. 249, 180-182. doi: 10.1016/s0304-3940(98)00407-8

Wang, B., Underwood, R., Kamath, A., Britain, C., McFerrin, M. B., McLean, P. J., et al. (2018). 14-3-3 proteins reduce cell-to-cell transfer and propagation of pathogenic alpha-synuclein. J. Neurosci. 38, 8211-8232. doi: 10.1523/ JNEUROSCI.1134-18.2018

Wang, T., and Hay, J. C. (2015). Alpha-synuclein toxicity in the early secretory pathway: how it drives neurodegeneration in Parkinsons disease. Front. Neurosci. 9:433. doi: 10.3389/fnins.2015.00433

Wang, W., Nguyen, L. T., Burlak, C., Chegini, F., Guo, F., Chataway, T., et al. (2016). Caspase-1 causes truncation and aggregation of the Parkinson's diseaseassociated protein alpha-synuclein. Proc. Natl. Acad. Sci. U.S.A. 113, 9587-9592. doi: $10.1073 /$ pnas.1610099113

Wang, W., Perovic, I., Chittuluru, J., Kaganovich, A., Nguyen, L. T., Liao, J., et al. (2011). A soluble alpha-synuclein construct forms a dynamic tetramer. Proc. Natl. Acad. Sci. U.S.A. 108, 17797-17802. doi: 10.1073/pnas.111326 0108

Wang, X., Becker, K., Levine, N., Zhang, M., Lieberman, A. P., Moore, D. J., et al. (2019). Pathogenic alpha-synuclein aggregates preferentially bind to mitochondria and affect cellular respiration. Acta Neuropathol. Commun. 7:41. doi: 10.1186/s40478-019-0696-4

Watson, M. B., Richter, F., Lee, S. K., Gabby, L., Wu, J., Masliah, E., et al. (2012). Regionally-specific microglial activation in young mice over-expressing human wildtype alpha-synuclein. Exp. Neurol. 237, 318-334. doi: 10.1016/j.expneurol. 2012.06.025

Watts, J. C., Giles, K., Oehler, A., Middleton, L., Dexter, D. T., Gentleman, S. M., et al. (2013). Transmission of multiple system atrophy prions to transgenic mice. Proc. Natl. Acad. Sci. U.S.A. 110, 19555-19560. doi: 10.1073/pnas. 1318268110

Waxman, E. A., Mazzulli, J. R., and Giasson, B. I. (2009). Characterization of hydrophobic residue requirements for alpha-synuclein fibrillization. Biochemistry 48, 9427-9436. doi: 10.1021/bi900539p 
Webb, J. L., Ravikumar, B., Atkins, J., Skepper, J. N., and Rubinsztein, D. C. (2003). Alpha-Synuclein is degraded by both autophagy and the proteasome. J. Biol. Chem. 278, 25009-25013. doi: 10.1074/jbc.M300227200

Weihofen, A., Liu, Y., Arndt, J. W., Huy, C., Quan, C., Smith, B. A., et al. (2019). Development of an aggregate-selective, human-derived alpha-synuclein antibody BIIB054 that ameliorates disease phenotypes in Parkinson's disease models. Neurobiol. Dis. 124, 276-288. doi: 10.1016/j.nbd.2018.10.016

Weinreb, P. H., Zhen, W., Poon, A. W., Conway, K. A., and Lansbury, P. T. Jr. (1996). NACP, a protein implicated in Alzheimer's disease and learning, is natively unfolded. Biochemistry 35, 13709-13715. doi: 10.1021/bi961799n

Wersinger, C., Jeannotte, A., and Sidhu, A. (2006a). Attenuation of the norepinephrine transporter activity and trafficking via interactions with alphasynuclein. Eur J. Neurosci. 24, 3141-3152. doi: 10.1111/j.1460-9568.2006.05 181.x

Wersinger, C., Rusnak, M., and Sidhu, A. (2006b). Modulation of the trafficking of the human serotonin transporter by human alpha-synuclein. Eur. J. Neurosci. 24, 55-64. doi: 10.1111/j.1460-9568.2006.04900.x

Whittaker, H. T., Qui, Y., Bettencourt, C., and Houlden, H. (2017). Multiple system atrophy: genetic risks and alpha-synuclein mutations. F1000Res. 6:2072. doi: 10.12688/f1000research.12193.1

Winner, B., Jappelli, R., Maji, S. K., Desplats, P. A., Boyer, L., Aigner, S., et al. (2011). In vivo demonstration that alpha-synuclein oligomers are toxic. Proc. Natl. Acad. Sci. U.S.A. 108, 4194-4199. doi: 10.1073/pnas.1100976108

Winslow, A. R., Chen, C. W., Corrochano, S., Acevedo-Arozena, A., Gordon, D. E., Peden, A. A., et al. (2010). alpha-Synuclein impairs macroautophagy: implications for Parkinson's disease. J. Cell Biol. 190, 1023-1037. doi: 10.1083/ jcb.201003122

Witt, S. N. (2013). Molecular chaperones, alpha-synuclein, and neurodegeneration. Mol. Neurobiol. 47, 552-560. doi: 10.1007/s12035-012-8325-2

Woerman, A. L., Stohr, J., Aoyagi, A., Rampersaud, R., Krejciova, Z., Watts, J. C., et al. (2015). Propagation of prions causing synucleinopathies in cultured cells. Proc. Natl. Acad. Sci. U.S.A. 112, E4949-E4958. doi: 10.1073/pnas.151342 6112

Wrasidlo, W., Tsigelny, I. F., Price, D. L., Dutta, G., Rockenstein, E., Schwarz, T. C., et al. (2016). A de novo compound targeting alpha-synuclein improves deficits in models of Parkinson's disease. Brain 139(Pt 12), 3217-3236. doi: 10.1093/brain/aww238

Wu, B., Liu, Q., Duan, C., Li, Y., Yu, S., Chan, P., et al. (2011). Phosphorylation of alpha-synuclein upregulates tyrosine hydroxylase activity in MN9D cells. Acta Histochem. 113, 32-35. doi: 10.1016/j.acthis.2009.07.007

Wu, F., Xu, H. D., Guan, J. J., Hou, Y. S., Gu, J. H., Zhen, X. C., et al. (2015). Rotenone impairs autophagic flux and lysosomal functions in Parkinson's disease. Neuroscience 284, 900-911. doi: 10.1016/j.neuroscience.2014.11.004

Wu, Q., Takano, H., Riddle, D. M., Trojanowski, J. Q., Coulter, D. A., and Lee, V. M. (2019). alpha-Synuclein (alphaSyn) preformed fibrils induce endogenous alphaSyn aggregation, compromise synaptic activity and enhance synapse loss in cultured excitatory hippocampal neurons. J. Neurosci. 39, 5080-5094. doi: 10.1523/JNEUROSCI.0060-19.2019

Wu, Y., Li, X., Zhu, J. X., Xie, W., Le, W., Fan, Z., et al. (2011). Resveratrol-activated AMPK/SIRT1/autophagy in cellular models of Parkinson's disease. Neurosignals 19, 163-174. doi: 10.1159/000328516

Xilouri, M., Brekk, O. R., Landeck, N., Pitychoutis, P. M., Papasilekas, T., Papadopoulou-Daifoti, Z., et al. (2013a). Boosting chaperone-mediated autophagy in vivo mitigates alpha-synuclein-induced neurodegeneration. Brain 136(Pt 7), 2130-2146. doi: 10.1093/brain/awt131

Xilouri, M., Brekk, O. R., Polissidis, A., Chrysanthou-Piterou, M., Kloukina, I., and Stefanis, L. (2016a). Impairment of chaperone-mediated autophagy induces dopaminergic neurodegeneration in rats. Autophagy 12, 2230-2247. doi: 10. 1080/15548627.2016.1214777

Xilouri, M., Brekk, O. R., and Stefanis, L. (2013b). alpha-Synuclein and protein degradation systems: a reciprocal relationship. Mol. Neurobiol. 47, 537-551. doi: 10.1007/s12035-012-8341-2

Xilouri, M., Brekk, O. R., and Stefanis, L. (2016b). Autophagy and alpha-synuclein: relevance to Parkinson's disease and related synucleopathies. Mov. Disord. 31, 178-192. doi: $10.1002 / \mathrm{mds} .26477$
Xilouri, M., Vogiatzi, T., Vekrellis, K., Park, D., and Stefanis, L. (2009). Abberant alpha-synuclein confers toxicity to neurons in part through inhibition of chaperone-mediated autophagy. PLoS One 4:e5515. doi: 10.1371/journal.pone. 0005515

Xu, J., Wu, X. S., Sheng, J., Zhang, Z., Yue, H. Y., Sun, L., et al. (2016). alphasynuclein mutation inhibits endocytosis at mammalian central nerve terminals. J. Neurosci. 36, 4408-4414. doi: 10.1523/JNEUROSCI.3627-15.2016

Xu, Y., Liu, C., Chen, S., Ye, Y., Guo, M., Ren, Q., et al. (2014). Activation of AMPK and inactivation of Akt result in suppression of mTOR-mediated S6K1 and 4EBP1 pathways leading to neuronal cell death in in vitro models of Parkinson's disease. Cell. Signal. 26, 1680-1689. doi: 10.1016/j.cellsig.2014.04.009

Xu, Z., Graham, K., Foote, M., Liang, F., Rizkallah, R., Hurt, M., et al. (2013). 14-33 protein targets misfolded chaperone-associated proteins to aggresomes. J. Cell Sci. 126(Pt 18), 4173-4186. doi: 10.1242/jcs. 126102

Yan, J. Q., Yuan, Y. H., Gao, Y. N., Huang, J. Y., Ma, K. L., Gao, Y., et al. (2014). Overexpression of human E46K mutant alpha-synuclein impairs macroautophagy via inactivation of JNK1-Bcl-2 pathway. Mol. Neurobiol. 50, 685-701. doi: 10.1007/s12035-014-8738-1

Yang, S. Y., Beavan, M., Chau, K. Y., Taanman, J. W., and Schapira, A. H. V. (2017). A human neural crest stem cell-derived dopaminergic neuronal model recapitulates biochemical abnormalities in GBA1 mutation carriers. Stem Cell Rep. 8, 728-742. doi: 10.1016/j.stemcr.2017.01.011

Yang, Y., Fukui, K., Koike, T., and Zheng, X. (2007). Induction of autophagy in neurite degeneration of mouse superior cervical ganglion neurons. Eur. J. Neurosci. 26, 2979-2988. doi: 10.1111/j.1460-9568.2007.05914.x

Yazawa, I., Giasson, B. I., Sasaki, R., Zhang, B., Joyce, S., Uryu, K., et al. (2005). Mouse model of multiple system atrophy alpha-synuclein expression in oligodendrocytes causes glial and neuronal degeneration. Neuron 45, 847-859. doi: 10.1016/j.neuron.2005.01.032

Zarranz, J. J., Alegre, J., Gomez-Esteban, J. C., Lezcano, E., Ros, R., Ampuero, I., et al. (2004). The new mutation, E46K, of alpha-synuclein causes Parkinson and Lewy body dementia. Ann. Neurol. 55, 164-173. doi: 10.1002/ana.10795

Zavodszky, E., Seaman, M. N., Moreau, K., Jimenez-Sanchez, M., Breusegem, S. Y., Harbour, M. E., et al. (2014). Mutation in VPS35 associated with Parkinson's disease impairs WASH complex association and inhibits autophagy. Nat. Commun. 5:3828. doi: 10.1038/ncomms4828

Zhang, Q., Xu, Y., Lee, J., Jarnik, M., Wu, X., Bonifacino, J. S., et al. (2020). A myosin-7B-dependent endocytosis pathway mediates cellular entry of alphasynuclein fibrils and polycation-bearing cargos. Proc. Natl. Acad. Sci. U.S.A. 117, 10865-10875. doi: 10.1073/pnas.1918617117

Zharikov, A. D., Cannon, J. R., Tapias, V., Bai, Q., Horowitz, M. P., Shah, V., et al. (2015). shRNA targeting alpha-synuclein prevents neurodegeneration in a Parkinson's disease model. J. Clin. Invest. 125, 2721-2735. doi: 10.1172/ JCI64502

Zhu, M., Rajamani, S., Kaylor, J., Han, S., Zhou, F., and Fink, A. L. (2004). The flavonoid baicalein inhibits fibrillation of alpha-synuclein and disaggregates existing fibrils. J. Biol. Chem. 279, 26846-26857. doi: 10.1074/jbc.M403129200

Zondler, L., Kostka, M., Garidel, P., Heinzelmann, U., Hengerer, B., Mayer, B., et al. (2017). Proteasome impairment by alpha-synuclein. PLoS One 12:e0184040. doi: 10.1371/journal.pone.0184040

Zou, J., Guo, Y., Wei, L., Yu, F., Yu, B., and Xu, A. (2020). Long noncoding RNA POU3F3 and alpha-Synuclein in Plasma L1CAM exosomes combined with beta-Glucocerebrosidase activity: potential predictors of Parkinson's disease. Neurotherapeutics. doi: 10.1007/s13311-020-00842-5 [Epub ahead of print].

Conflict of Interest: The authors declare that the research was conducted in the absence of any commercial or financial relationships that could be construed as a potential conflict of interest.

Copyright $\odot 2020$ Fouka, Mavroeidi, Tsaka and Xilouri. This is an open-access article distributed under the terms of the Creative Commons Attribution License (CC BY). The use, distribution or reproduction in other forums is permitted, provided the original author(s) and the copyright owner(s) are credited and that the original publication in this journal is cited, in accordance with accepted academic practice. No use, distribution or reproduction is permitted which does not comply with these terms. 